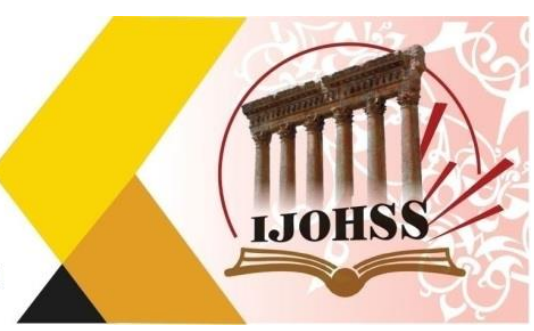

\title{
تقويض المعنى وتوليد الدلالة في الرسم التجريدي (نماذج مختارة)
}

\author{
م. د. حسين شاكر قاسم حسون العيداني \\ مديرية تربية البصرة \\ وزارة التربية ـ العراق تيعرة
}

البريد الاككتروني: Thelion2007hhh@gmail.com

الماخص

يسلط البحث الموسوم الضوء مفهوم تقويض المعنى وتوليد الدلالة في الرسم التجريدي نماذج مختارة ، فتضمن البحث اربع فصول ، خُصص الفصل الاول لبيان مشكلة البحث و التي تمخضت عن التساؤلات الاتية : كيف يولد المعنى في النصوص البصرية التجريدية ؟ وهل لتلك النصوص البصرية قابلية على التقويض في المعنى؟ وما علاقة النصوص التجريدية بتوليد الدلالة ؟ أما الفصل الثاني فتضمن ثلاث مباحث تناول المبحث الاول - قراءة فلسفية ودلالية في مفهوم تقويض المعنى ، فيما عني المبحث الثاني التجريد بين المفهوم والدلالة ، أما المبحث

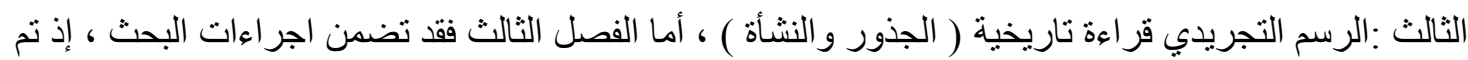
فيه تحديد اطار مجتمع البحث ، واختيار نماذج العينة البالغة (4) اربعة أعمال فنية ، ونم استعر اض المعالجات

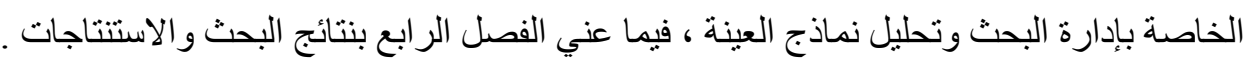

الكلمات المفتاحية: تقويض المعنى، توليد الدلالة، الرسم التجريدي. 


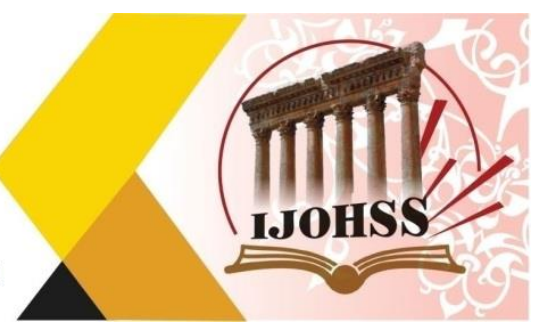

\title{
Undermining Meaning and Generating Significance in Abstract Painting (A selected models)
}

\author{
Dr. Hussein Shaker Qassem Hassoun Al-Eidani \\ Basra Education Directorate \\ Ministry of Education - Iraq \\ Email: Thelion2007hhh@gmail.com
}

\begin{abstract}
The tagged research sheds light on the concept of undermining meaning and generating significance in abstract painting selected models. The research included four chapters. The first chapter was devoted to clarifying the research problem, which resulted in the following questions: How is meaning generated in visual abstract texts? Are these visual texts the ability to undermine the meaning? What is the relationship of abstract texts to generate significance? As for the second chapter, it included three sections that dealt with the first topic - a philosophical and semantic reading of the concept of undermining meaning, while the second topic concerned abstraction between concept and significance, and the third topic: abstract drawing, a historical reading (roots and origins), and the third chapter included research procedures, as it was It defines the framework of the research community, and selects the sample models amounting to (4) four artistic works, and the treatments of the research management and analysis of the sample models were reviewed, while the fourth chapter is concerned with the research results and conclusions.
\end{abstract}

Keywords: undermining meaning, generating semantics, abstract painting. 


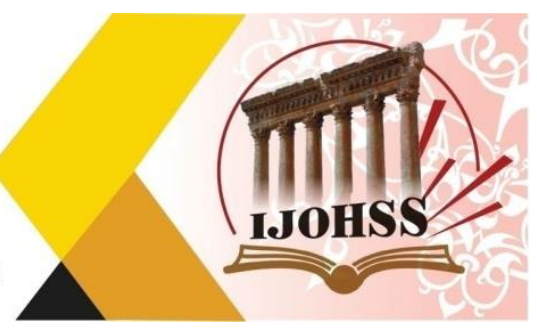

\section{الفصل الاول}

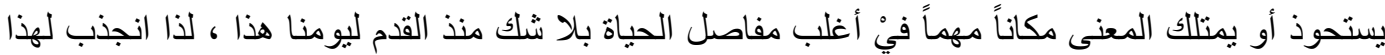

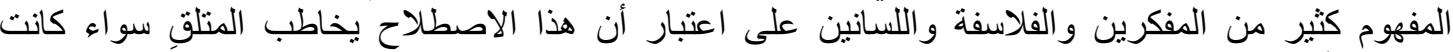

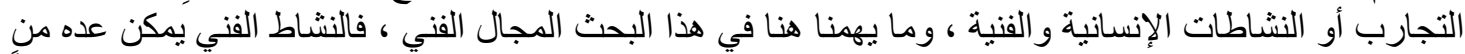

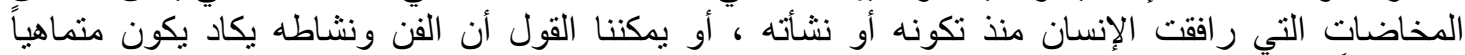

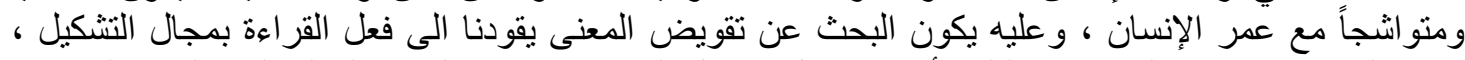

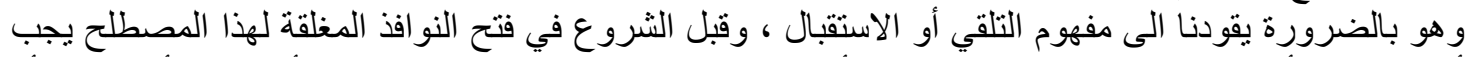

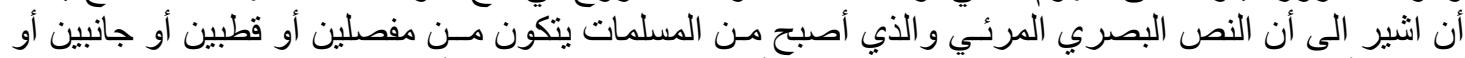

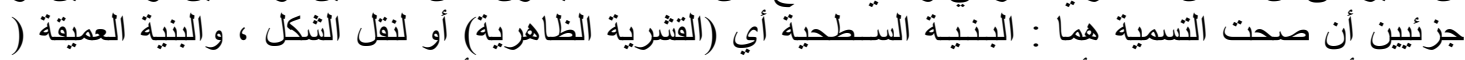

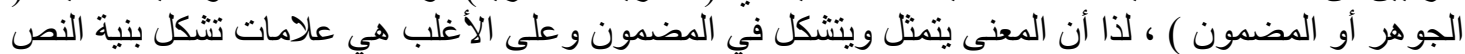

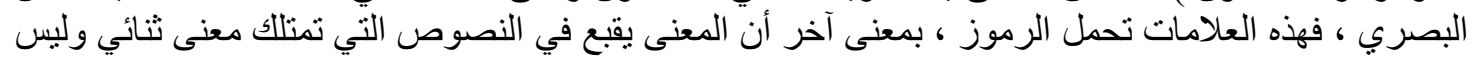

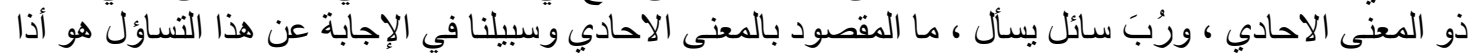

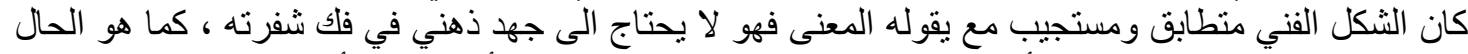

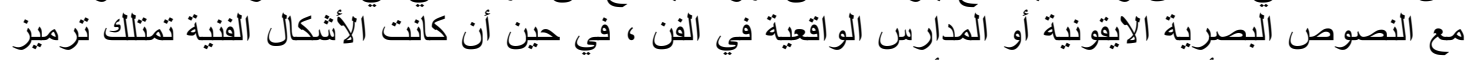

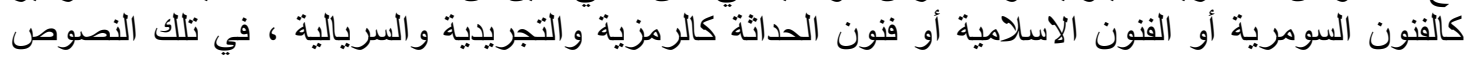

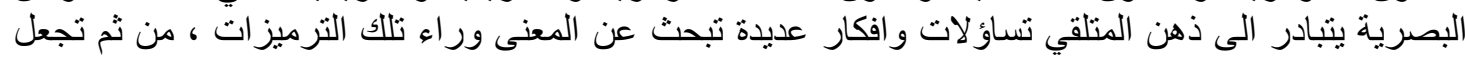

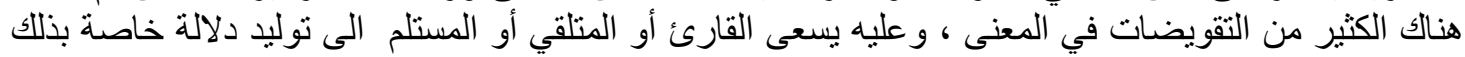

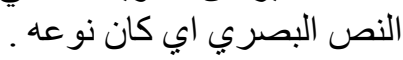

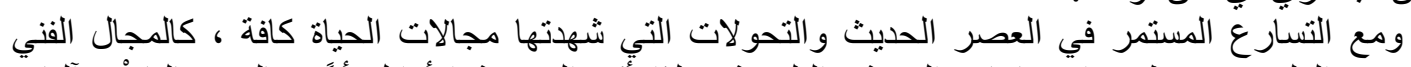

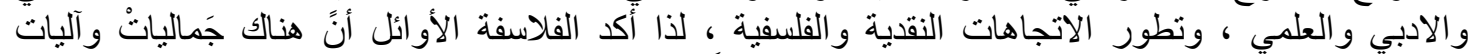

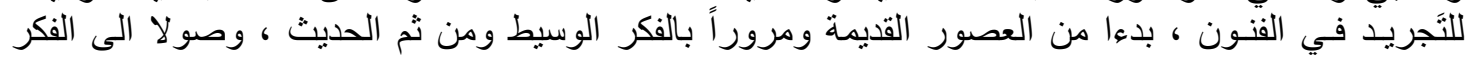

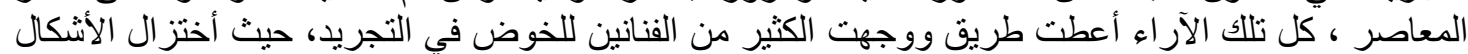

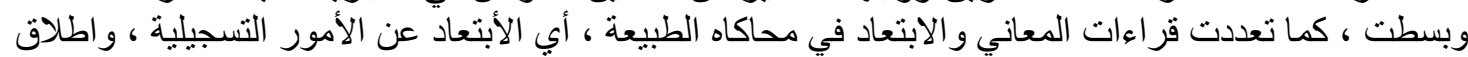

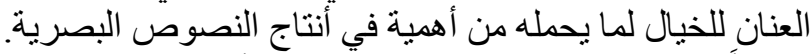

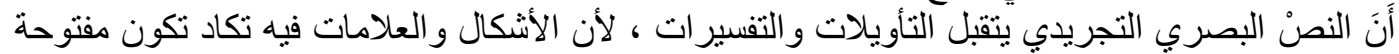

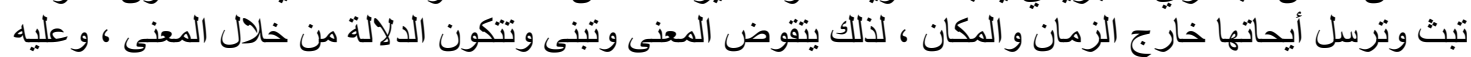

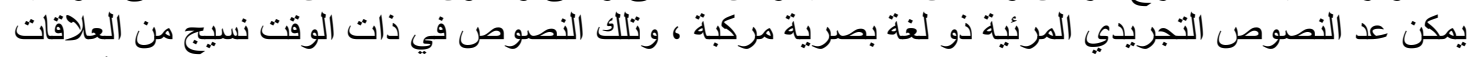

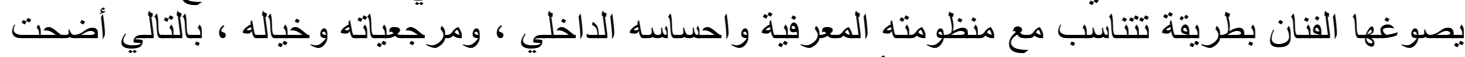

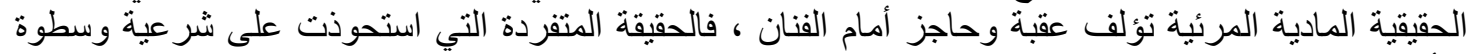

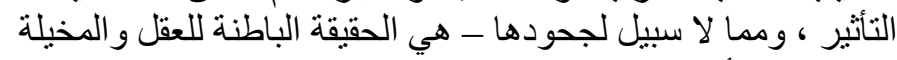

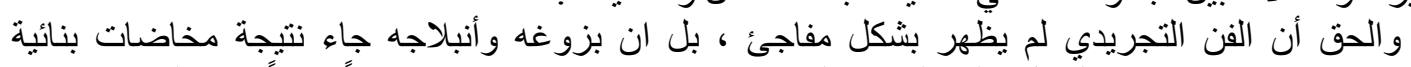

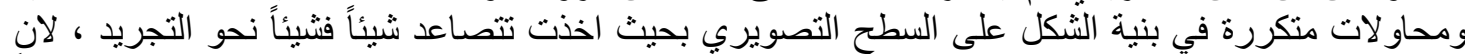

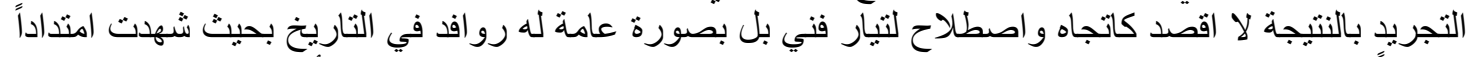

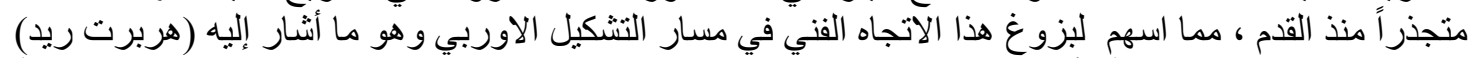

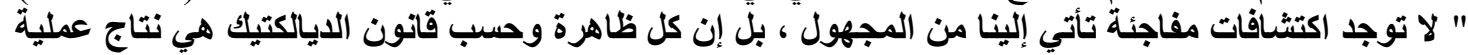

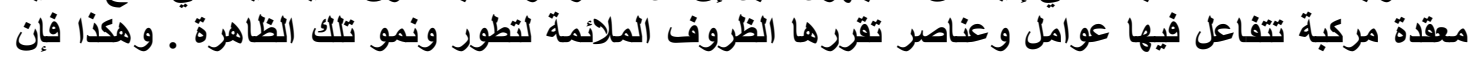

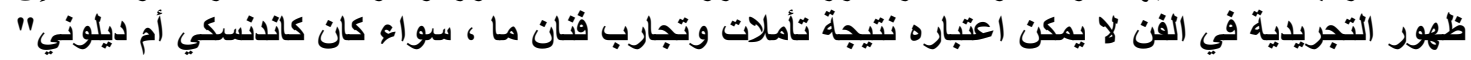

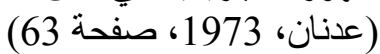

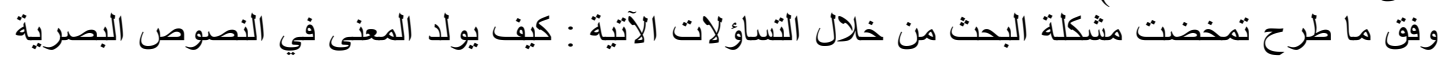

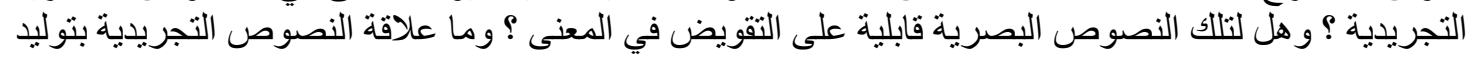
الدلالة ؟ وسبيلنا في تناول مشكلة هذا المصطلح هو التنقيب والبحث و الحفر في الافكار الرئيسة التي تتعلق بمفهوم 


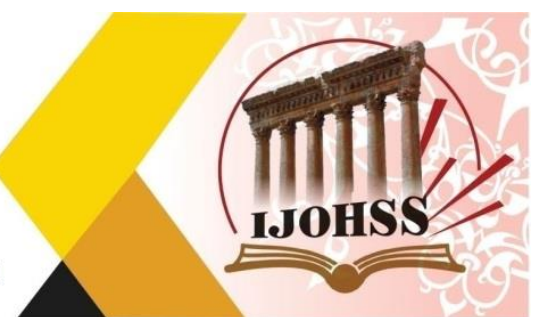

تقويض المعنى ومدى علاقتها او تواشجه بتوليد الدلالة سيعاً للوصول الى معانِ خفية أو جو انب تتعلق بالمنحى

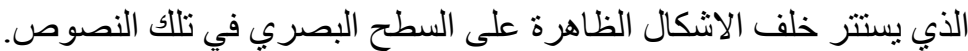

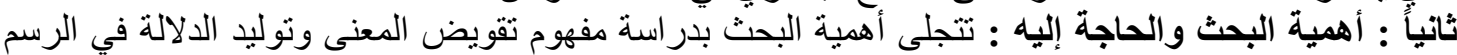

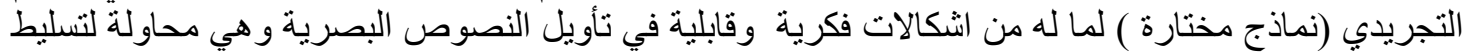

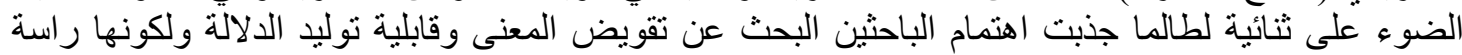

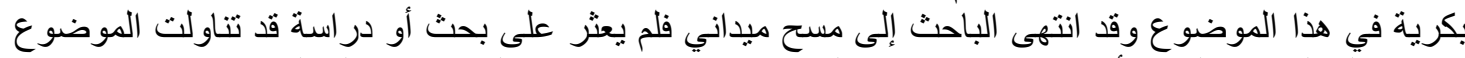

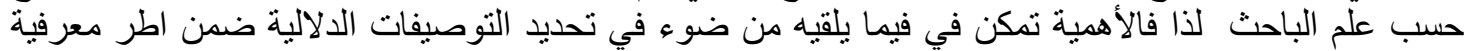

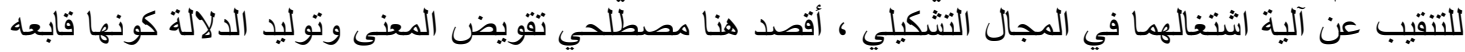

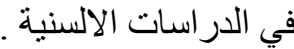

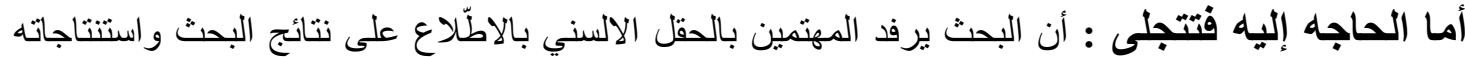

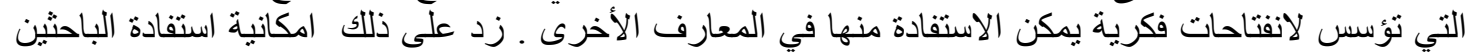

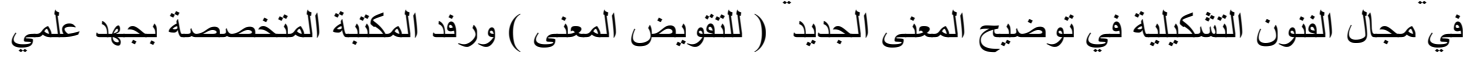

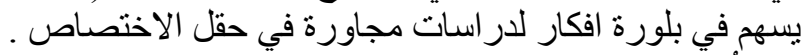

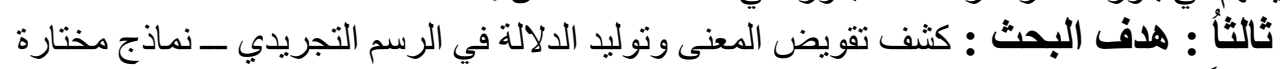

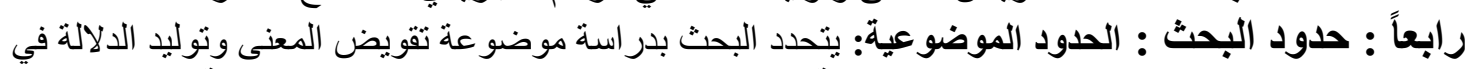

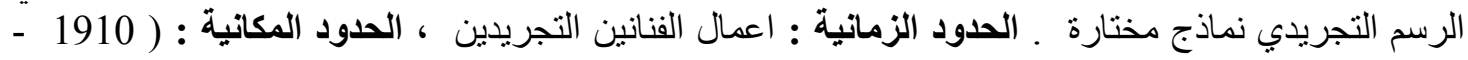

خامساً : تحديد المصطلحات .

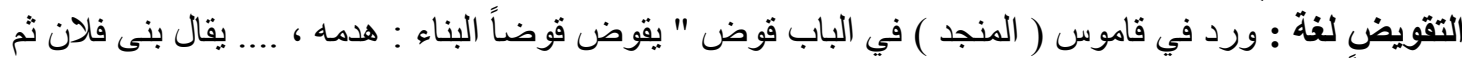

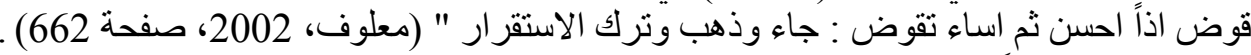

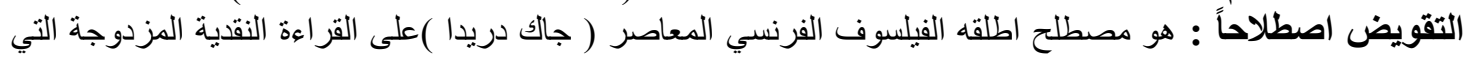

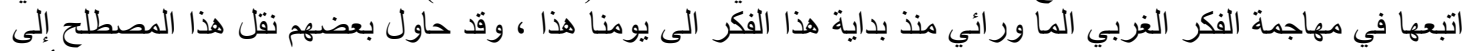

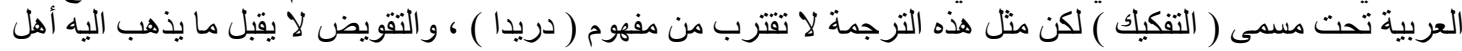

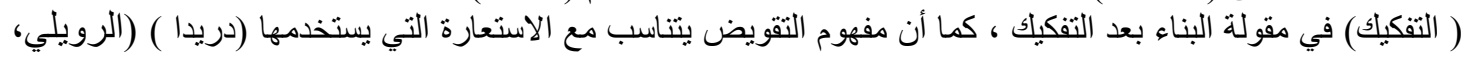

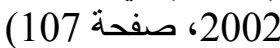
المعنى لغة : و المعنى هو ما يقصد بالثيء ، و وإثتقاقاً فإنَّ مفردة المعنى مشتقة من عنيت بالكلام كذا ، قصدت

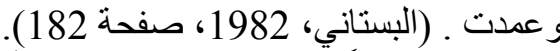

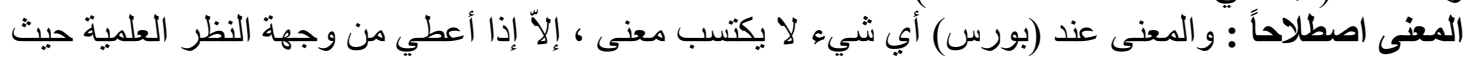

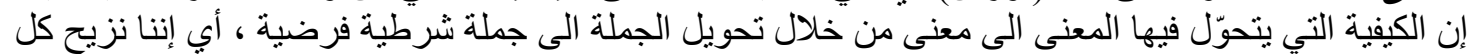

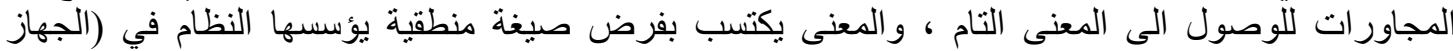
المفاهيمي) الذي من خلاله يكتسب الأشياء معناها سواء كان ولئ وظيفي أو جمالي. (مورنون، 1975، الصفحات . (152- 150 تقويض المعنى : ير اد بهذا المصطلح من قبل الباحث هي الاشكال و الدلالات التي تقود الى تولبد معاني مختلفة

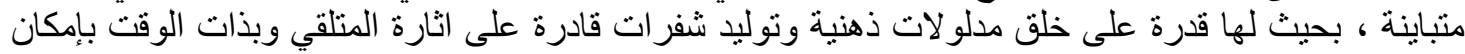

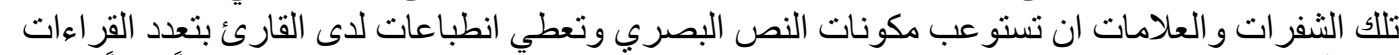

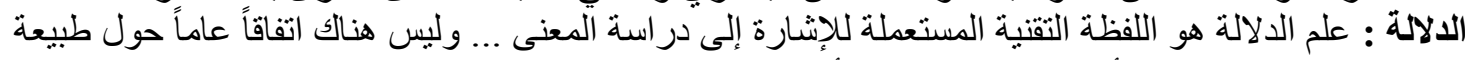

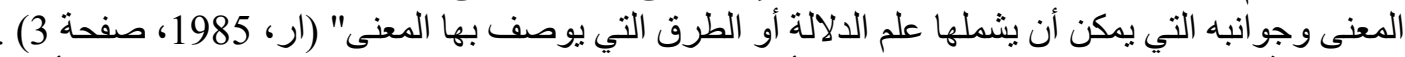

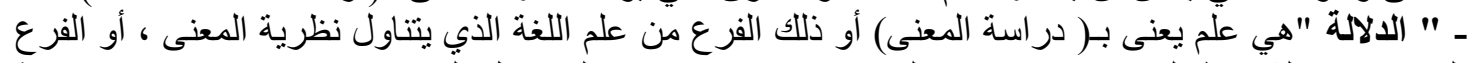

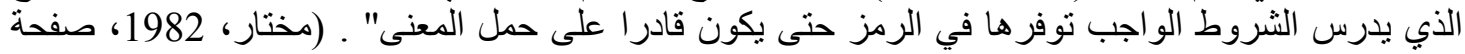

ـ تثلقى الدلالة بالمعنى المراد إيصاله فهي : "تصور ذهني لأشياء موجودة في العالم الخارجي ، تنعلق بإنتاج

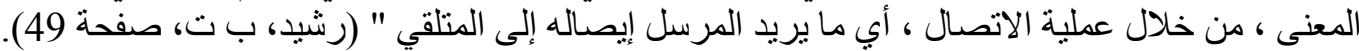




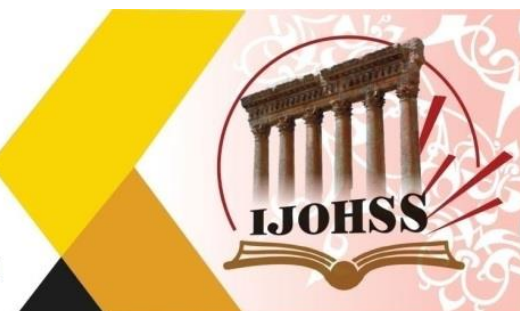

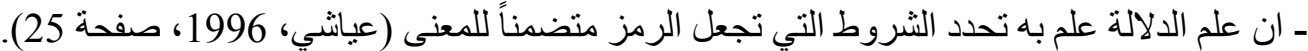

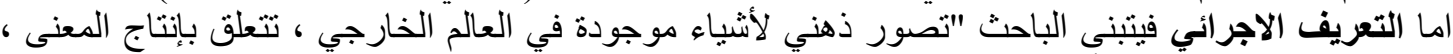

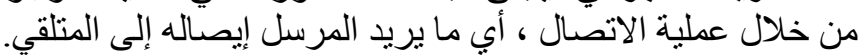

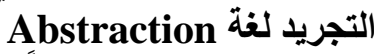

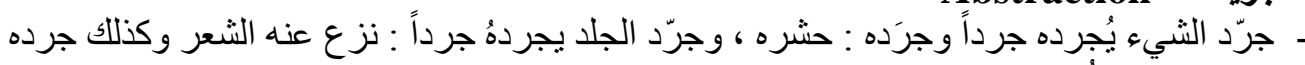
التجريد اصطظلاحاً : Abstraction

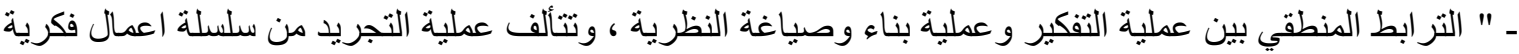

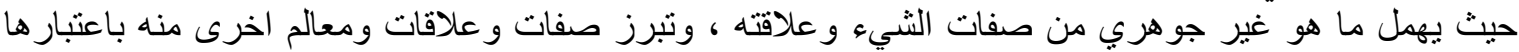

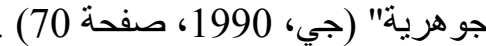

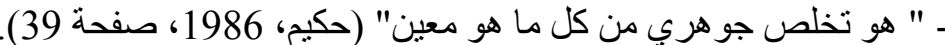

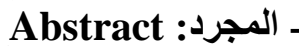

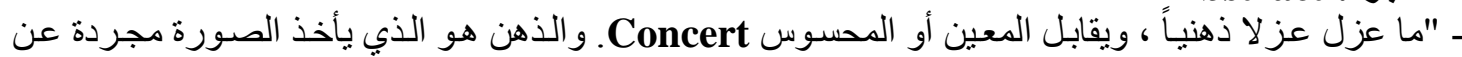
المادة ولواحقها وهي: الكم و الكيف و الأين" (العربية، الكابل 1979، صفحة 171)

تجريا:Abstraction

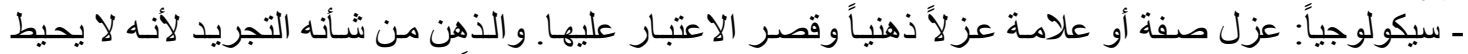

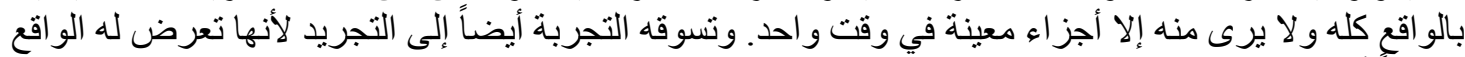

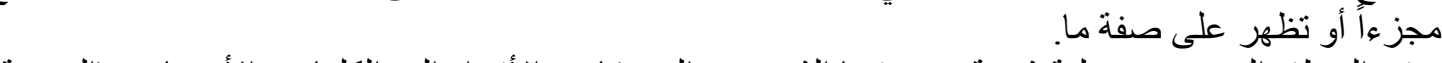
ـ في المنطق الصوري: عملية ذهنية يسير فيها الذهن من الجزيئات و الأفر اد إلى الكليات والأصناف. (العربيـة،

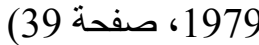

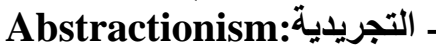

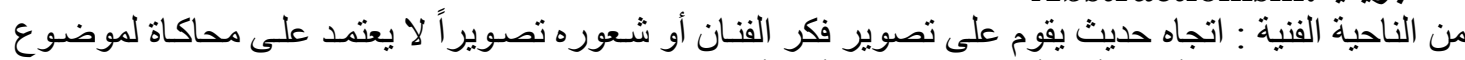

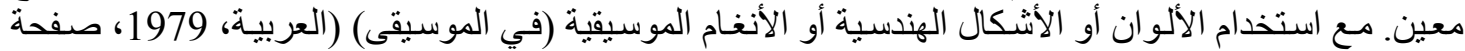

ـ ـ المجرد هو الذي يبدو خارجاً عن علاقاته مع بقية الاشياء او ما هو وحدة خالية من الاختلافات (خياط، ب ت ، صفحة 117) مرن

$$
\text { المتن النظري أو الإطأر النظري }
$$

\section{المبحث الاول}

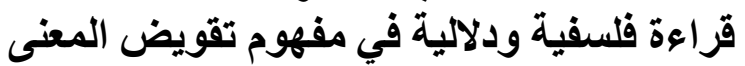

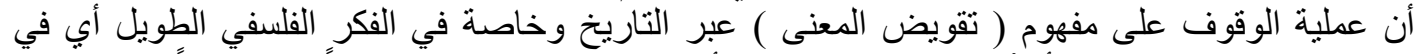

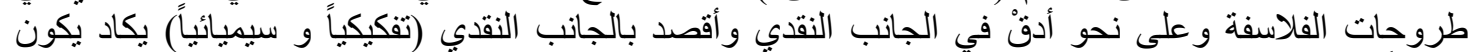

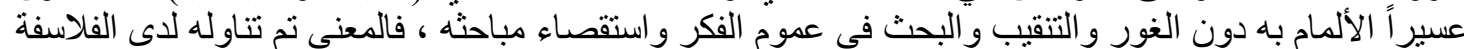

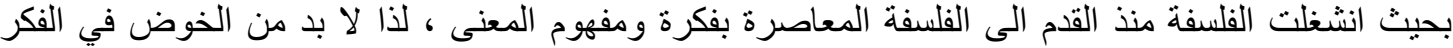

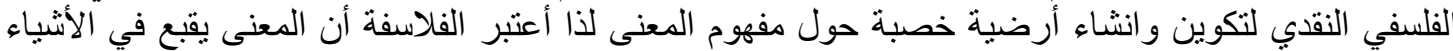

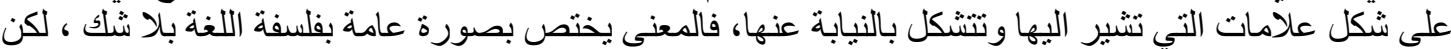

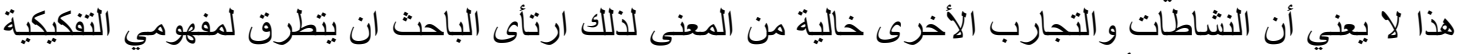

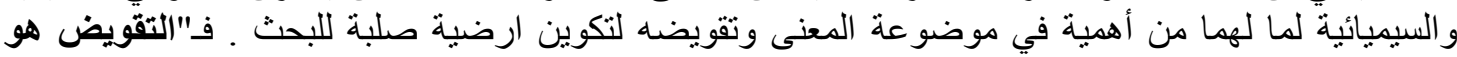

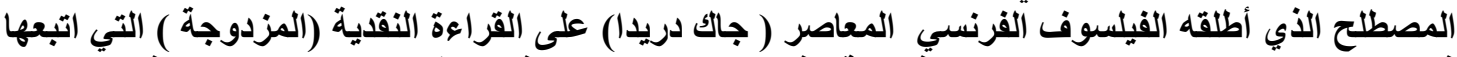

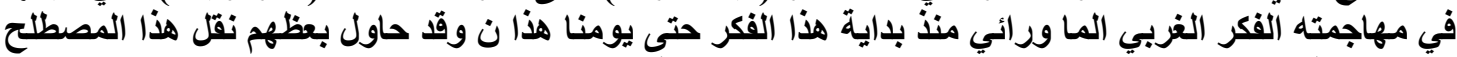

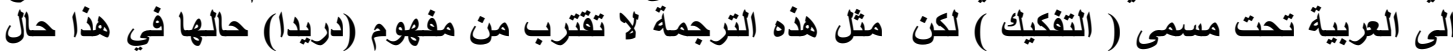

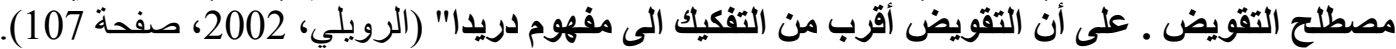




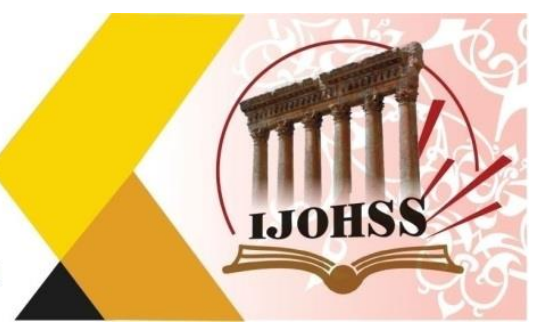

اولاً : التفكيكية وانزياح المعنى الثنابت .

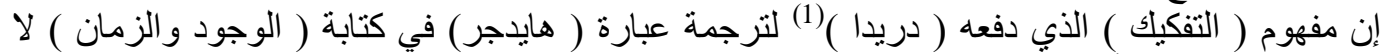

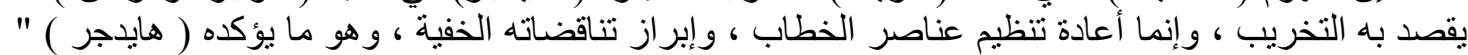

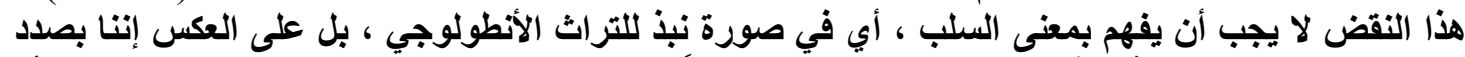

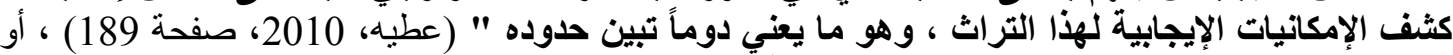

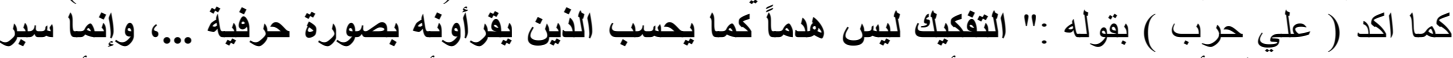

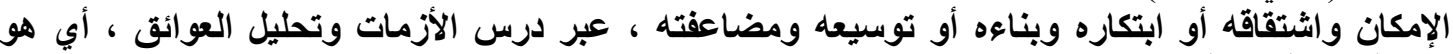

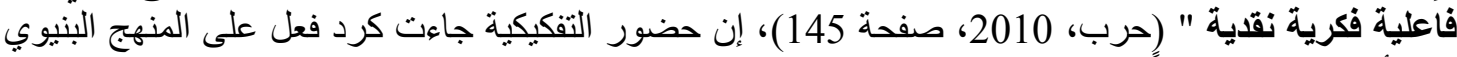

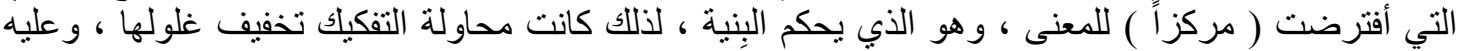

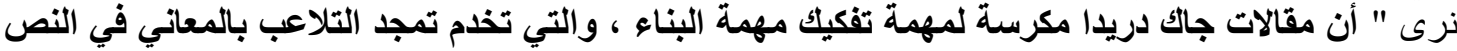

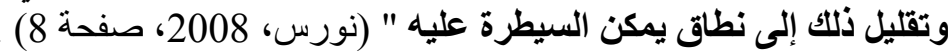

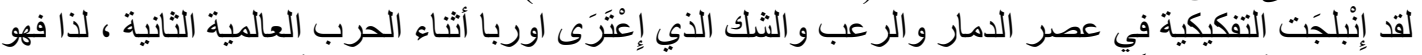

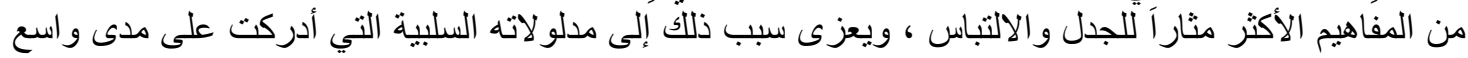

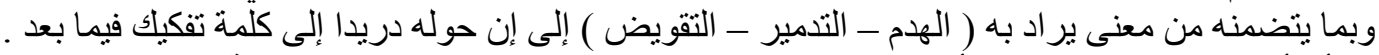

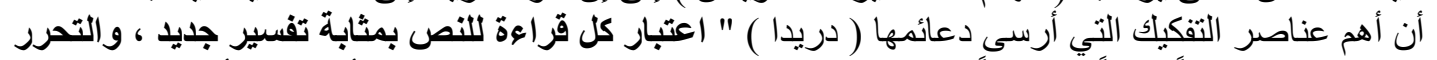

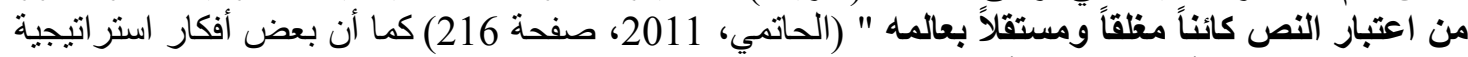

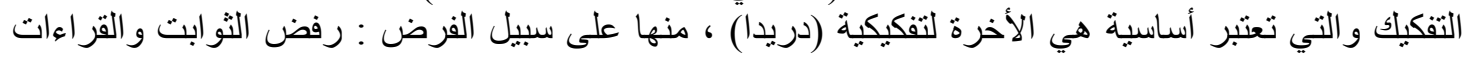

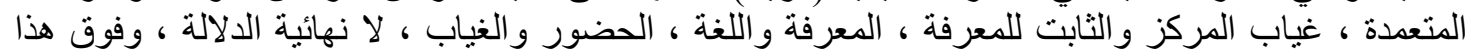

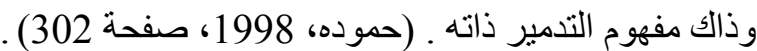

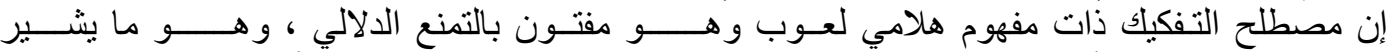

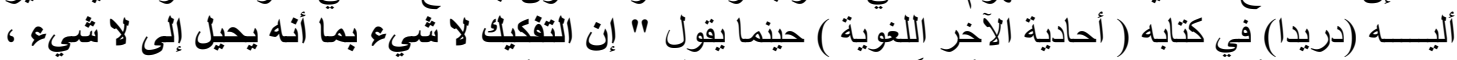

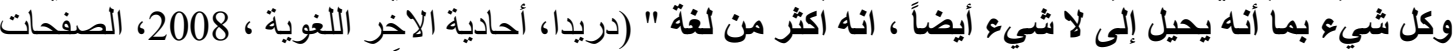

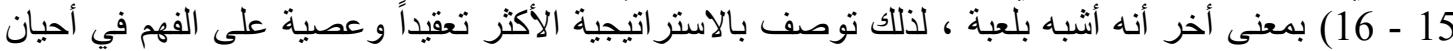

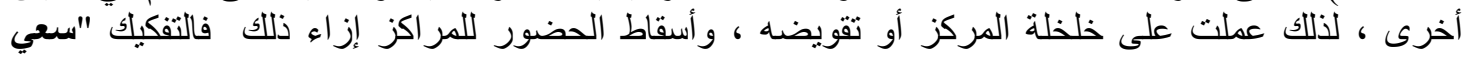

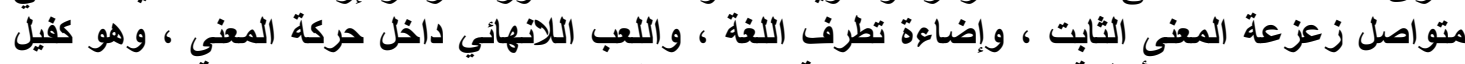

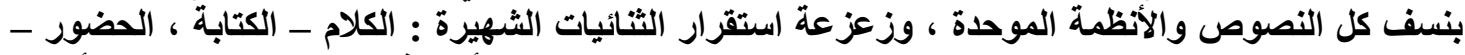

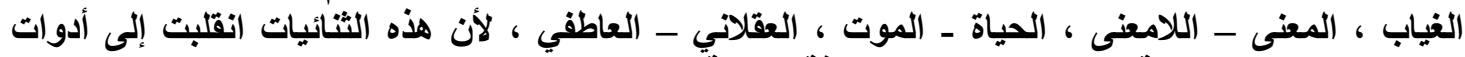

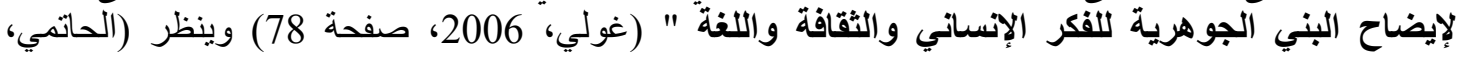

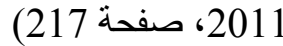
تجدر الإشارة أن التفكيكية كحركة فكرية ذات نهادات متعددة ، اعتمدت على الفلسفة وصر اعات الفكر الفلسفي

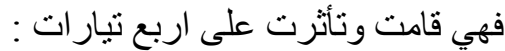

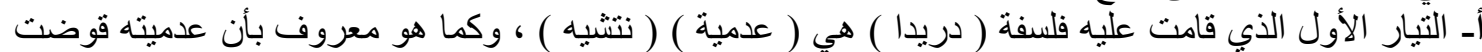

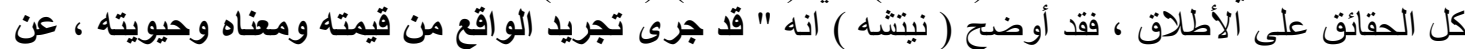

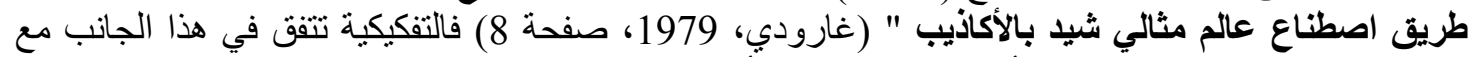

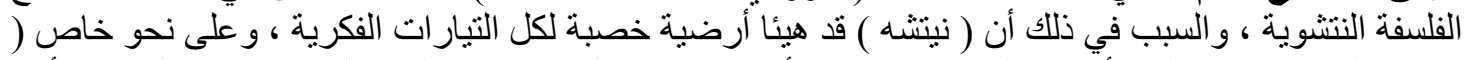

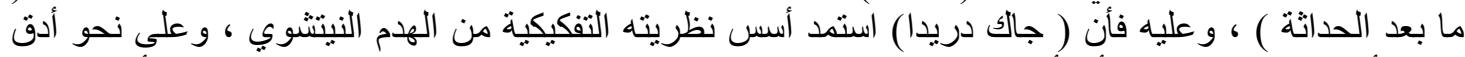

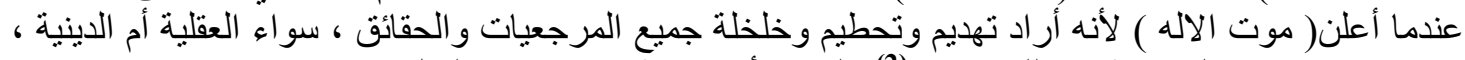

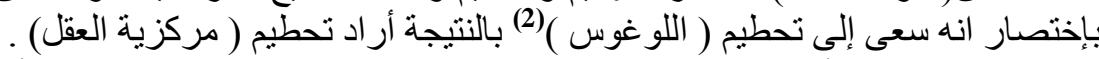

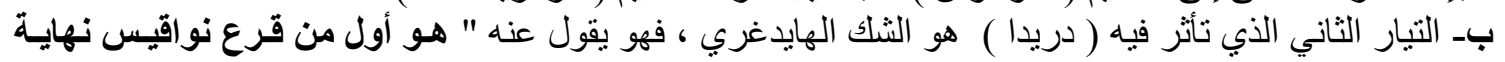

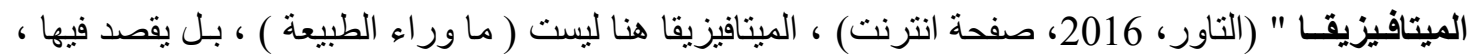

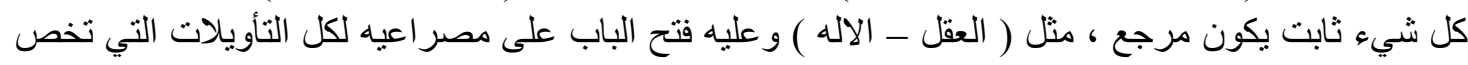

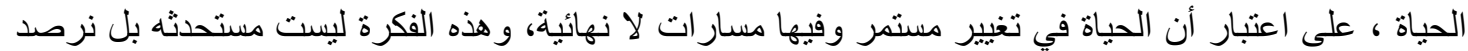




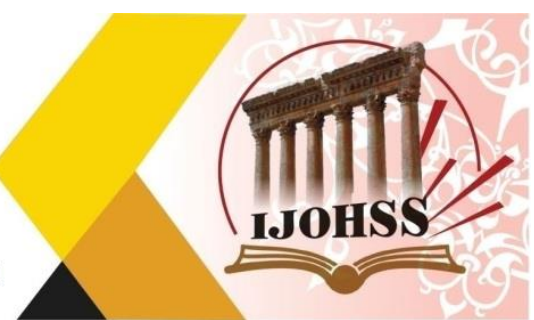

إرهاصاتها عند فيلسوف الجدل الأول (هرقليطيس ) بمقولته ( انك لا تنزل النهر الواحد مرتين فأن مياه جديدة

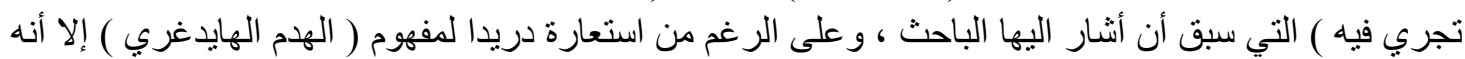

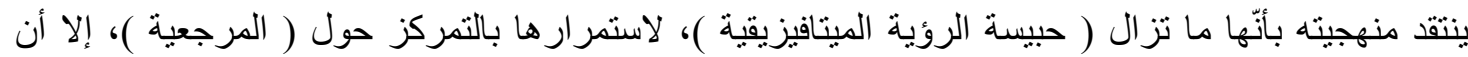

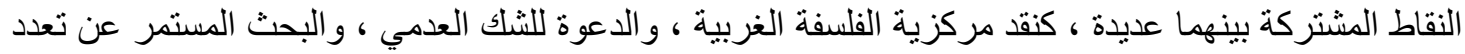

المعاني (الحي، 2018، صفحة انترنت).

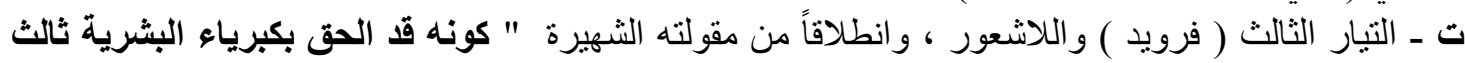

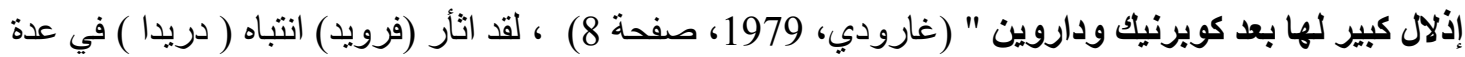

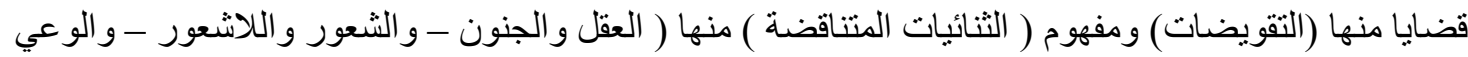

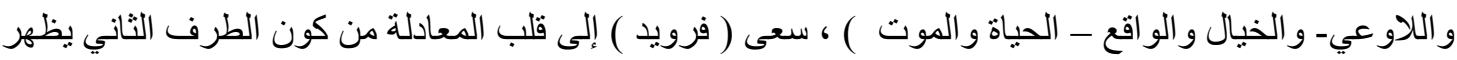

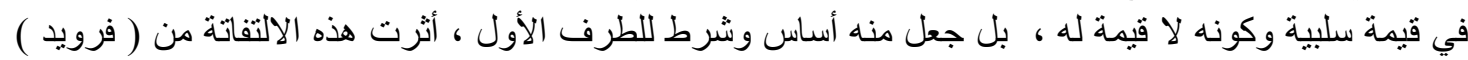

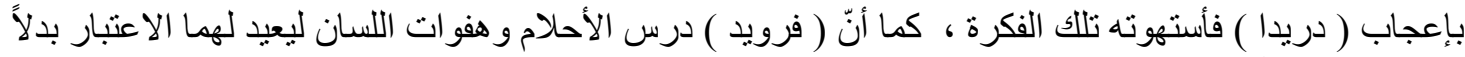

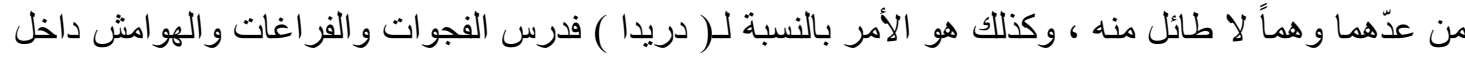

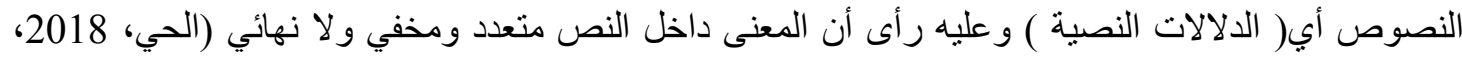

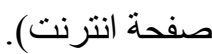

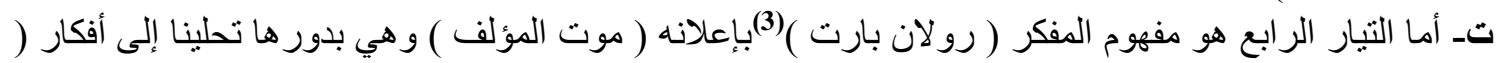

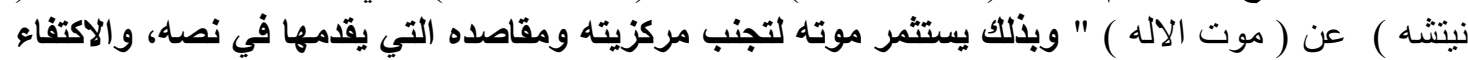

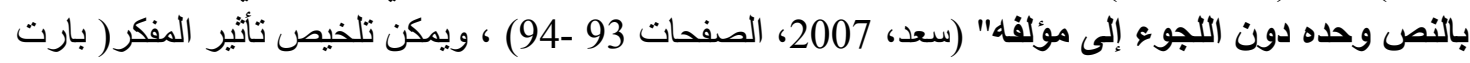

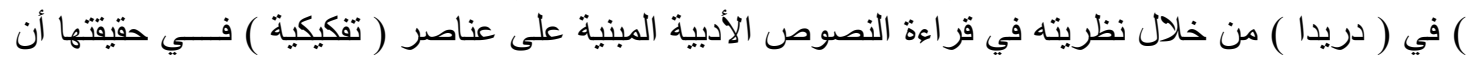

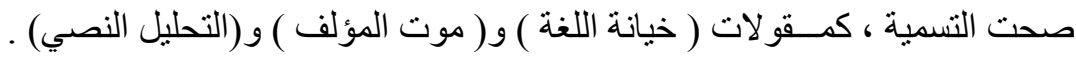

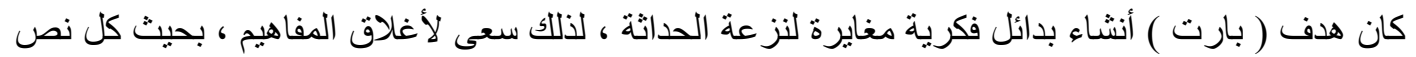

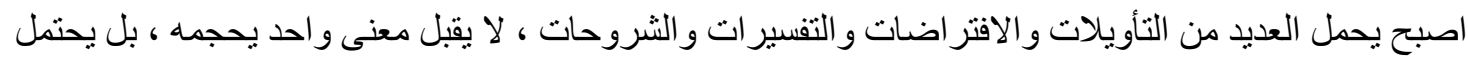

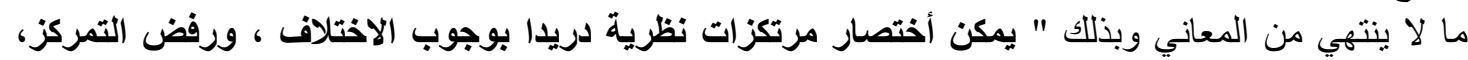

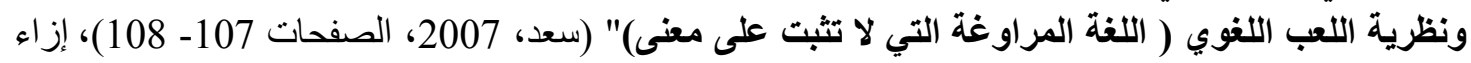

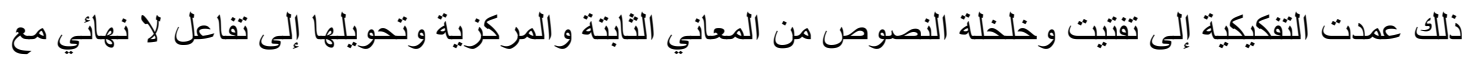

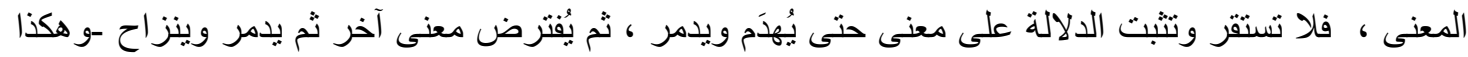

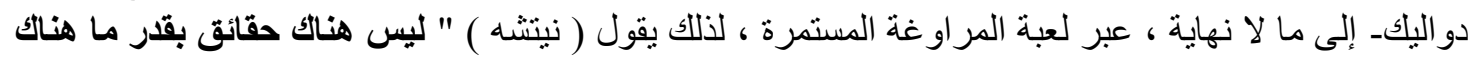
تفسيرات ، وما يمكن تأكيده كحقيقة هو لغو بدون معنى ... هذا هو بيان ما بعد الحداثة " (الحيدري، 2012،

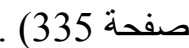
أما أذا اردنا ربط التفكيك في الحقل الفني وهو مجال بحثنا ، فنجد أن النصوص المرئية لتيار ات ما بعد الحداثة

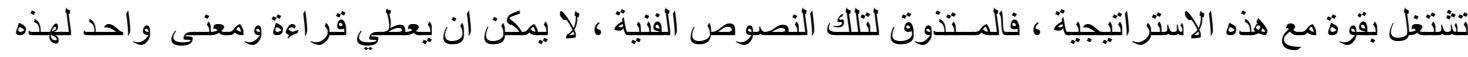

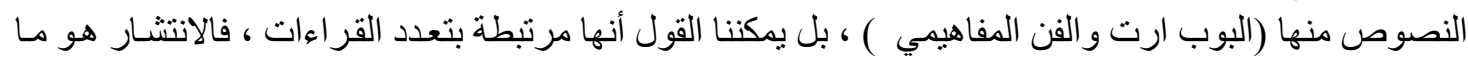

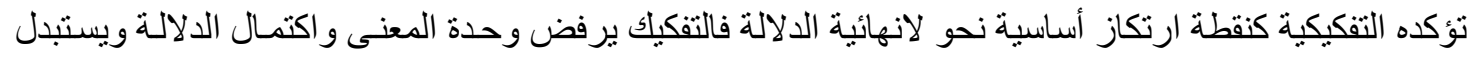

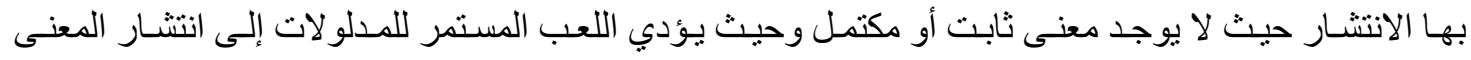

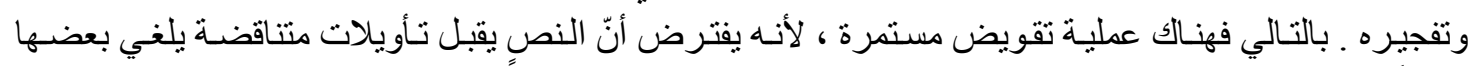

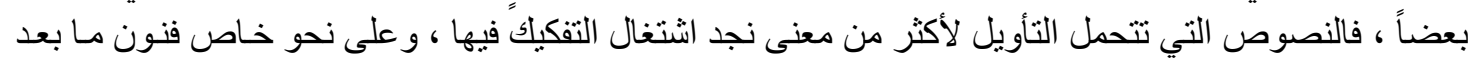

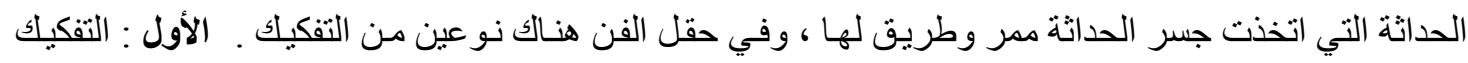

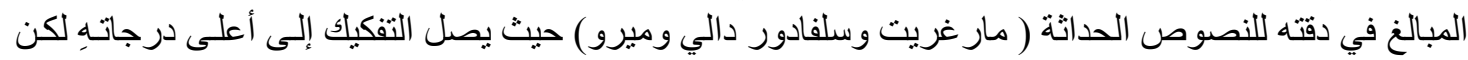




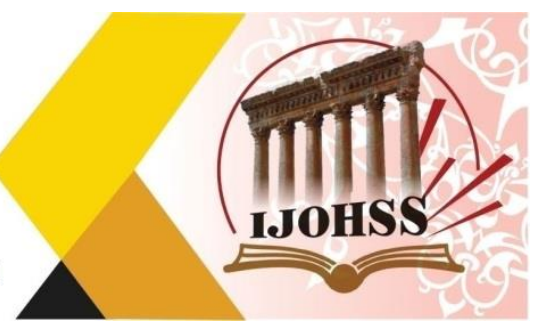

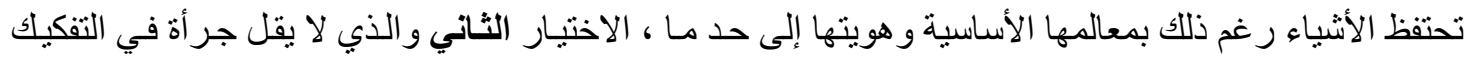

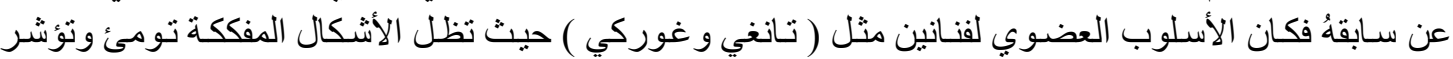

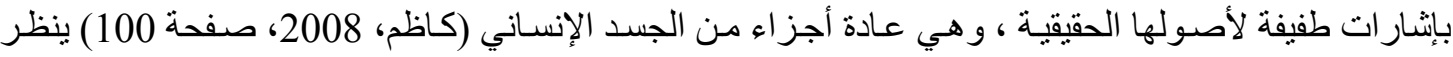

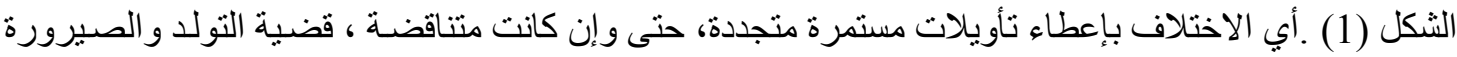

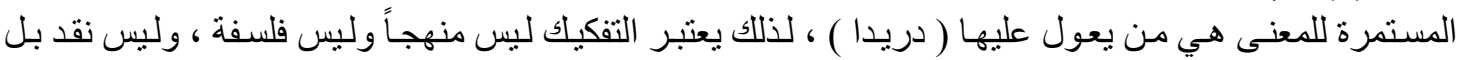
تقويض مستمر.

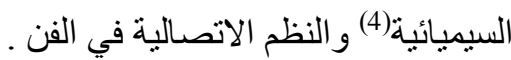

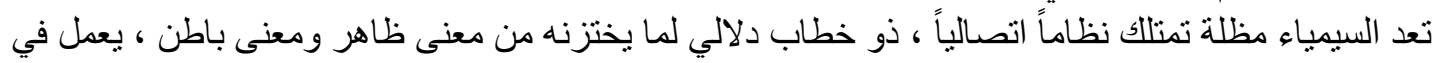

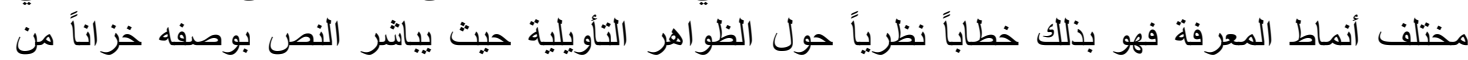

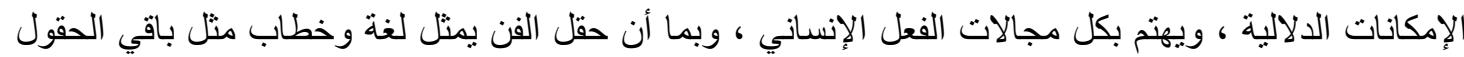

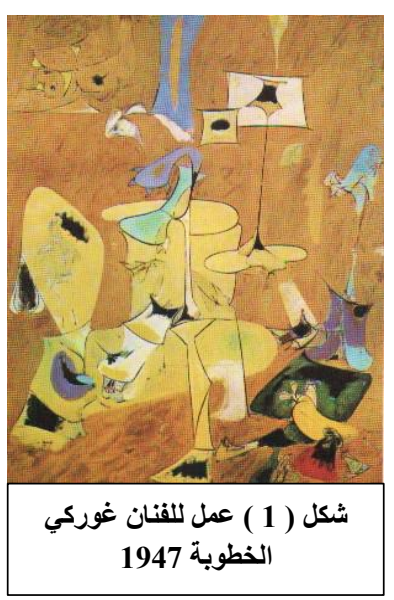

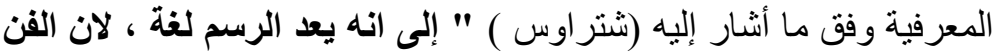

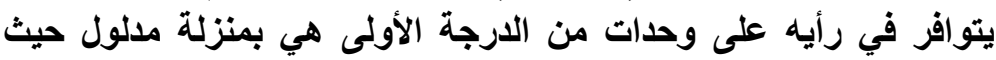

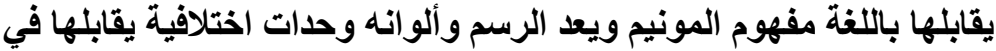

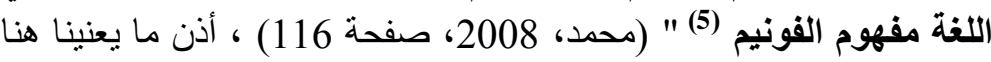

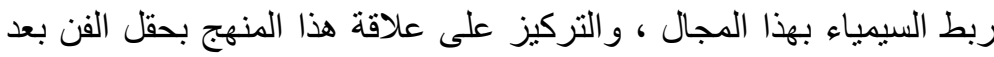

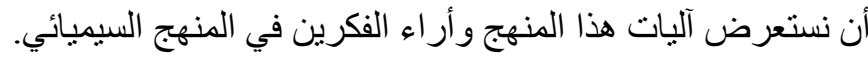

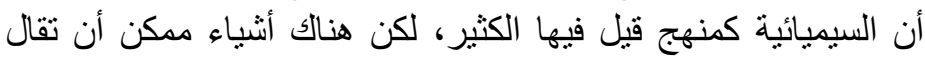

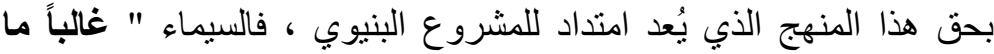

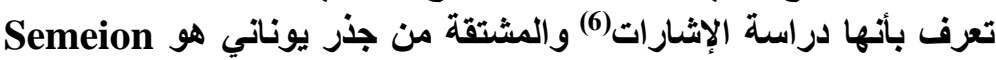

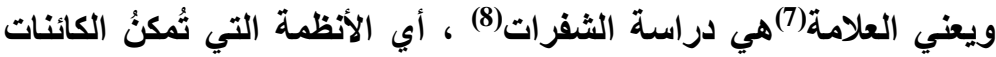

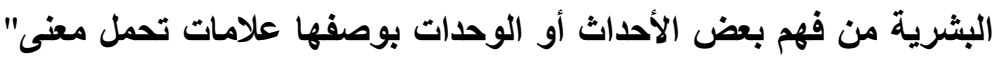

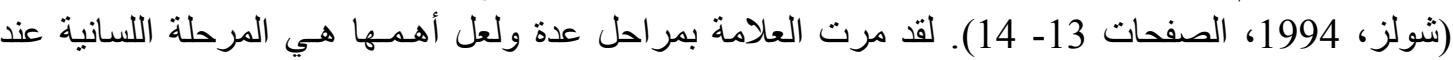

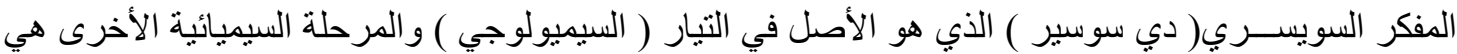

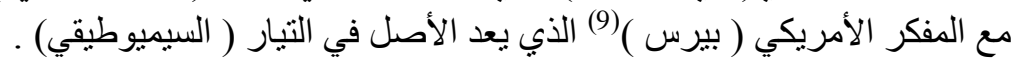

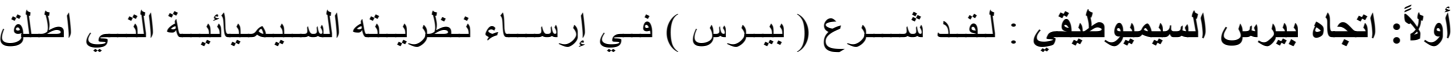

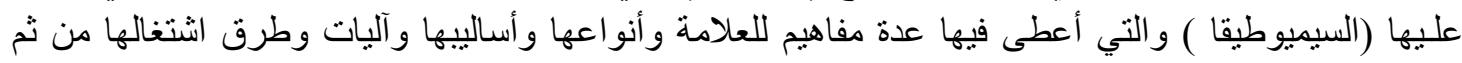

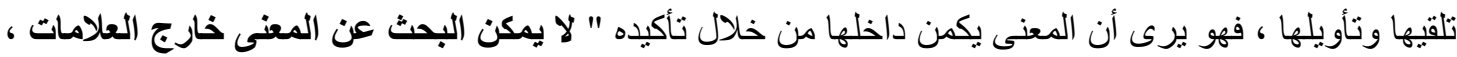

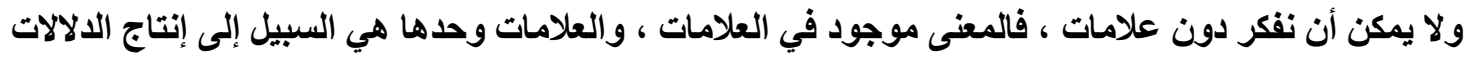

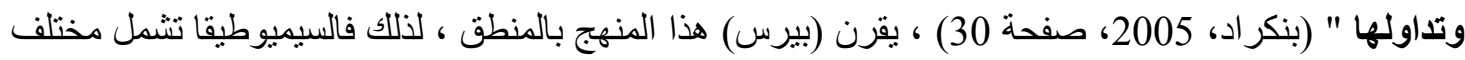

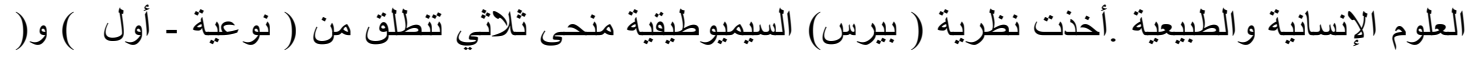

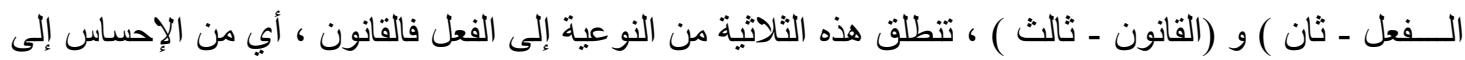

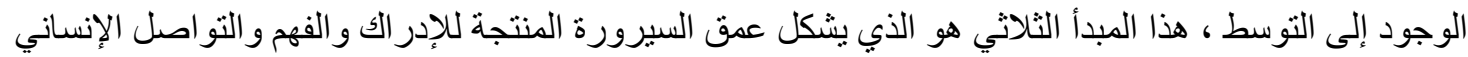

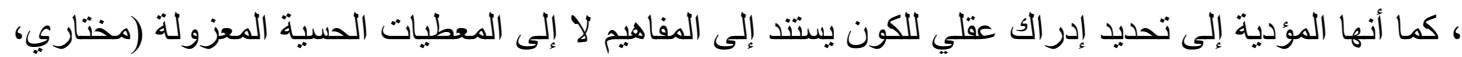

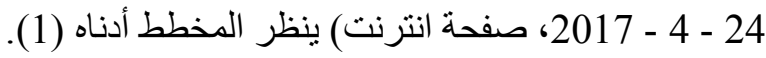



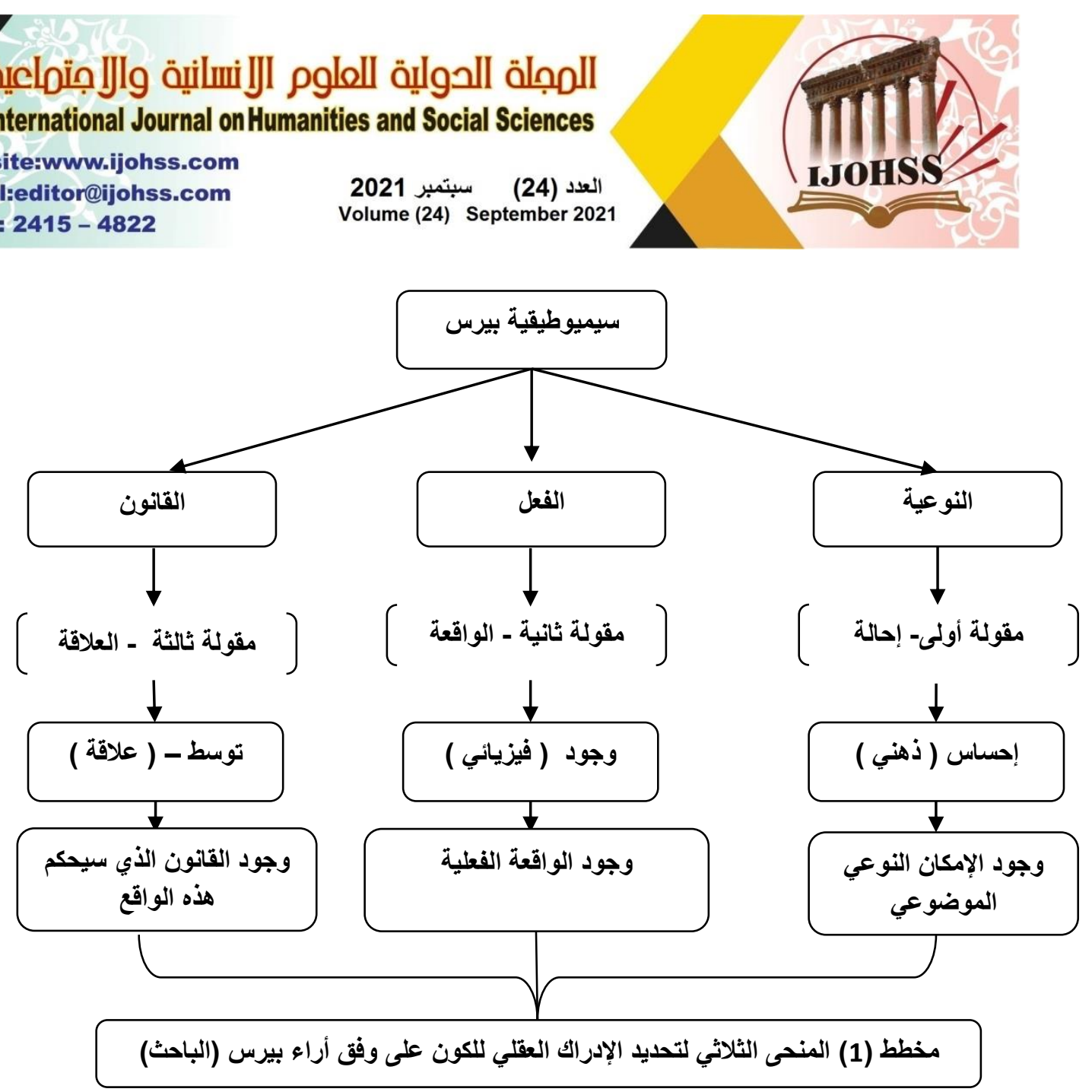

يمكن أن يطبق البرنوكول الرياضي حسب تصور ( بيرس ) في كل ظواهر الكون ، كما يمكن عده أداة فعالة

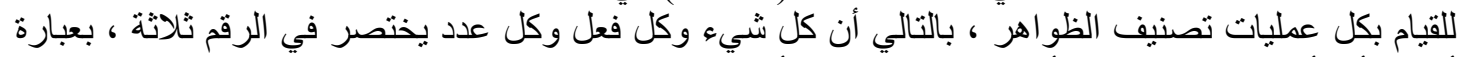

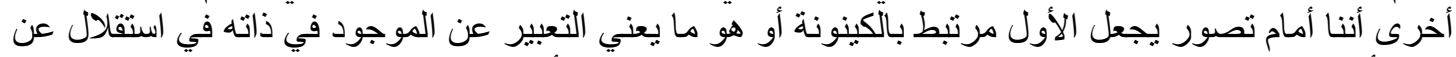

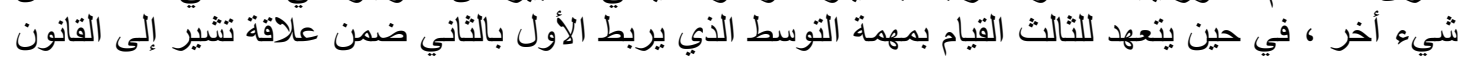
و الضرورة و الفكر ـ (بنكر اد، 2005، الصفحات 42- 47) ينظر المخطط (2)

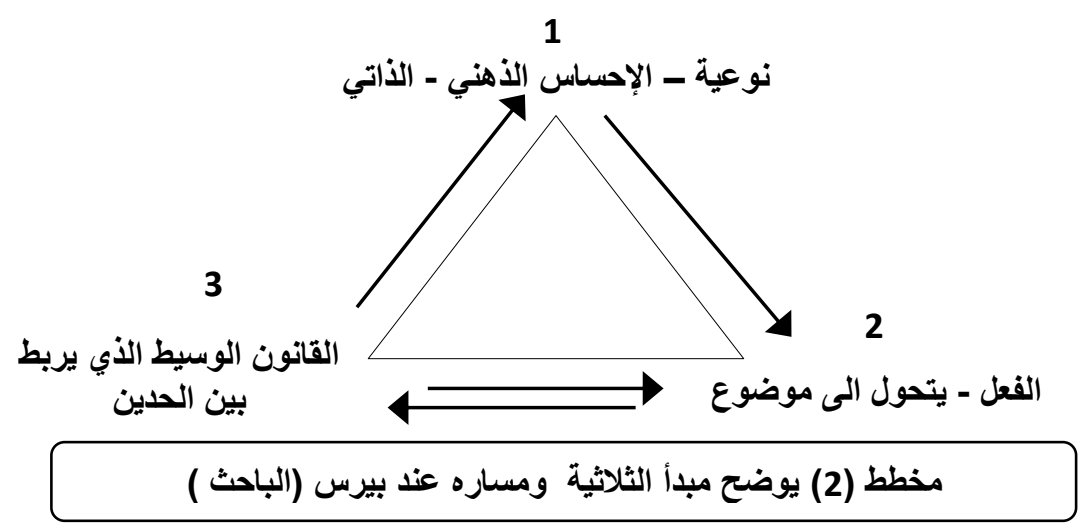




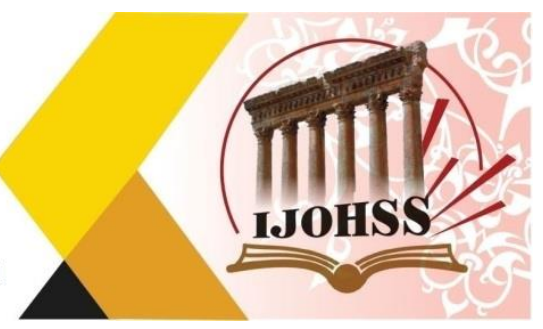

يستشف الباحث بأن التجربة الفنية على ضوء نظرية ( بيرس ) تدرك بإعتبار ها نتاجاً لمستويات ثلاث ( أول -

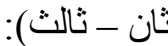

الأولى : التجربة في حال الإمكان ــــ تصور ات ذهنية خاضعة للتركيب و الحـــف والإضافة (صورة ذهنية

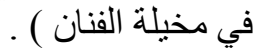

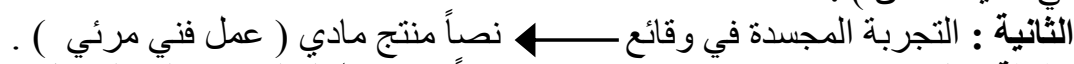

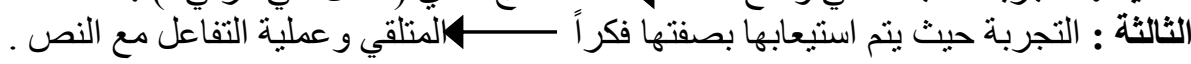

أي أن الحدود الإدر اكية على وفق نظرية ( بيرس) لا يمكن إن تقف عندما يكونه ذهن الفنان وحده ، و والا

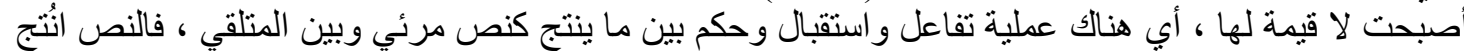

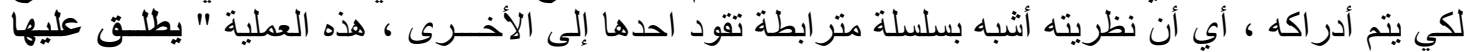

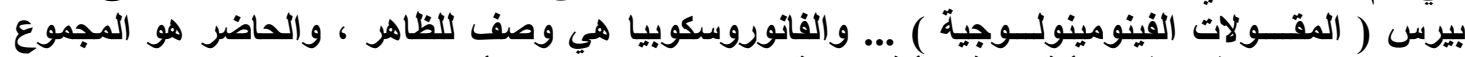

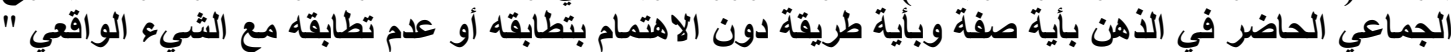

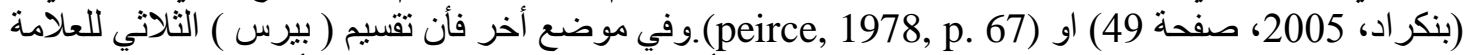

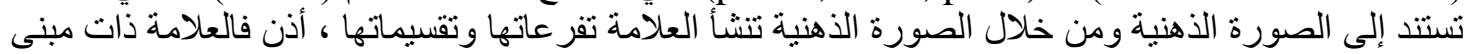

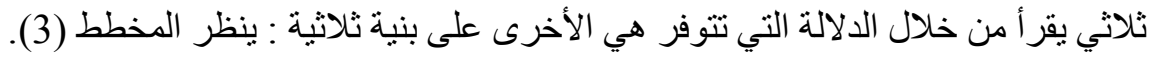

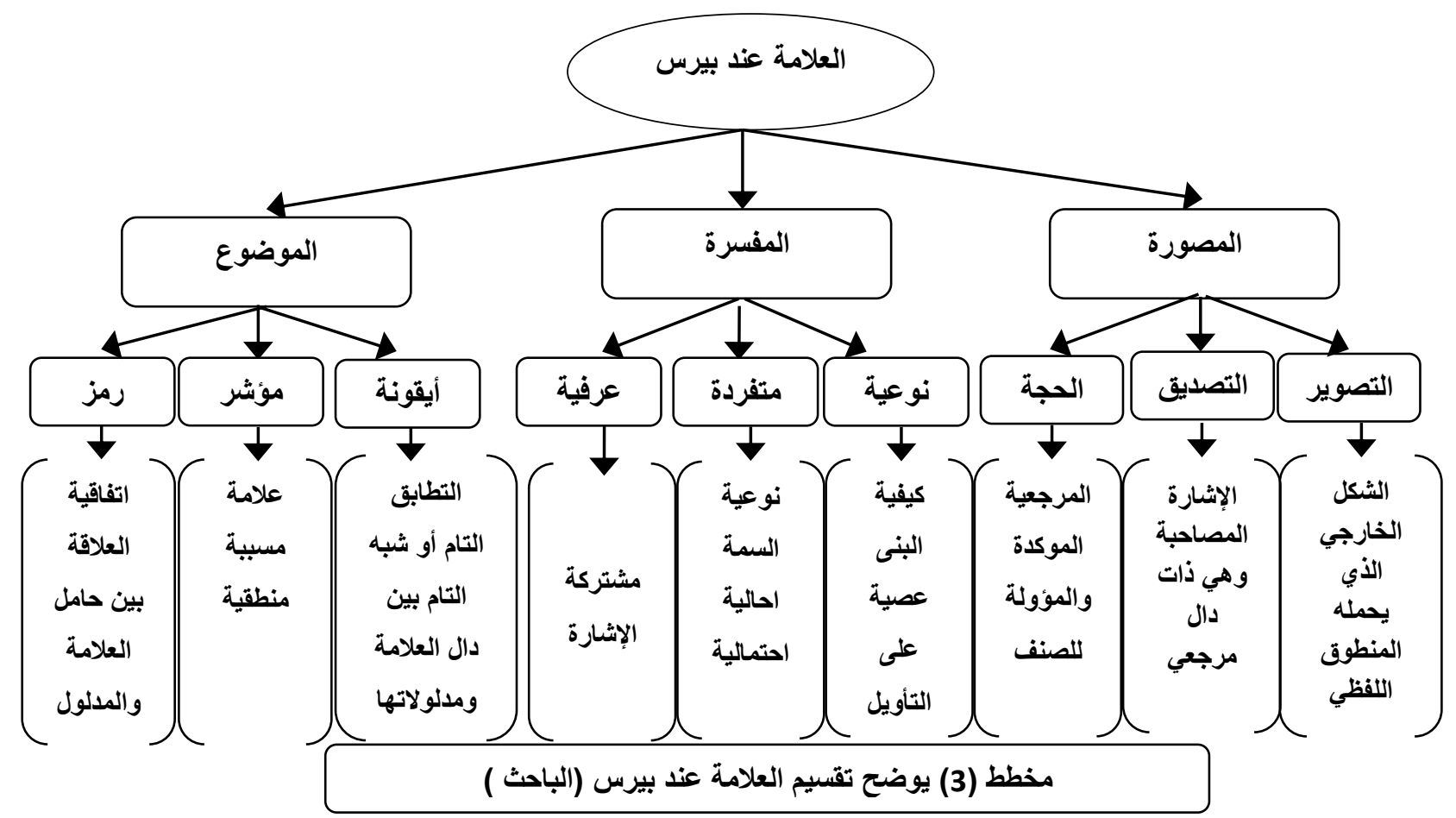




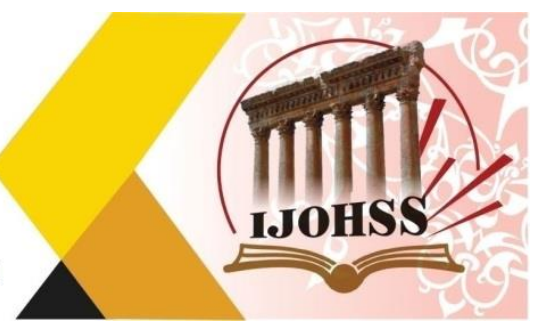

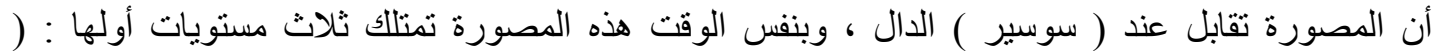

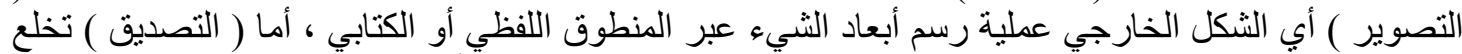

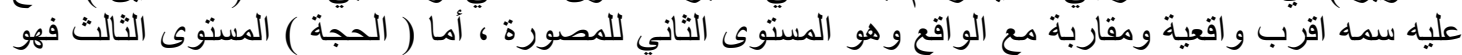

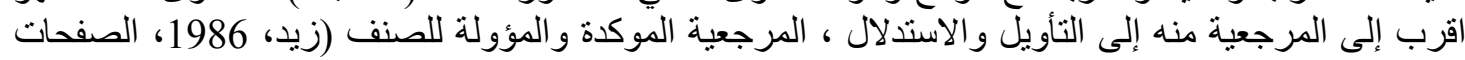

. 27 - 26

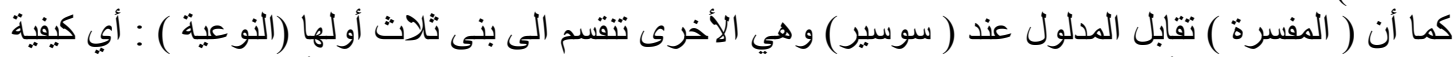

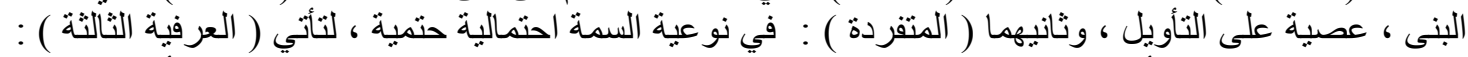

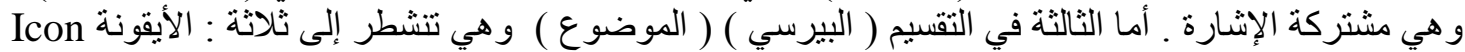

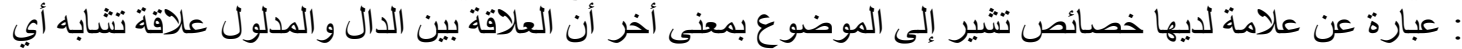

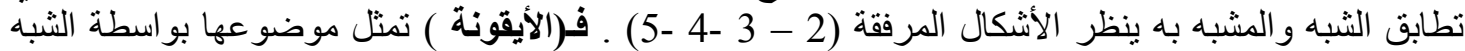

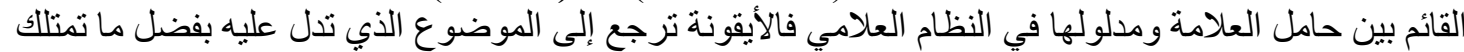

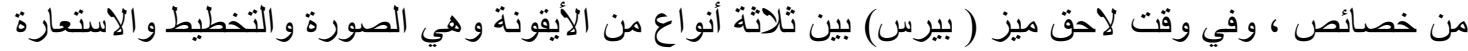

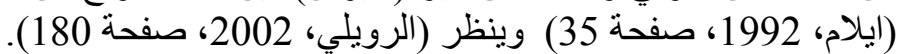
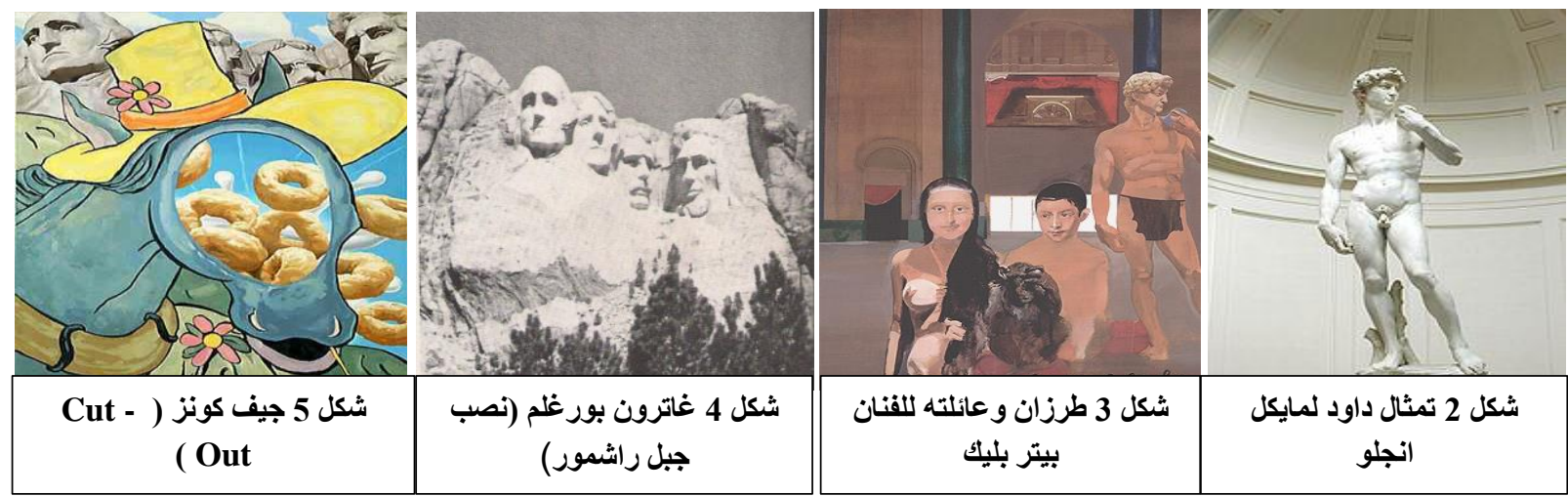

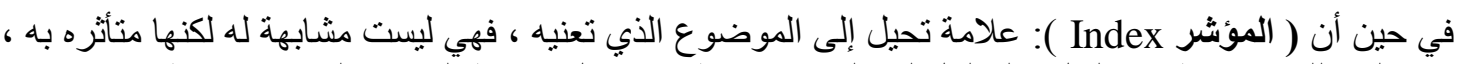

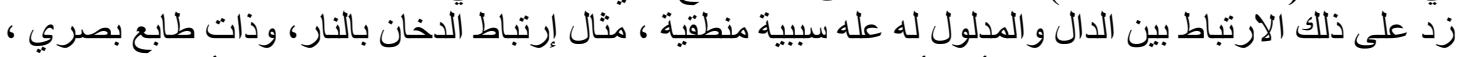

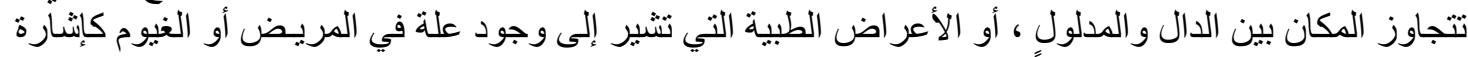

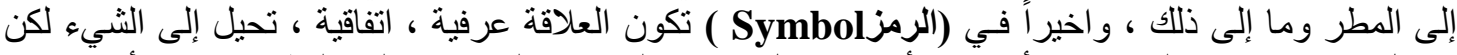

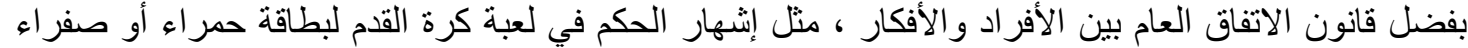

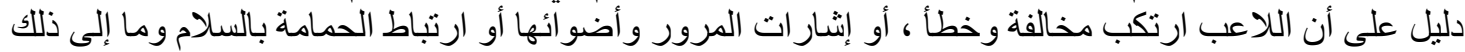

ثانياً : اتجاه سوسير السيميولوجي : يعد ( سوسير ) جز ء مهج وفعال واحد أقطاب المنهج السيميائي ، فقد ركز

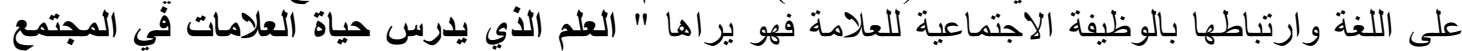

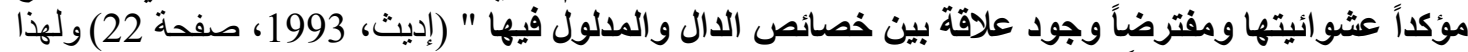

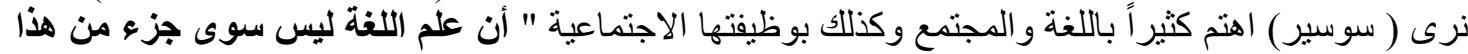

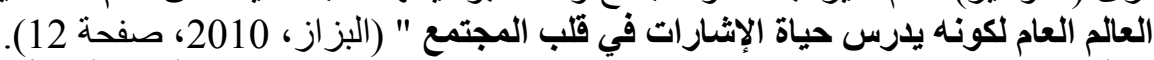

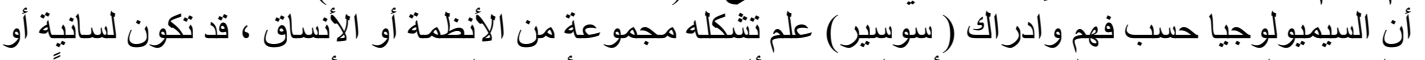

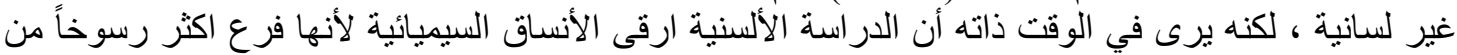

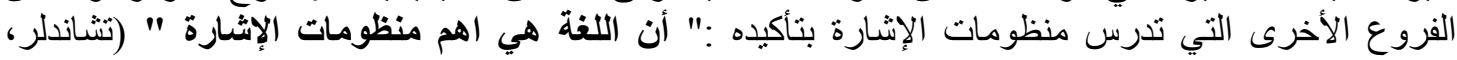

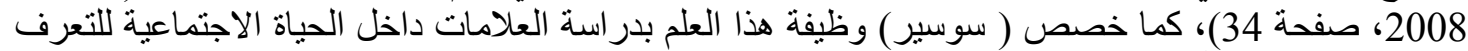

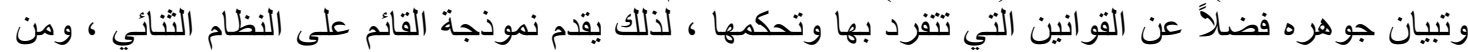

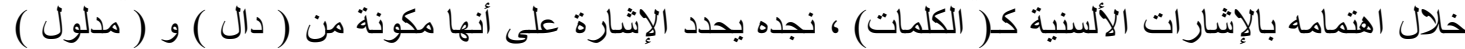

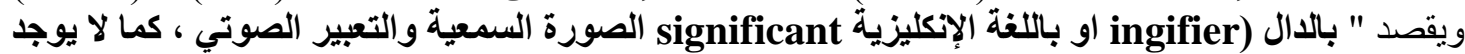




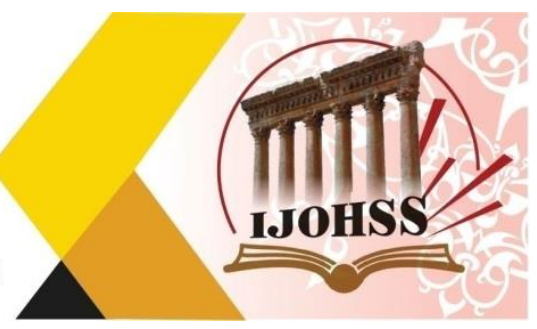

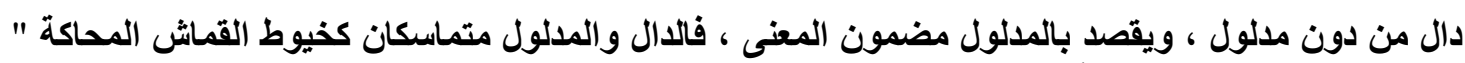

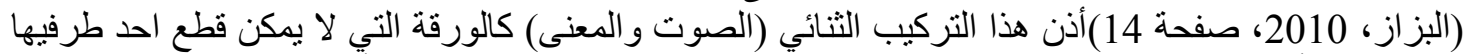

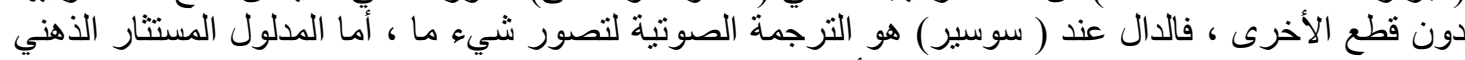
لهذا الدال ولتقريب وجهة النظر ينظر المخطط أدناه (4).
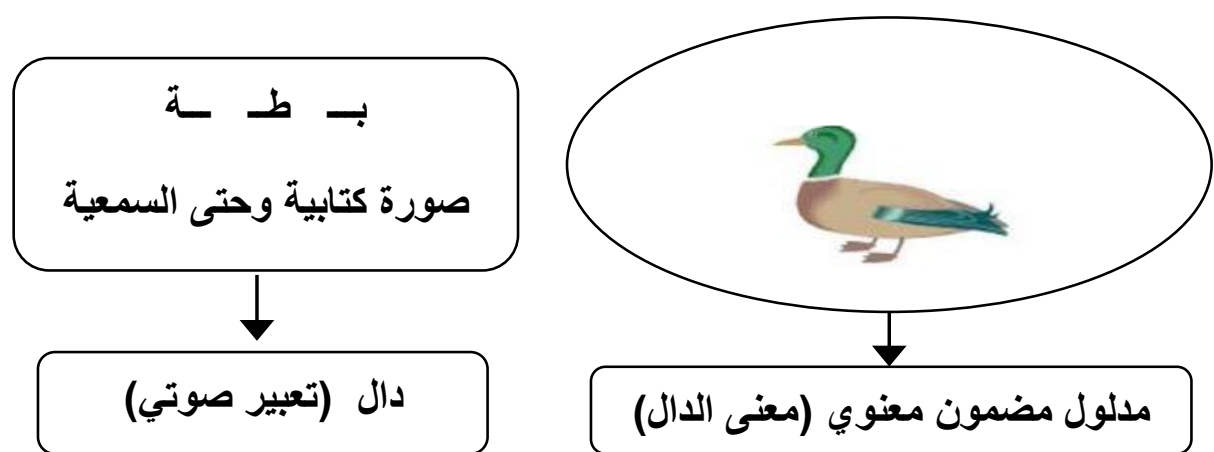

مخطط 4 يوضح اشتغال الدال والمدلول عند دي سوسير كإثـارة لغوية ( الباحث)

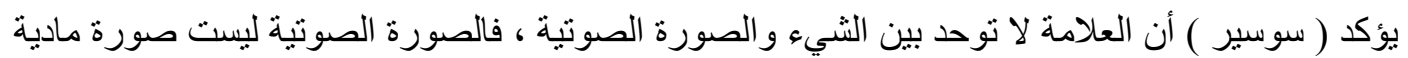

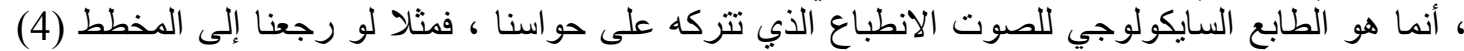

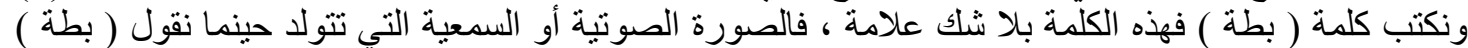

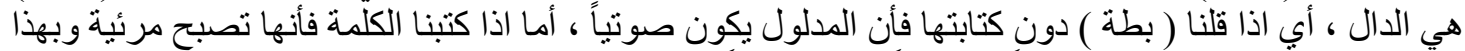

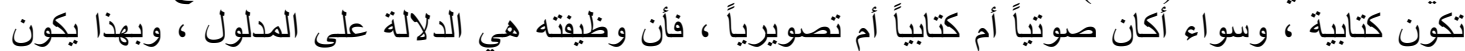

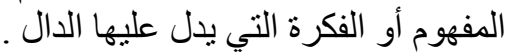

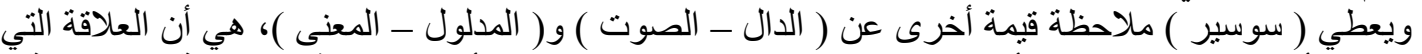

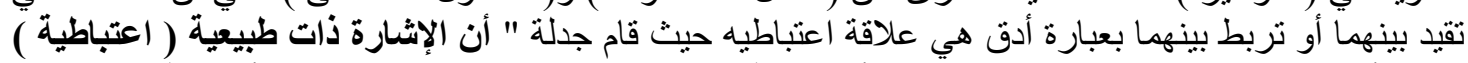

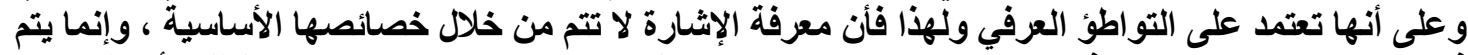

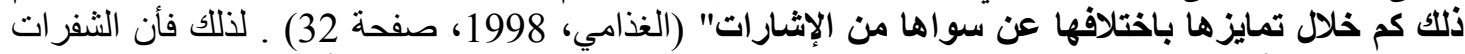

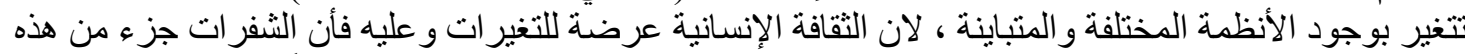

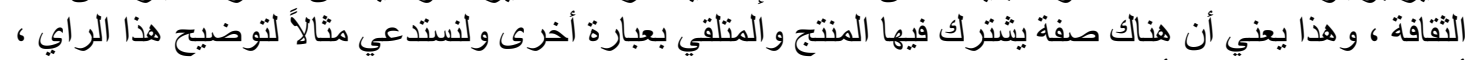

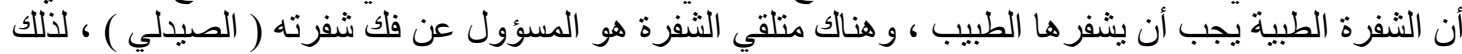

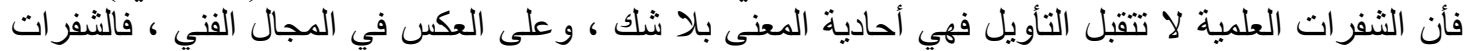

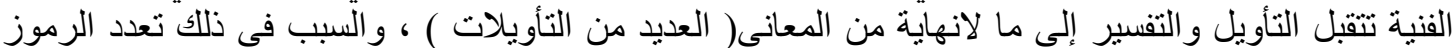

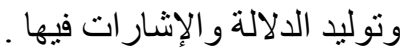

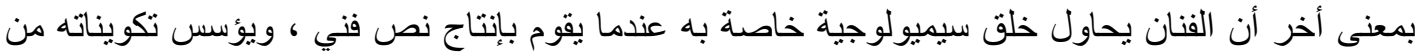

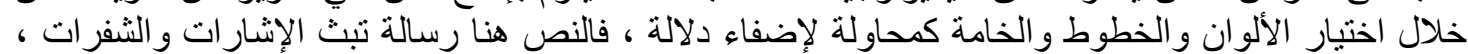

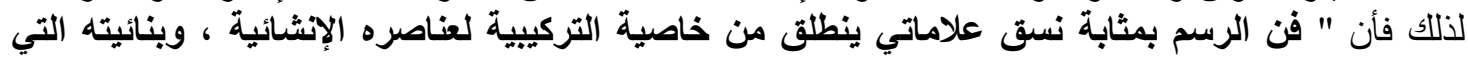

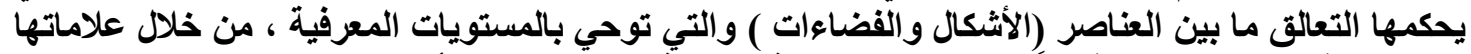

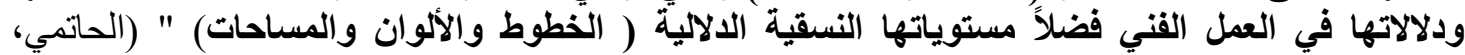

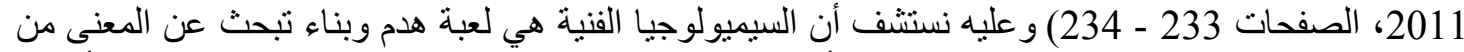

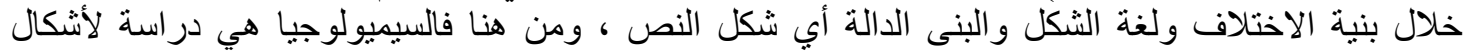

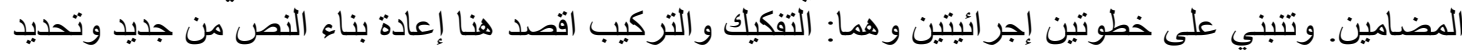

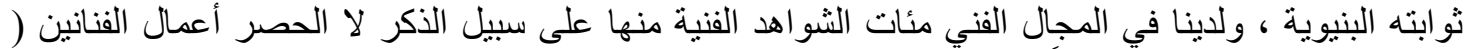

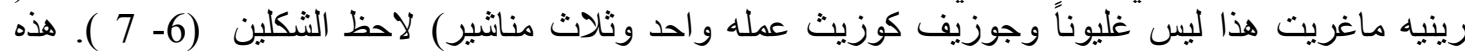




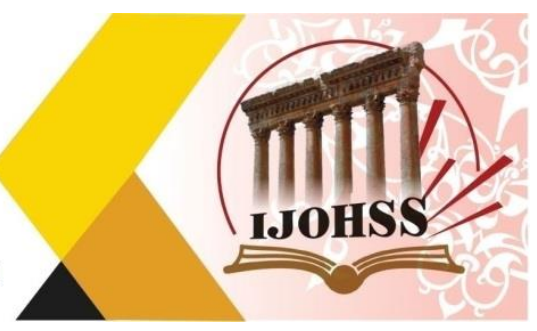

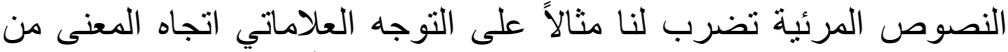

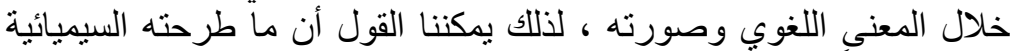

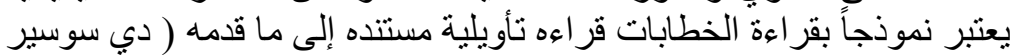

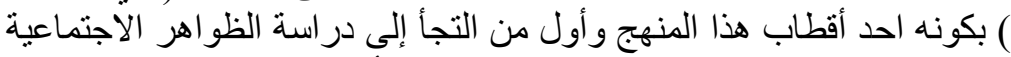

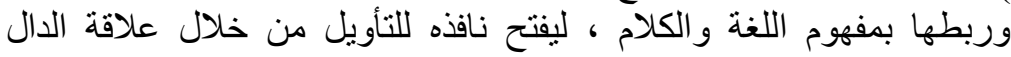

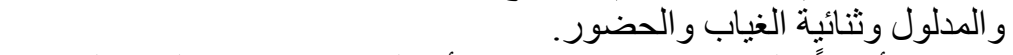

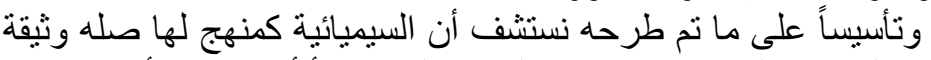

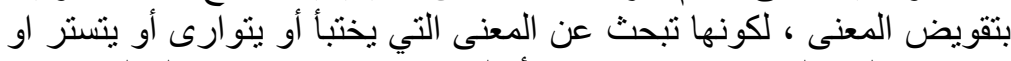

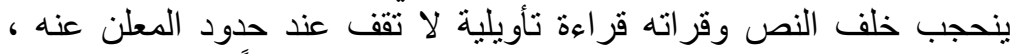
فالنص الفني ليس مجرد خطاب ينتجه الفنان ليبقى محتفظاً بمعنى ثابت لابت على على

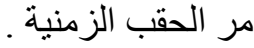

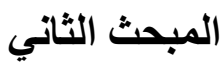 \\ الرسم التجريدي قراعة تاريخية ( الجذور والنشأة )}

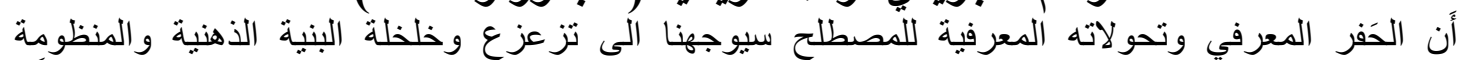

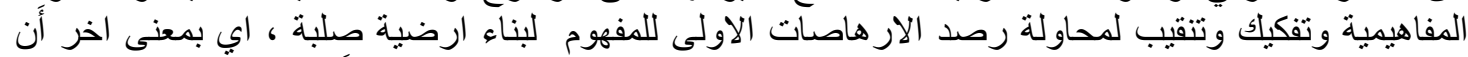

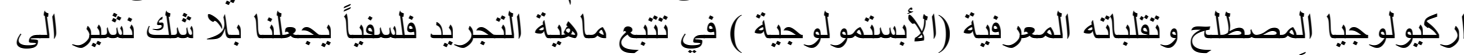

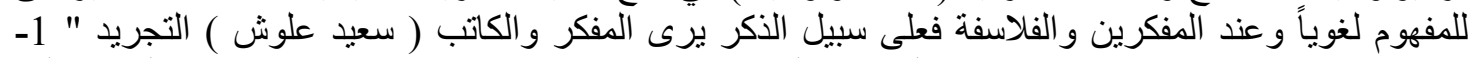

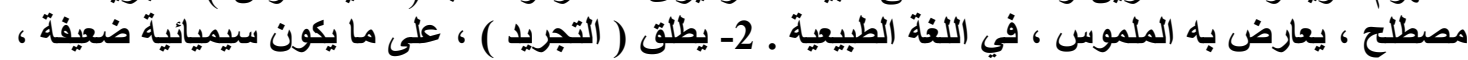

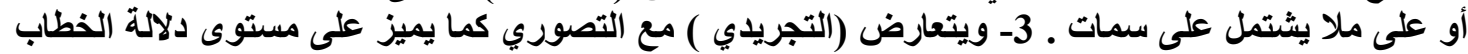

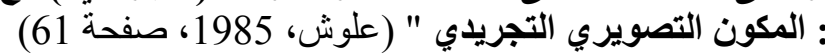
التجريد في الفن التهوير

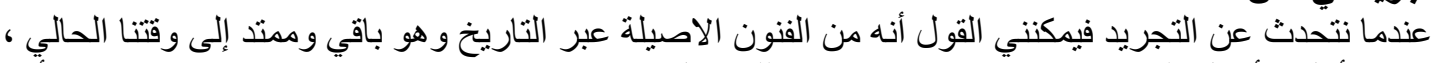

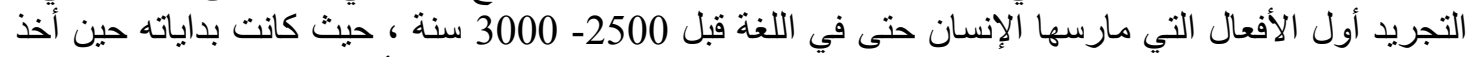

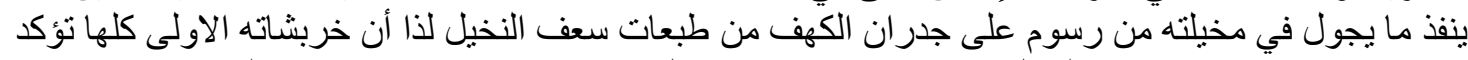

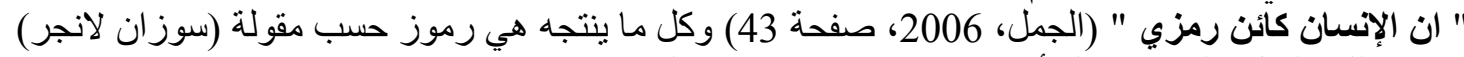

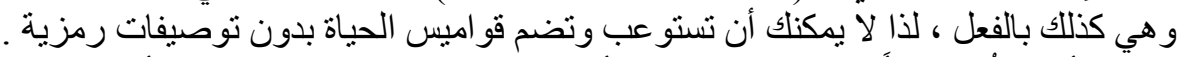

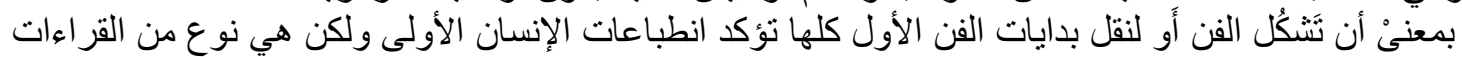

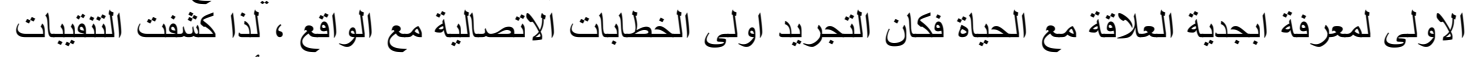

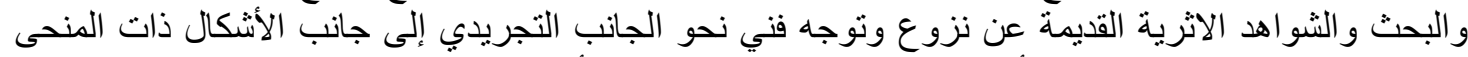

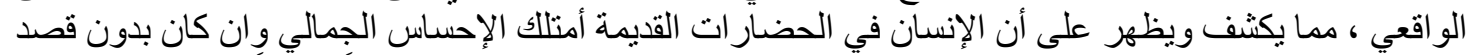

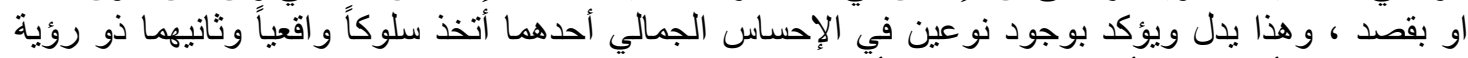

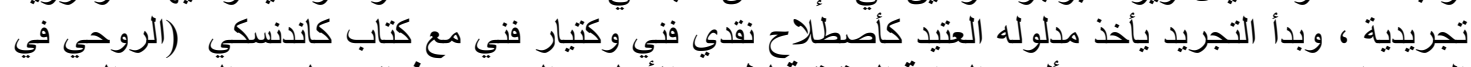

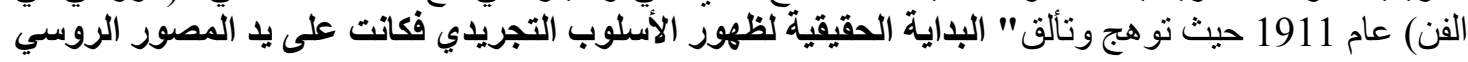




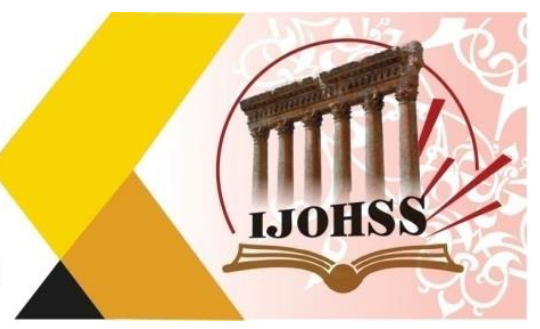

الكبير كندنسكي " (اسماعيل، 1974، صفحة 192) ، ، قبل ذللك فان التجريد فهو نزعة شاملة في كل في أَعمال

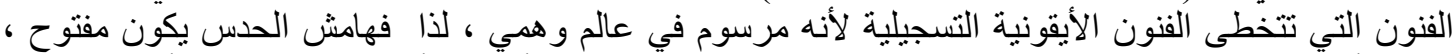

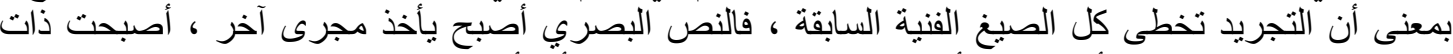

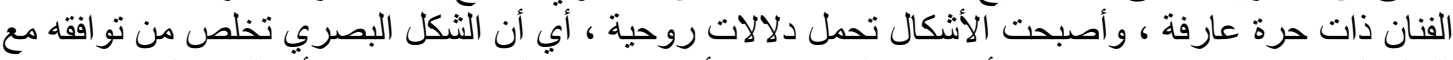

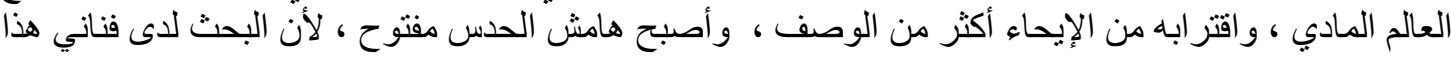

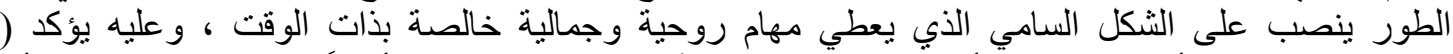

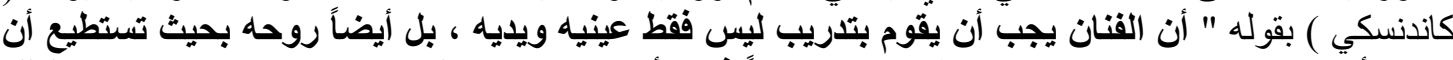

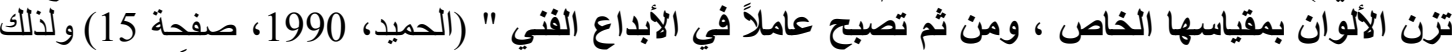

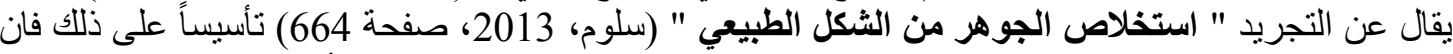

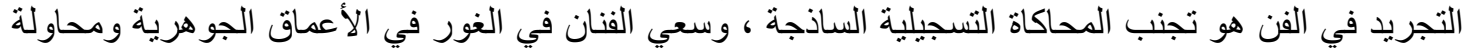

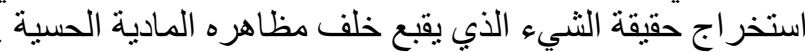
يمكنني القول أن الفن التجريدي أشنرق وتو هج مع كتاب ( كاندنسكي) الثهير ( الروحية في الفن) وهو " ظاهرة

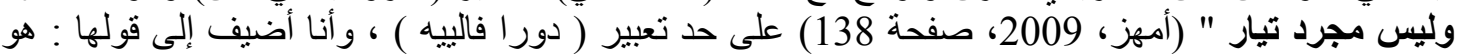

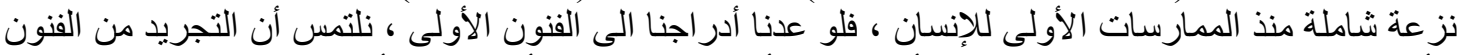

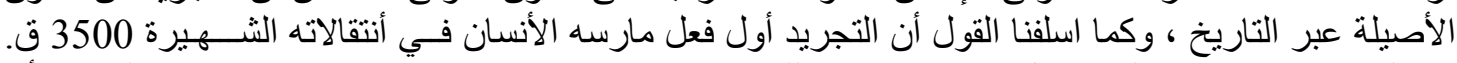

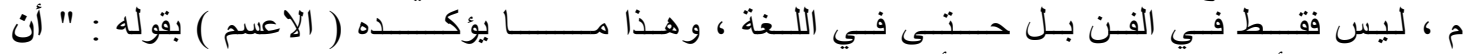

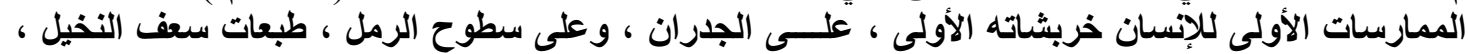

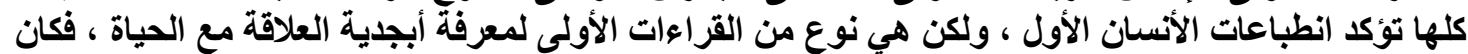

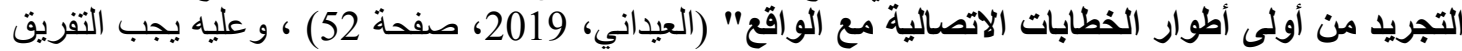

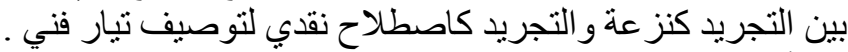

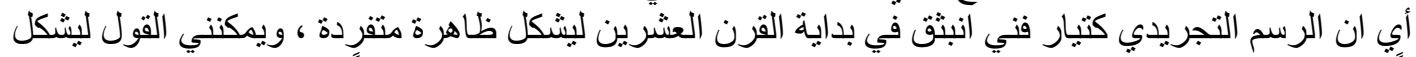

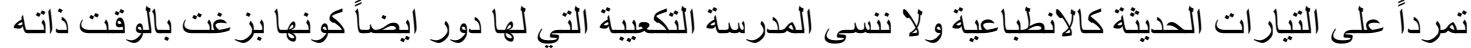

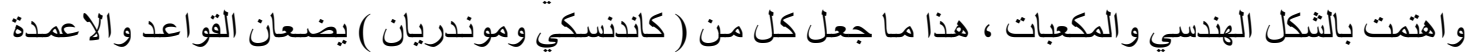

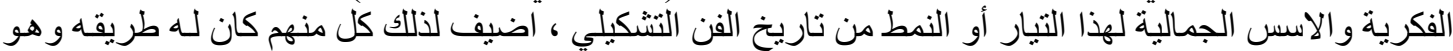

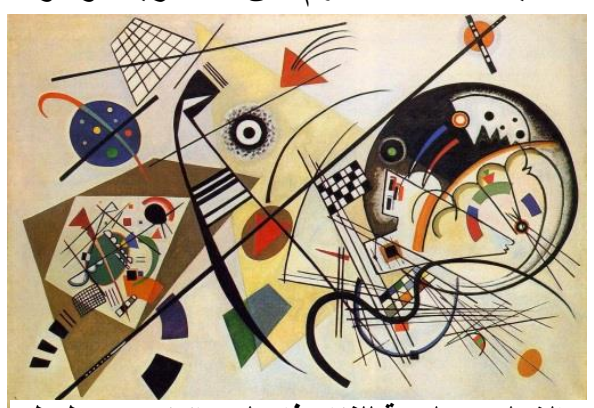

الثكل (8) لوحة للفنان فاسيلي كاندنسكي خطوط مستعرضة 1923

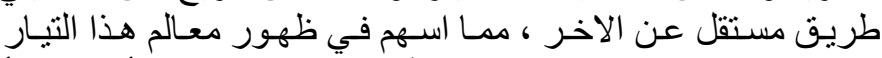

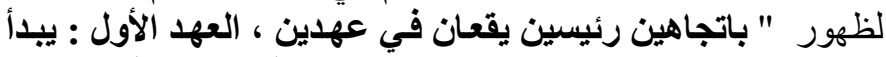

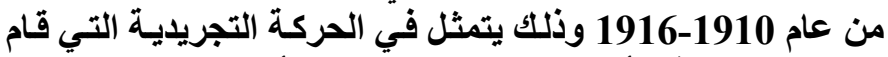

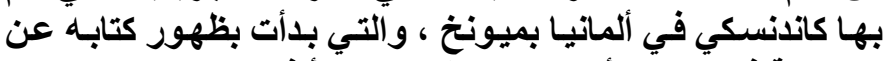

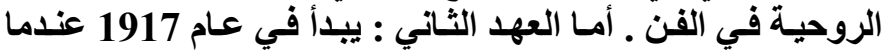

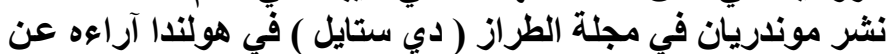

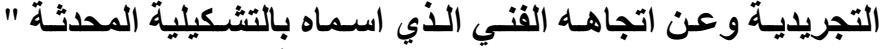

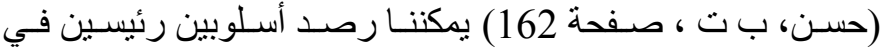

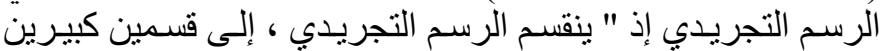

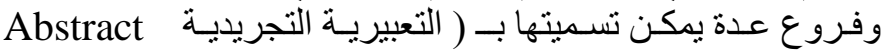
Geometric و (Expressionism (Abstractionism ) وقد تز عم النزعة الأولى( فاسيلي كاندنسكي )، بينما تز عم النز عة الأخرى (بيت موندريان

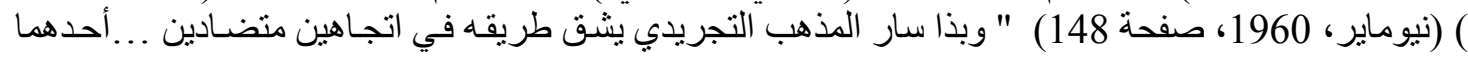

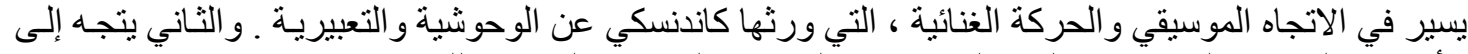

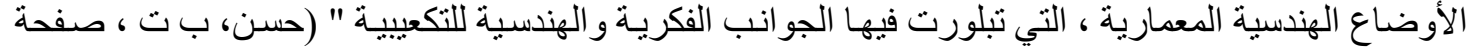

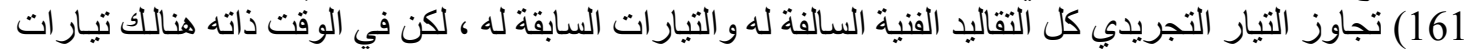

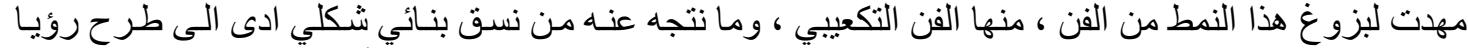
مغايرة وجديدة عن العالم الحسي بحيث تركت الحسي خلفها وتخلت عن العالم المرئي أن صحت التسية التسمية واتجهت 


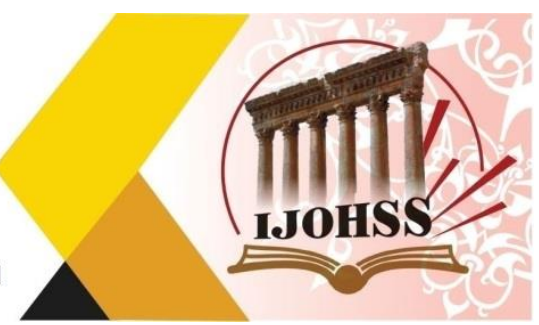

الىى التوجهه نحو الجمـال السـامي و هذه تتفق مـع طروحات الفلاسفة منهم ( افلاطون و كانت ) لتطرح بنـاءات هندسية.

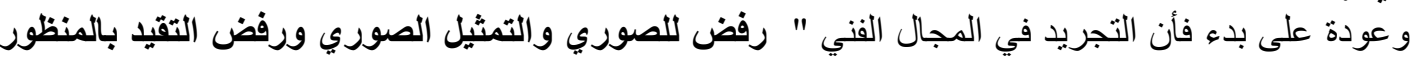

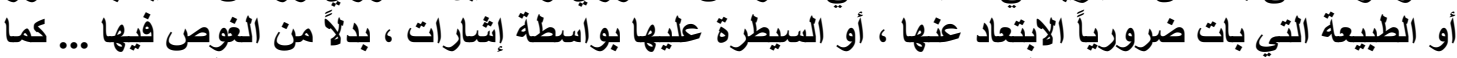

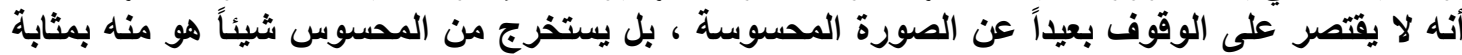

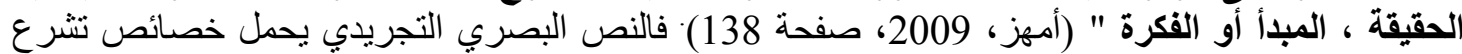

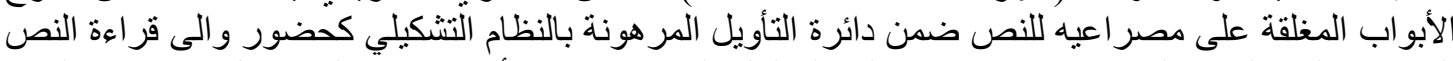

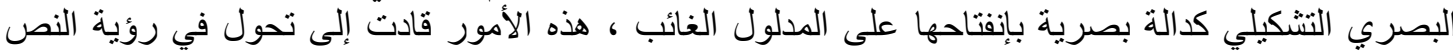

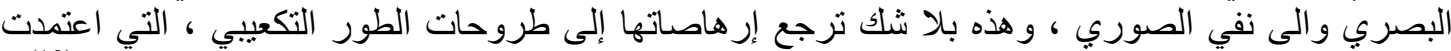

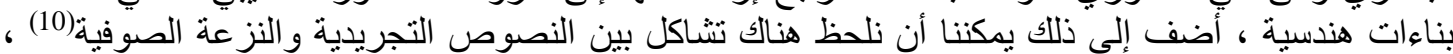

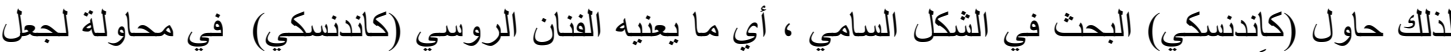

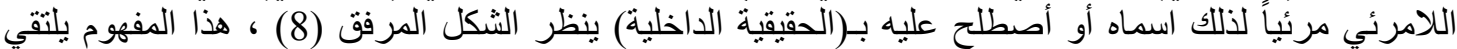

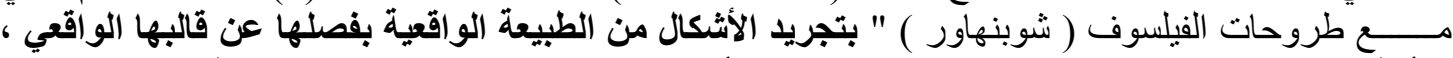

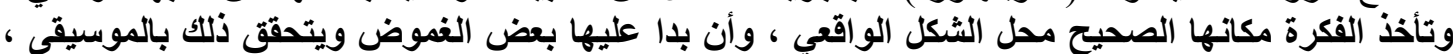

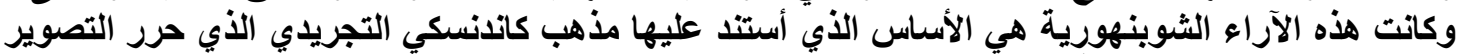

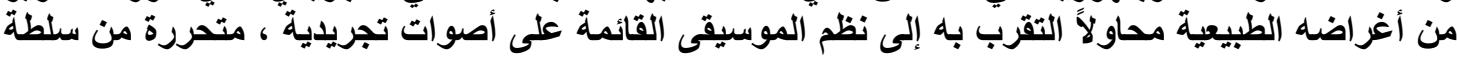

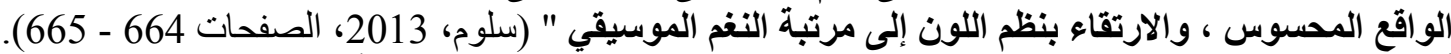

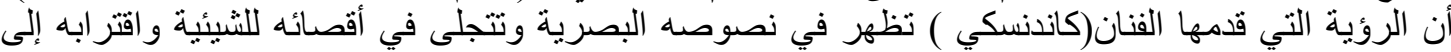

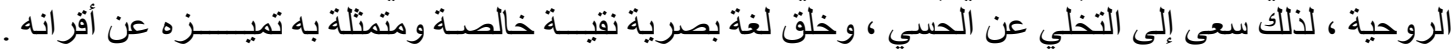

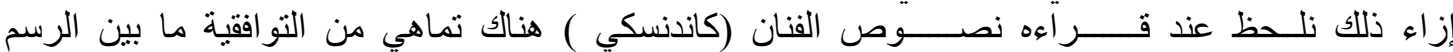

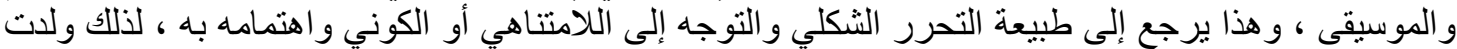

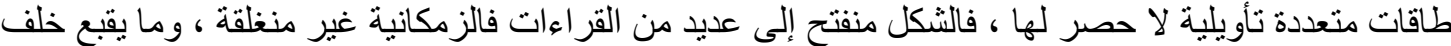

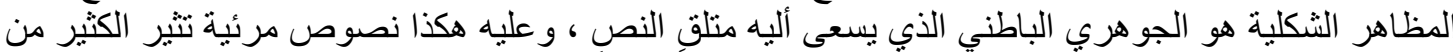

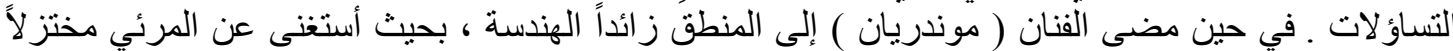

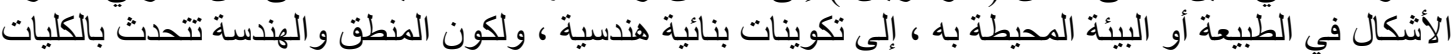

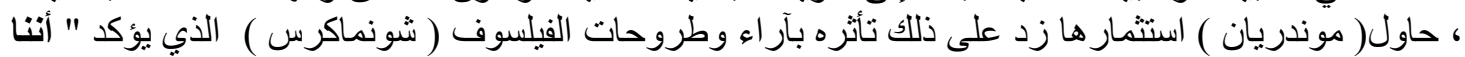

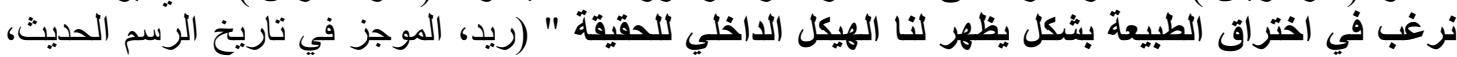
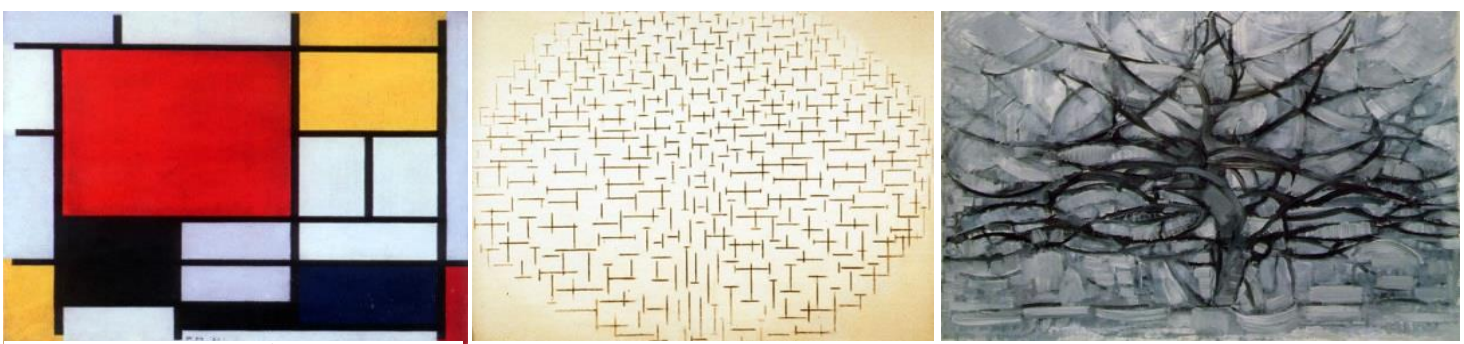

الثكل (9) لوحة للفنان موندريان الثجرة الثكل (10) لوحة للفنان موندريان الرصيف الثكل (11) لوحة للفنان موندريان تكوين ، لورئ

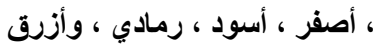
و والمحيط تكوين 10 - 1915

الرمادية 1912

(1921) 


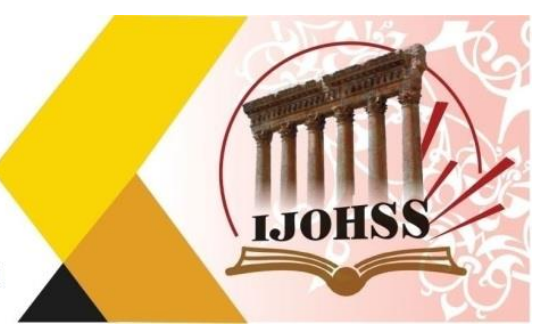

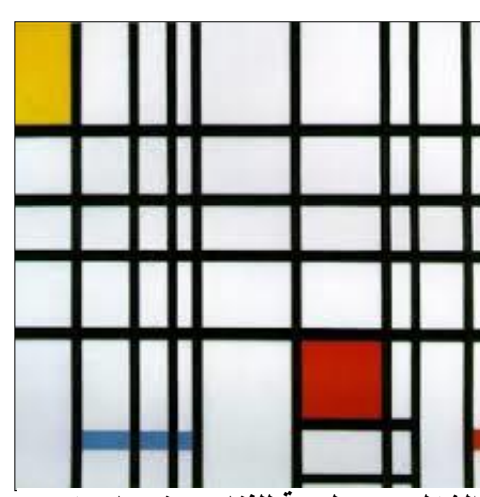

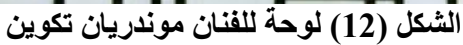
، أصفر ، أسود ، رمادي لـنان موندريان ، وأزرق

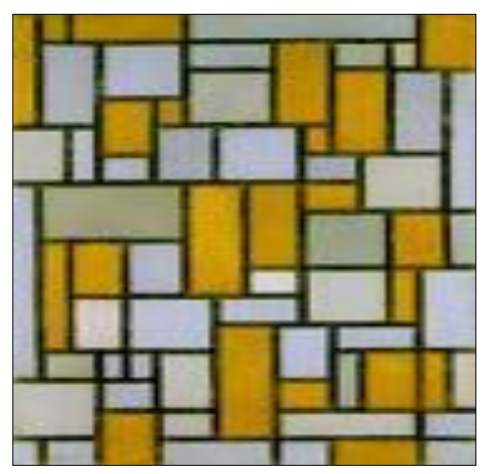

الثكل (13) لوحة للفنان موندريان تكوين

أن نصوص موندريان يتضح فيها نسق الإزاحات التي جعلت من هذا

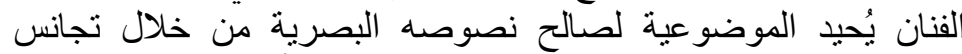

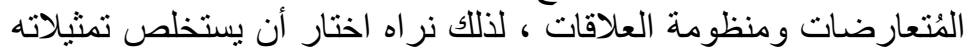

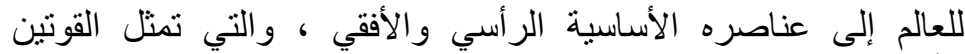

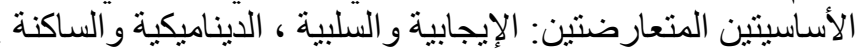

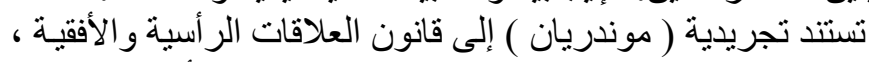

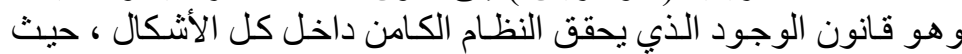

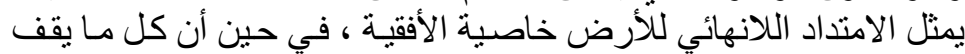

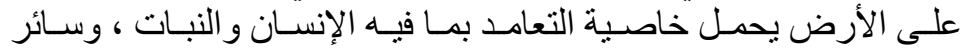

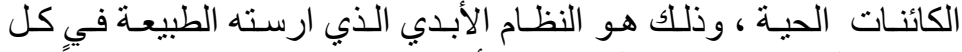

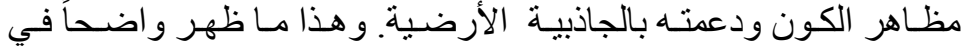
الكثير من أعمال الفنان التي يظهر فيها التعامد بين التين الخطوطو الأشكال

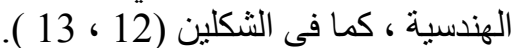

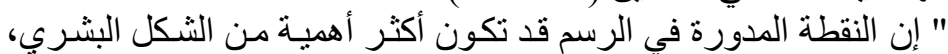

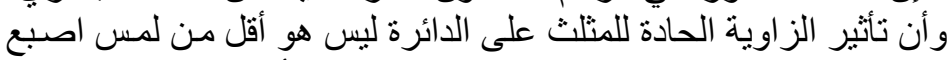

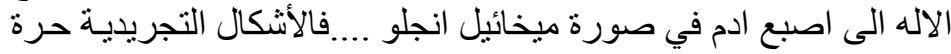

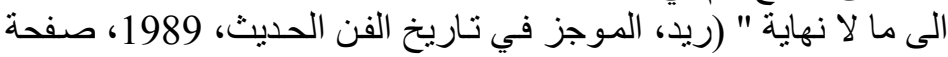

من هنا نجد أن الأعمال التجريدية التي منلت اتجاهات الرسم التجريدي

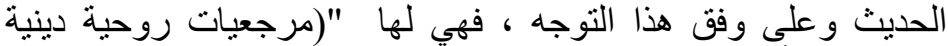

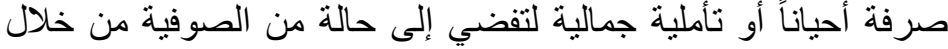

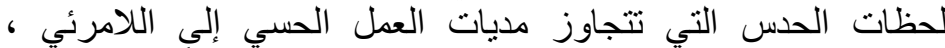

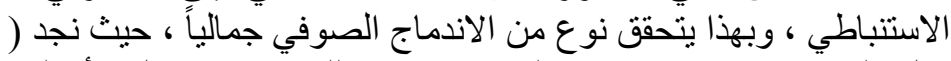

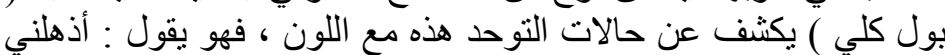

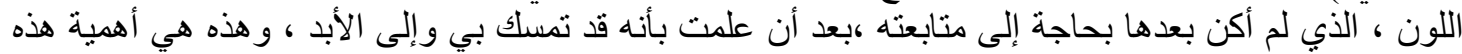

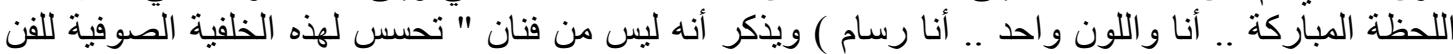

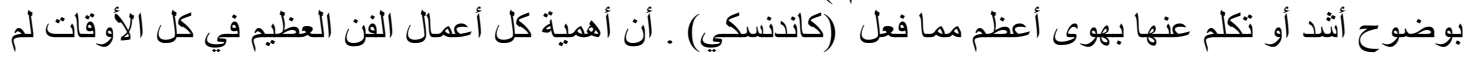

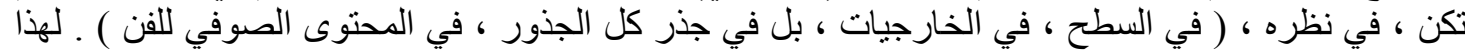

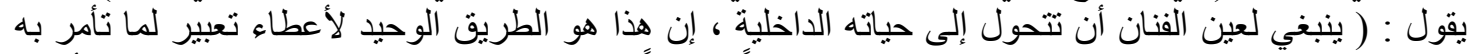

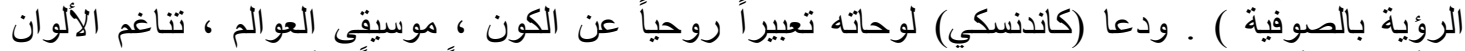

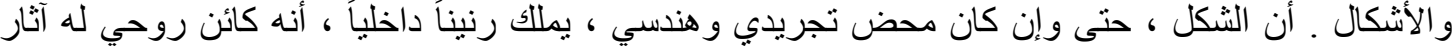

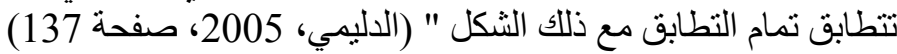

\section{الفصل الثالث

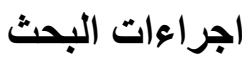

اولا : أطار مجتمع البحث : يتكون اطار مجتمع البحث من (50 ) نصاً بصرياً فنياً لأعمال الفنانين التجريديين

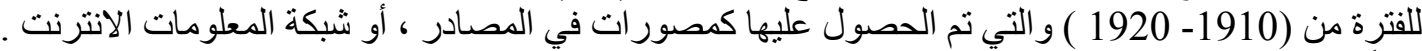

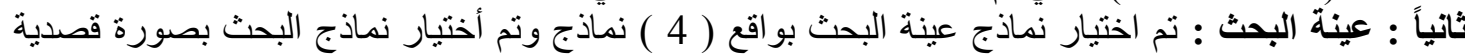

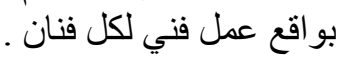




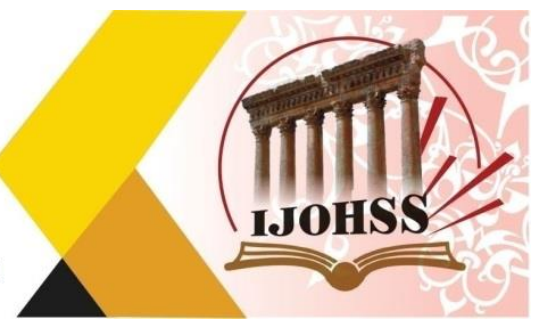

ثُالثاً : أداة البحث : أعتمد الباحث أداة الملاحظة التي تخدم البحث الحالي في كثير من طروحاته لأنها تساعد على الإنى

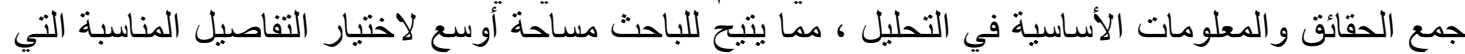

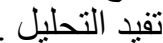

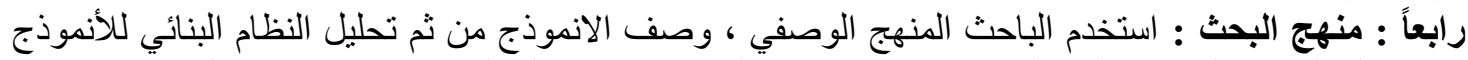

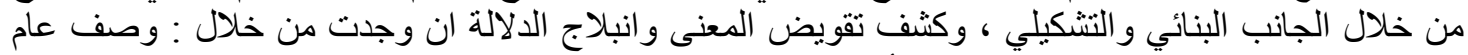

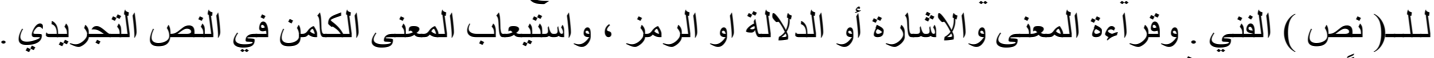

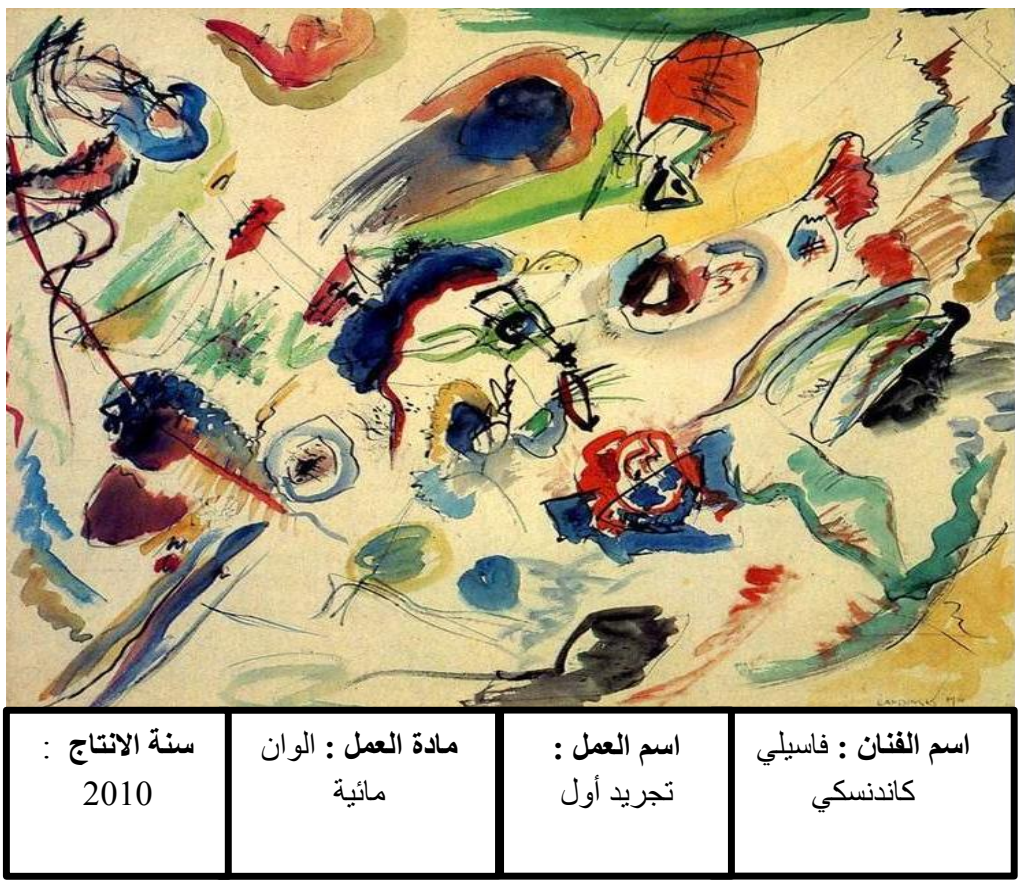

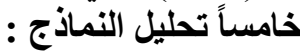
) انموذج (1)

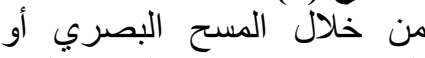
العياني ، نرصد النص النص الفني يتألف من مجمو عة لونية منتشرة على السطح التصويري بحيث استخدم الفنان (كاندنسكي) الوان الان

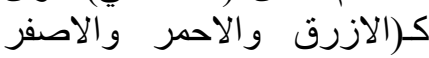
وبعض تدرجاته تلك الالوان

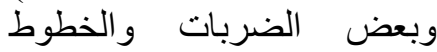

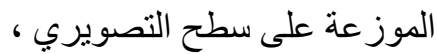
ينسب هذا النص التى الاعمال التجريدية بل هو بوابة هذا التبار التيال

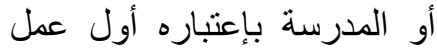

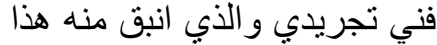
التيار في حقل الرسم الحديث. ان الاشكال البنائية للسطح النية التصويري تكمن في استنطاق النيكالية

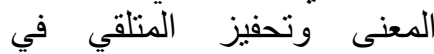

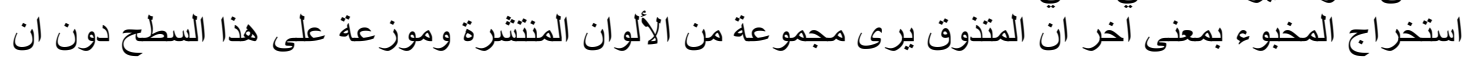

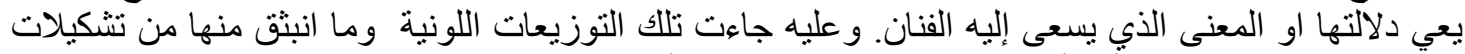

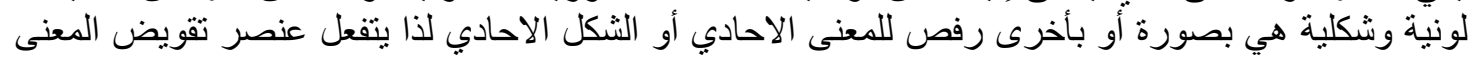

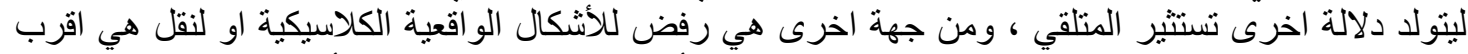

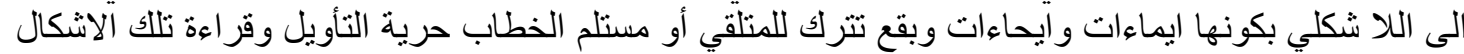

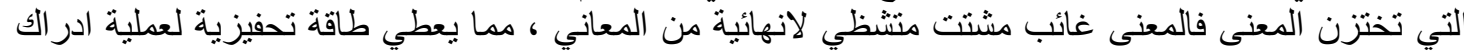

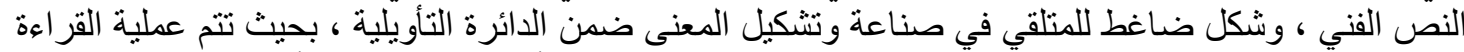

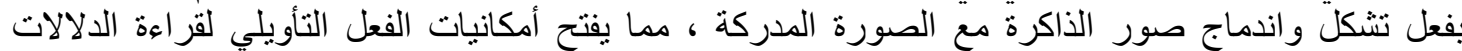

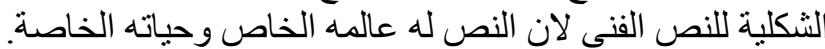

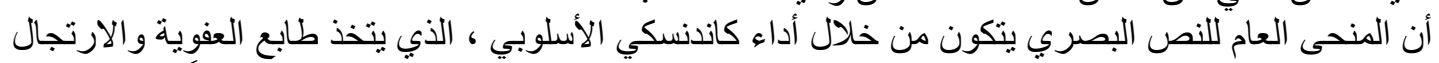

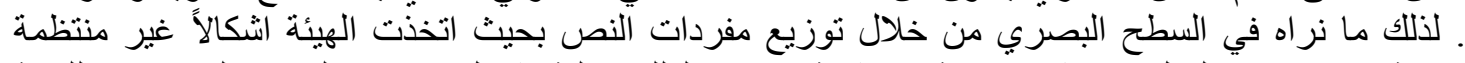

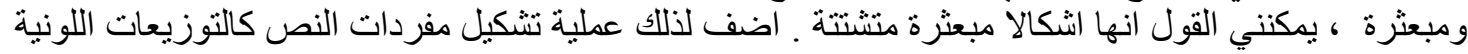

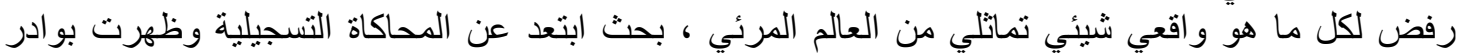

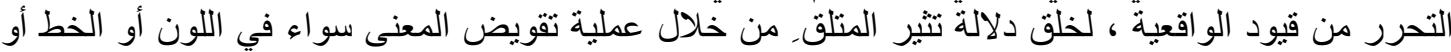

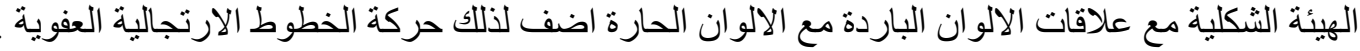




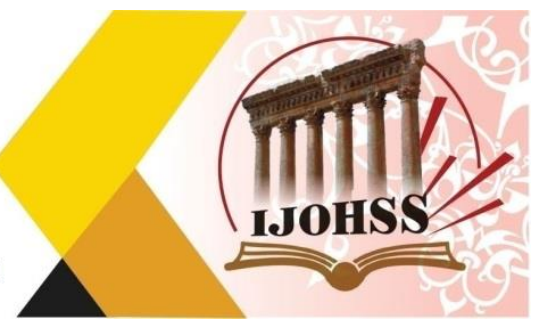

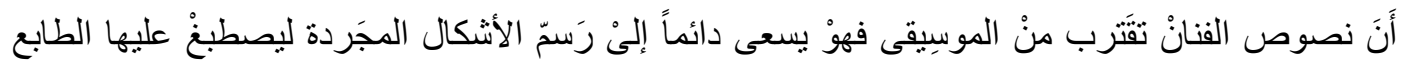

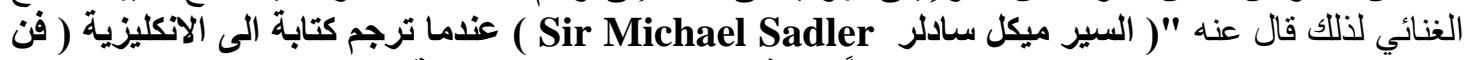

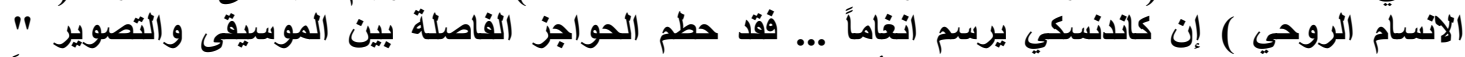

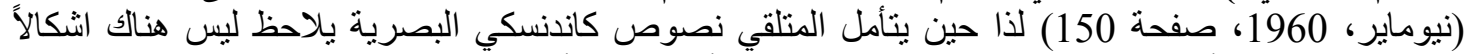

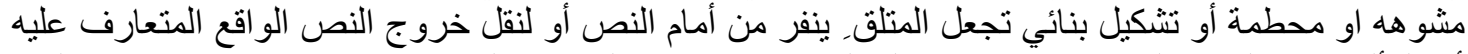

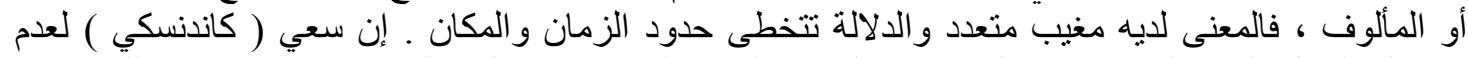

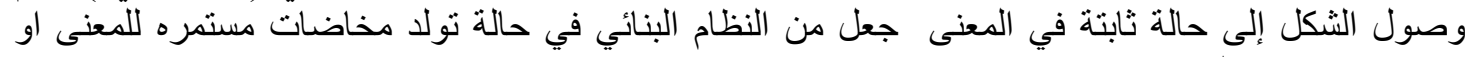

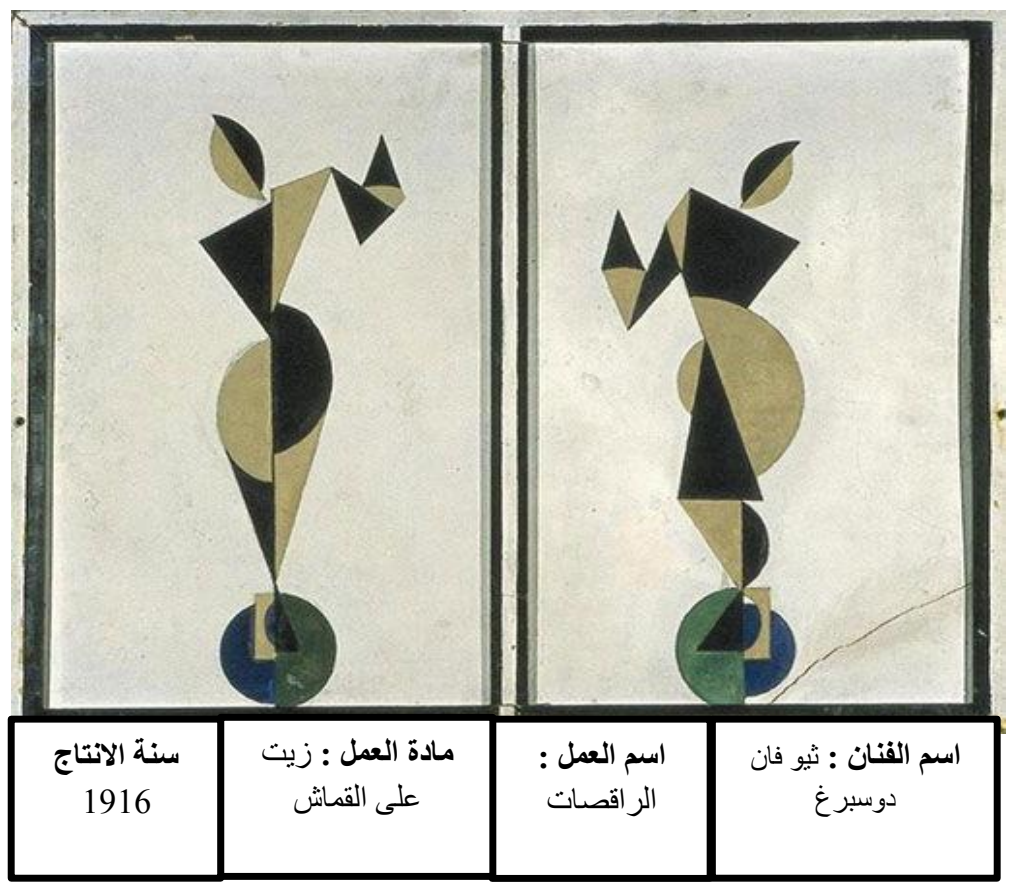

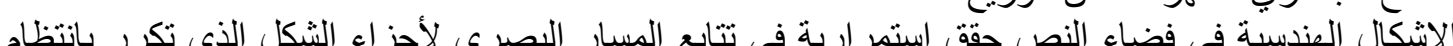

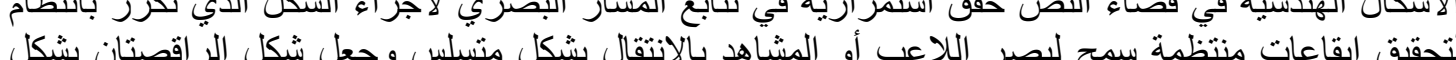

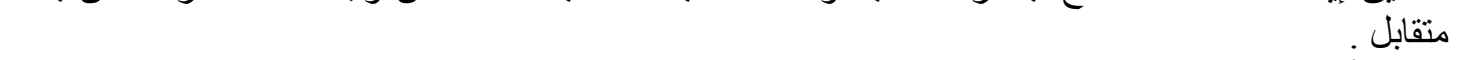

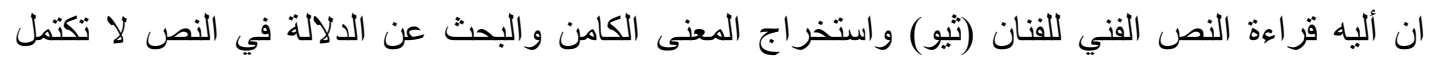

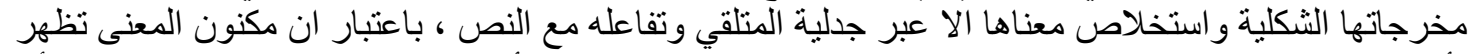

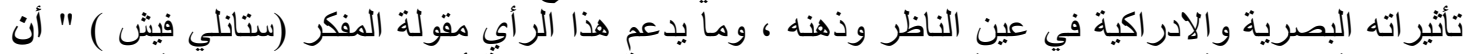

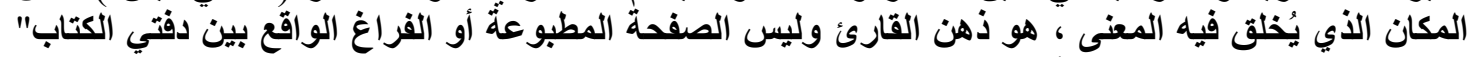

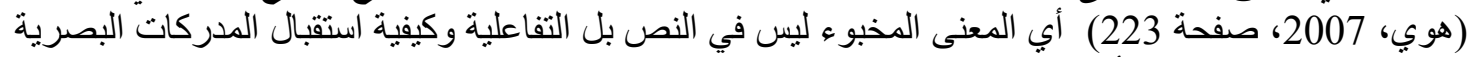

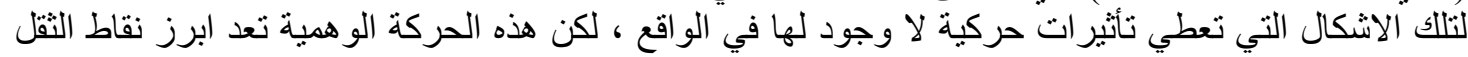

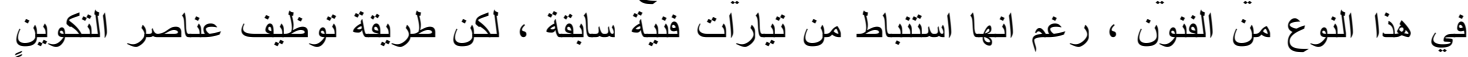

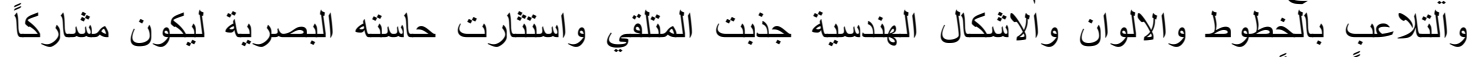

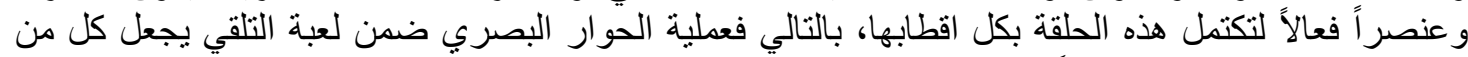

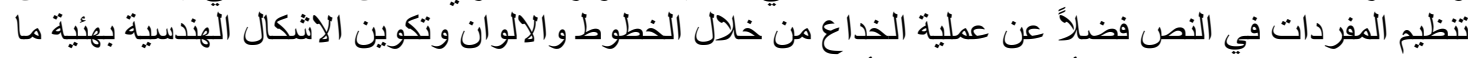

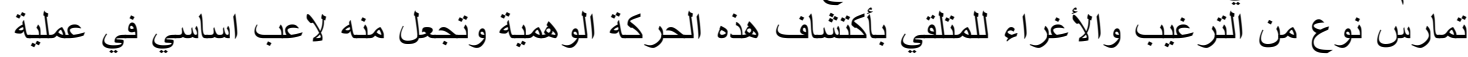

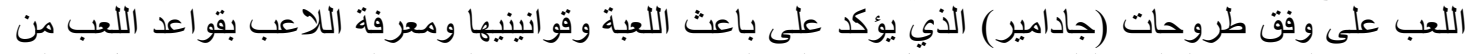

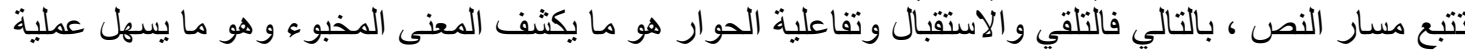

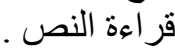



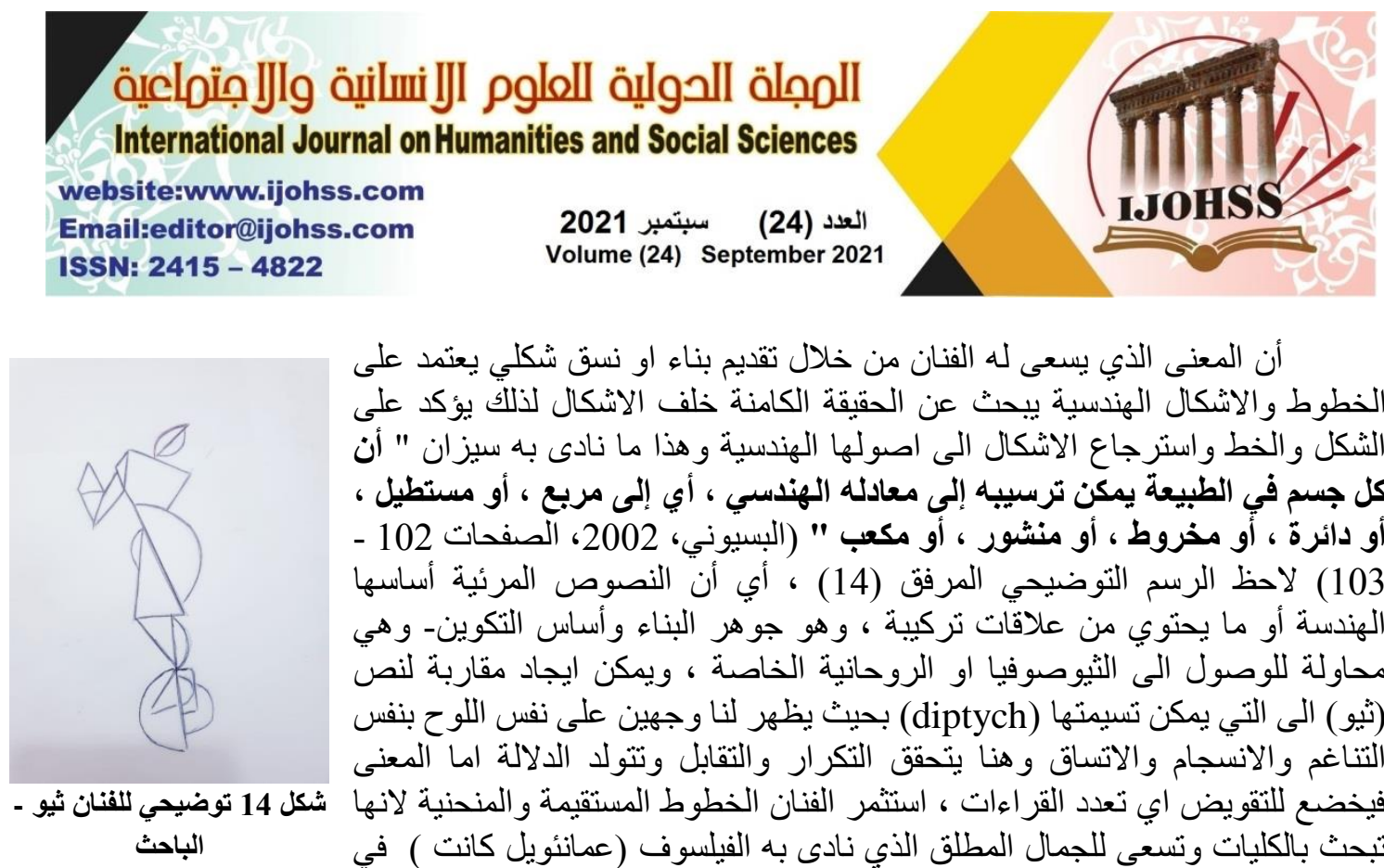

أن المعنى الذي يسعى له الفنان من خلال تقديم بناء او نسق شكلي بعتمد على لألى الألى

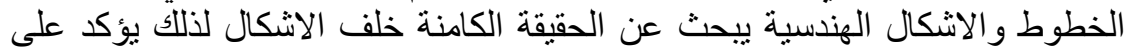

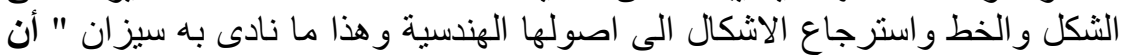

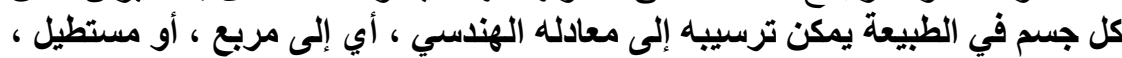

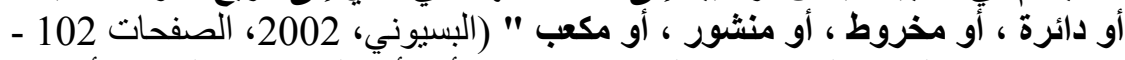

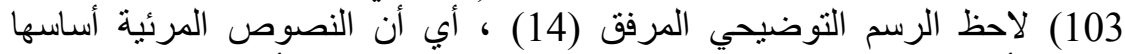

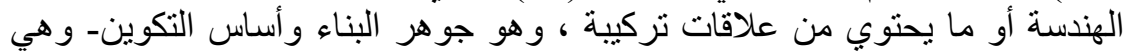

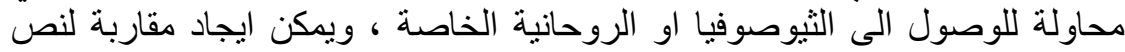

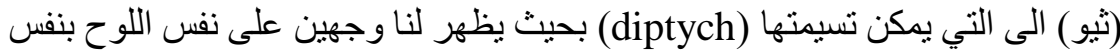

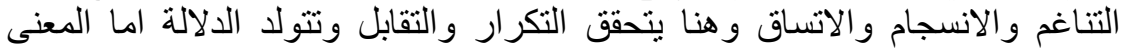

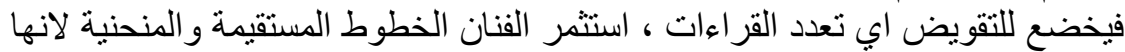

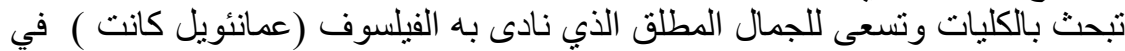

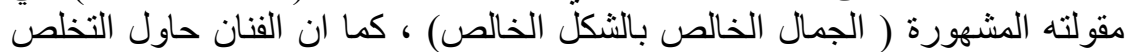

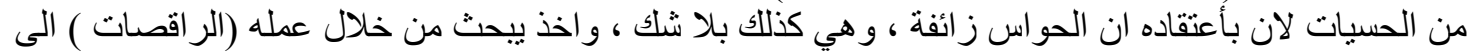

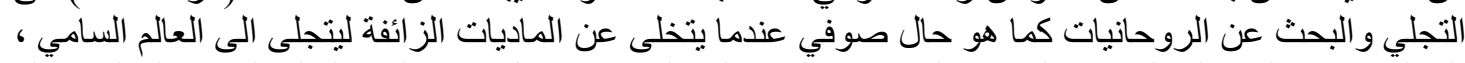

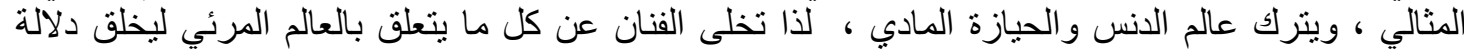

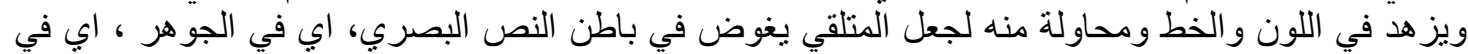

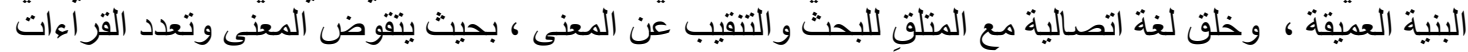

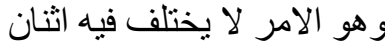

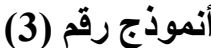

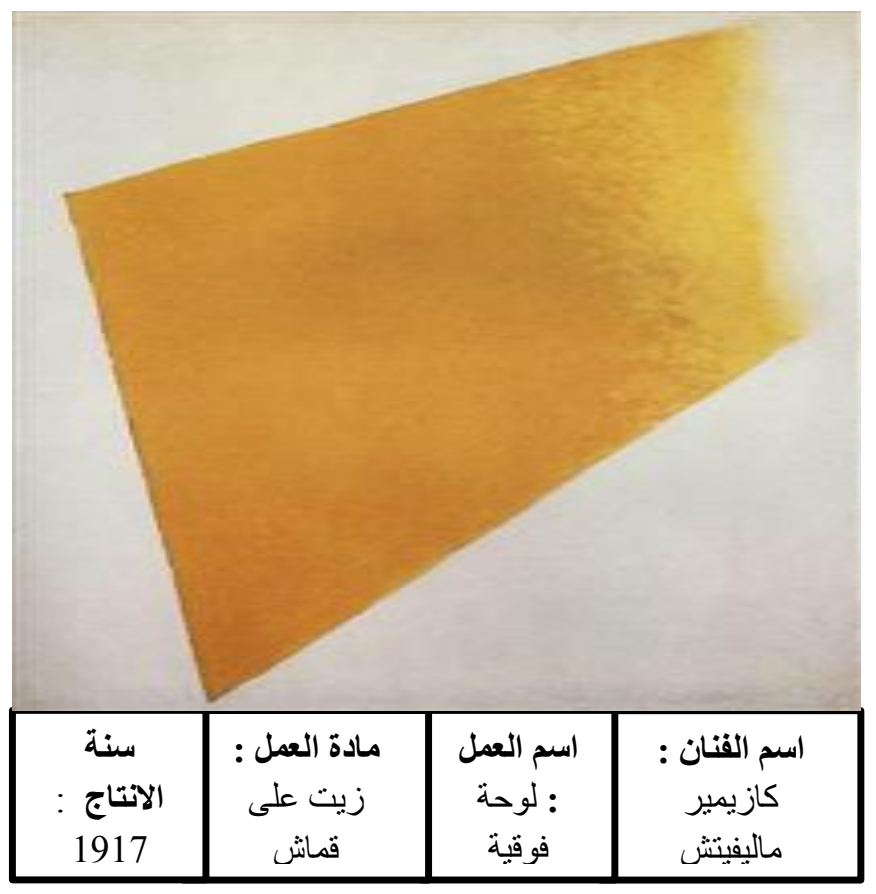

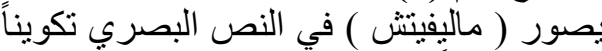

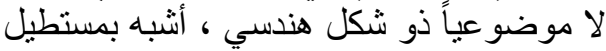

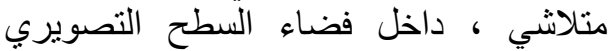
وكأنه يعطي تصور لمعنى ودلالة الى الامتداد التئي

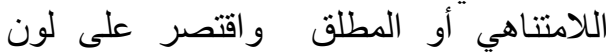
الاصفر ، سعى الفنان الى السمو الى الى الاحساس

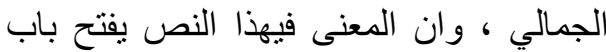
التأويل على مصر اعيه لأن نوليد الدالئلي بأتي بابي

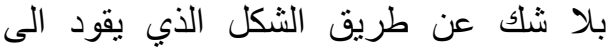
المعنى فاذا كان الثنكل يتسم بالز هد على التئي اعنبار ان السطح التصويري يختزل بداخله شكلاً واحداً يجمع ما بين المربع والمستطيل ولوناً الفنان ماليفيتش من الفنانين التجريدين الذي يعتبر كثير التجريب ويسعى التى معالجة التئي سطوحه التصويرية بأستمرار وكثيبر وكنير التنقيب بحيث يبحث عن اسلوب يميزه بالتران عن اقرانه من

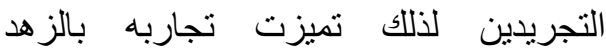
و واستخدام الاشكال الهندسية ، لأنه يعتقد ان العمل بهذه الطريقة تعطيه حرية اكبر ويعتبر الفنان مؤسس الحركة

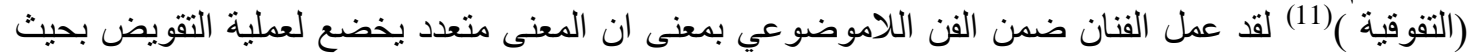

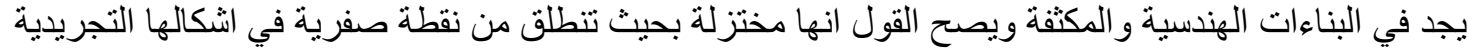
ليتجه الّى اللامتناهي المطلق ما فوق المرئي الكلي . 


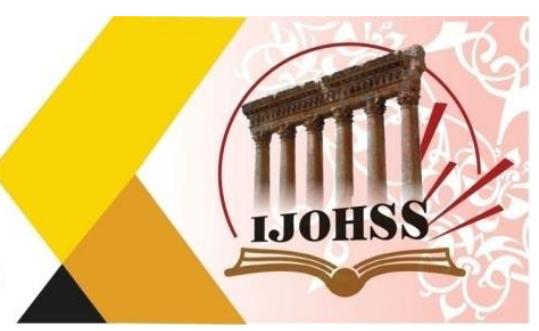

فقد استلهم الفنان الطروحات الأفلاطونية في تمجيده للجمال وعلاء سلطته من خلال الاشكال الهندية التي نادى التها

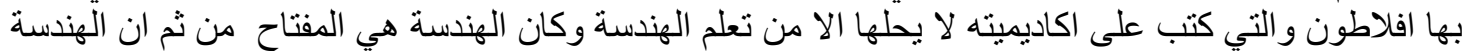

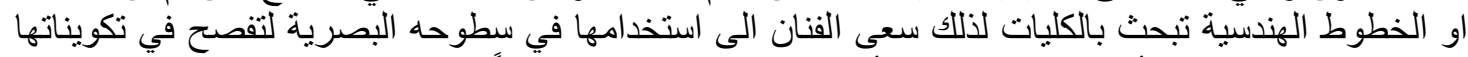

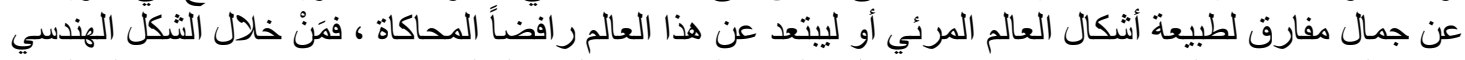

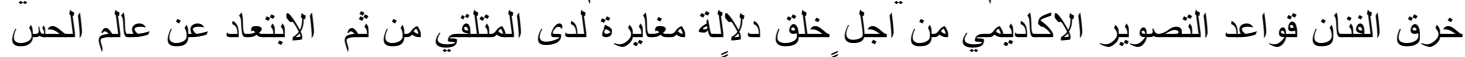

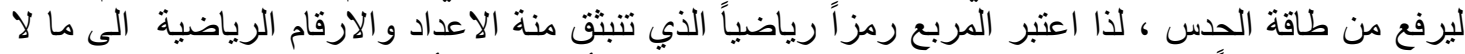

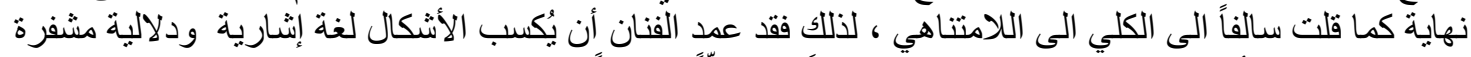

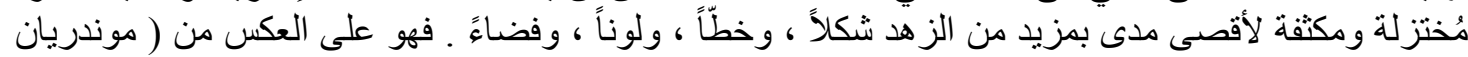

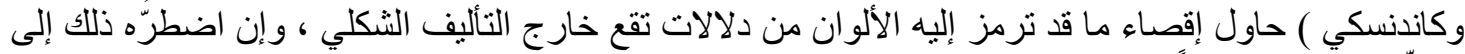
التخلّي عن اللون تماماً. يسعى الفنان الهولندي موندريان الى تخطي الو اقع وتحرره من ضرورة الفئ تمثيل الاثياء باحثاً عن المعنى او لنقل الجمال

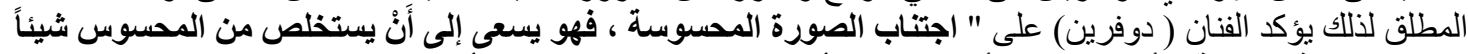

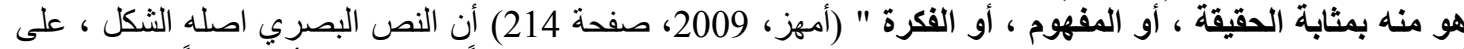

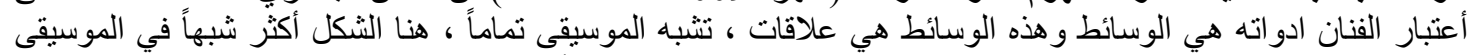

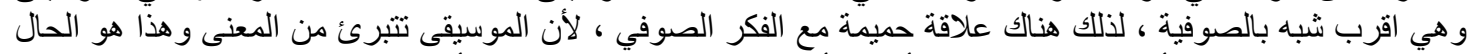

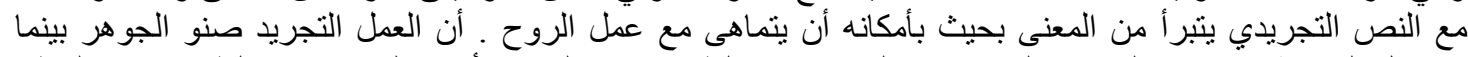

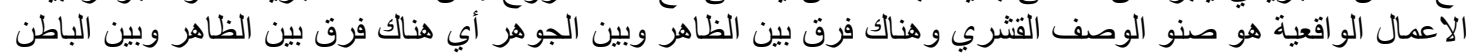

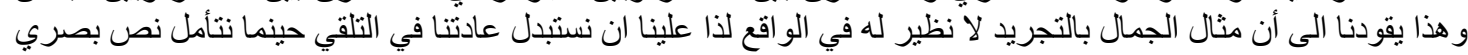

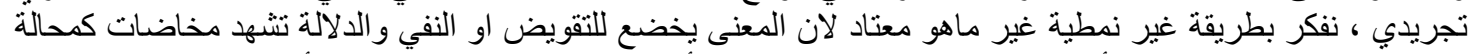

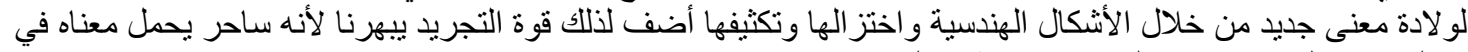

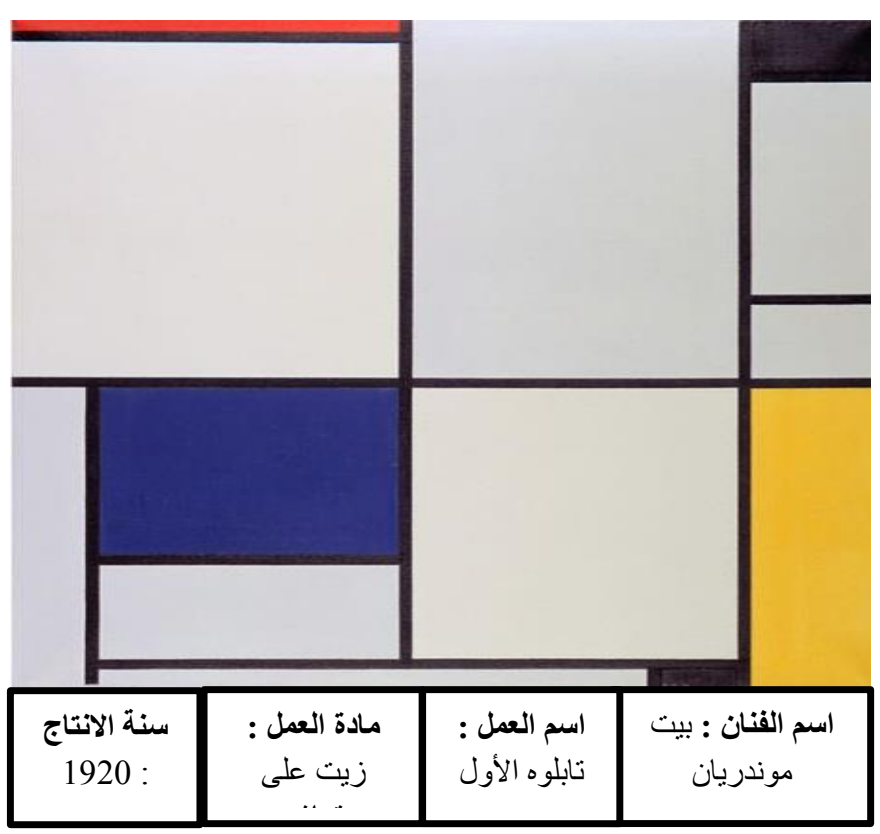

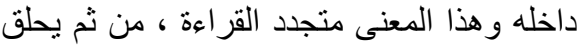
وييتعد عن عالم الحس ويتبرأ من كل ما فا هو

(4) انموذج رقئ اثرنا في ثثايا البحث ان التجريدية تنقسم

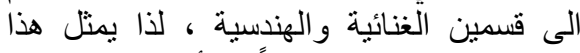

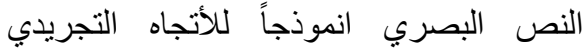
الهندسي و الذي تزعمده الفنان (بيت موندريان)

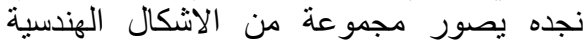

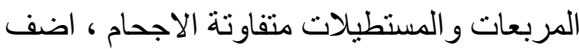

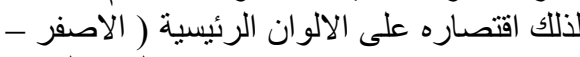

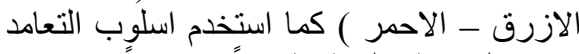
من خلال تقاطع الخطوط افقياً و عمودياً.

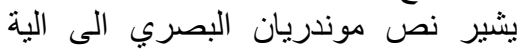

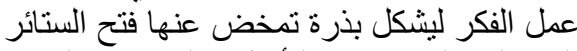

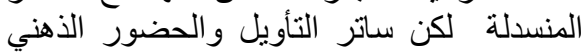

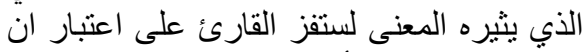

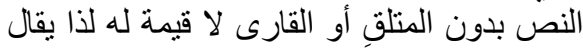

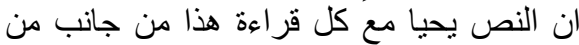
جانب اخر المعنى الذي يطرحه النص اقصد هند هنا البنية العميقة مع تعالقها من البنية السطحية القترية الظاهرية - يمكنني

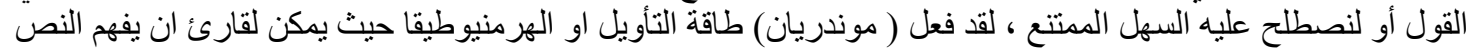

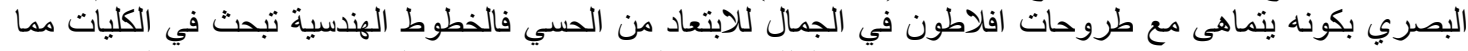

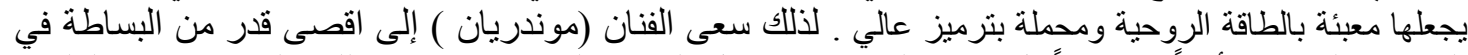

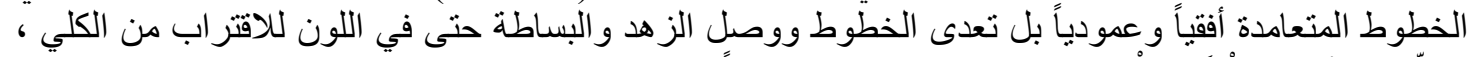

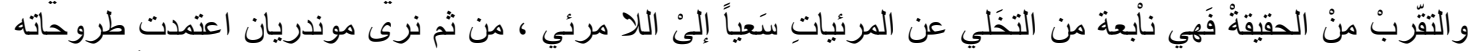

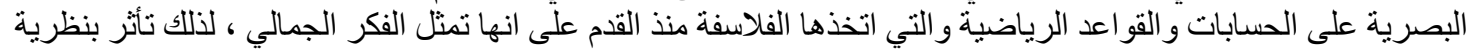




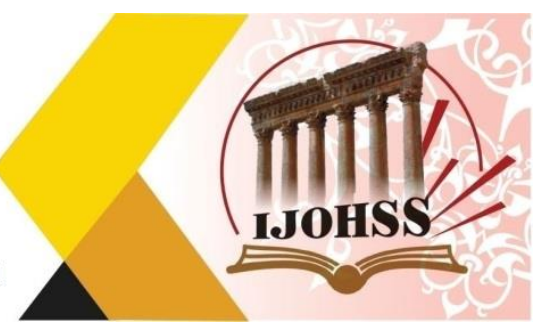

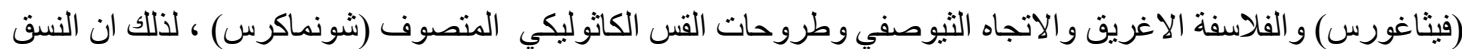

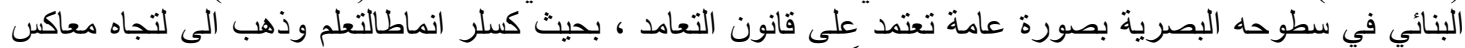

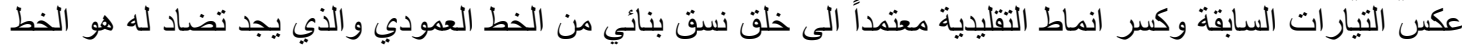

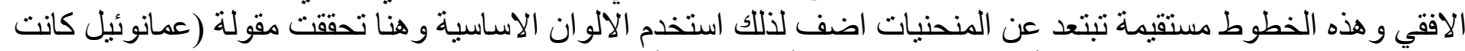

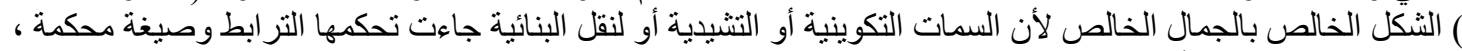

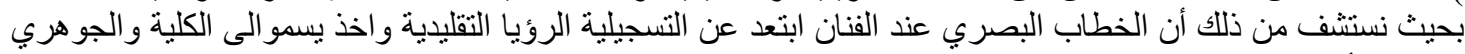

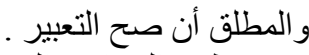

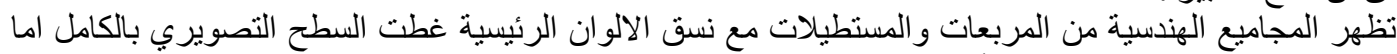

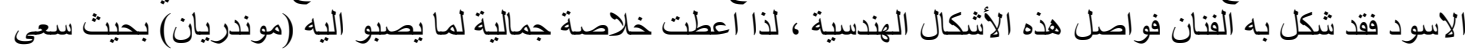

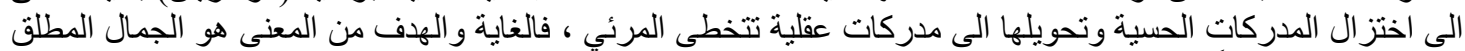

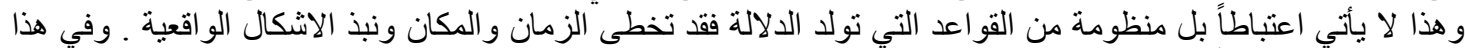

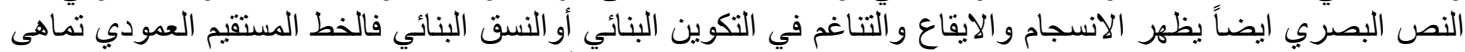

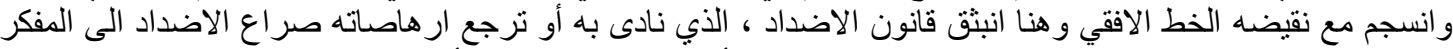

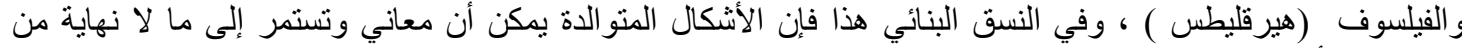

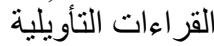

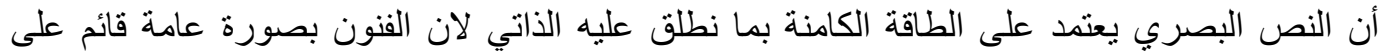

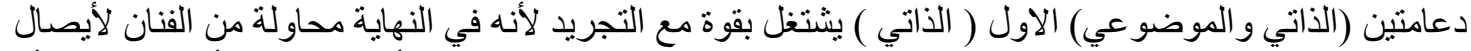

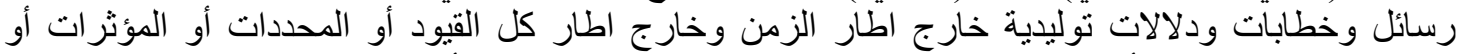

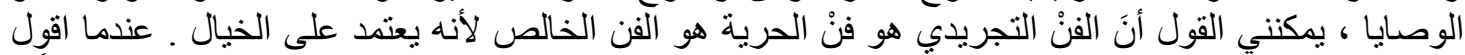

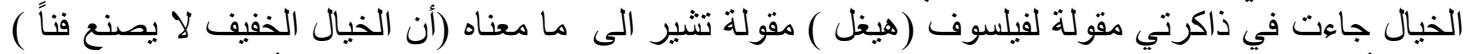

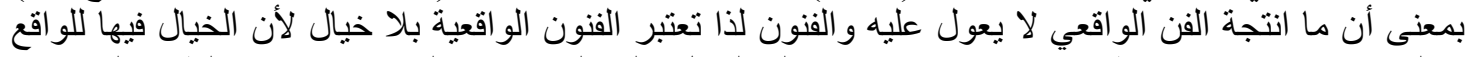

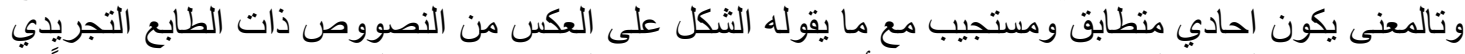

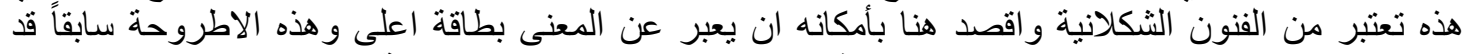

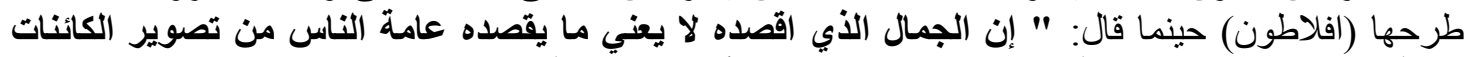

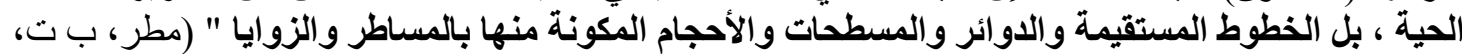

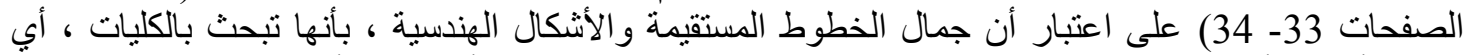

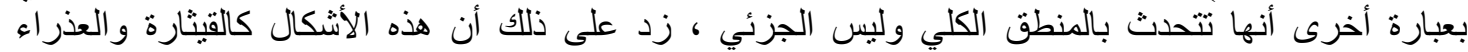

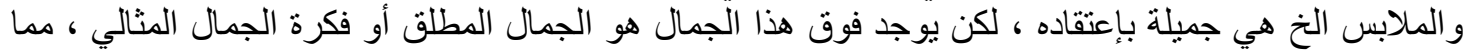

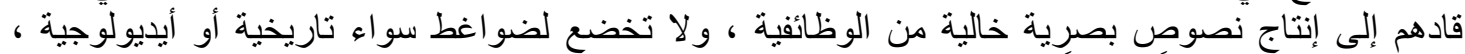

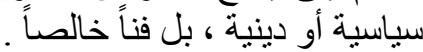

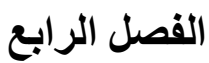 نتائج واستنتاجات البحث}

اولاً نتائج البحث ومناقشتنها : 1- اظهرت الأدراسة أنَ تقويض المعنى في في النص التجريدي يعتمد على طبيعة الأنساق البنائية فالأشكال الهندسية

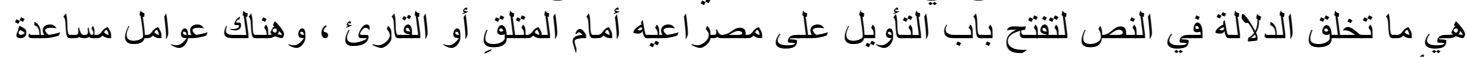

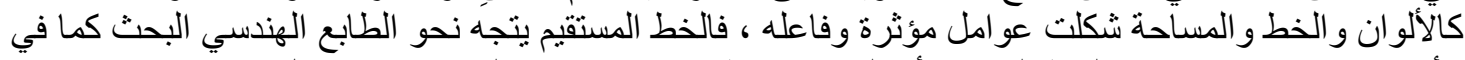

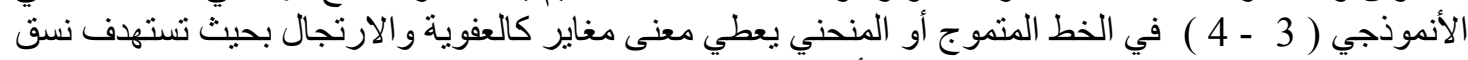

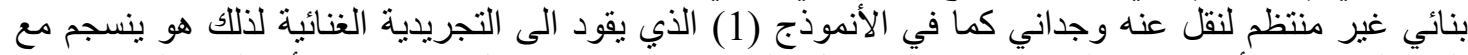

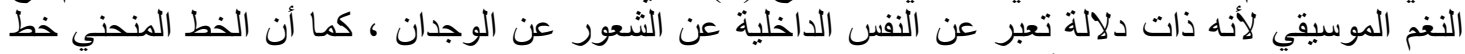

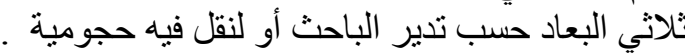

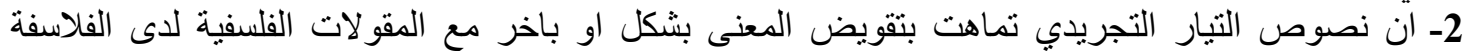
وخاصة مع طروحات ( فيثاغورس و افلاطون و عمانئويل كانت و هيغل ) و هذا ينطبق على جميع نماذج البحث بلا لان 


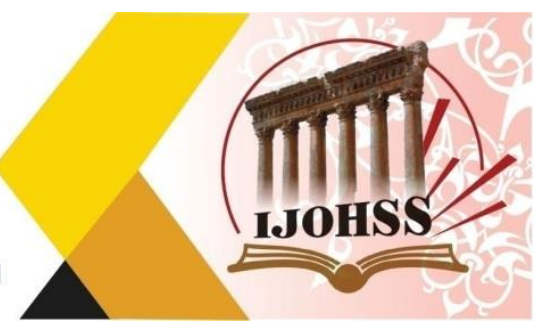

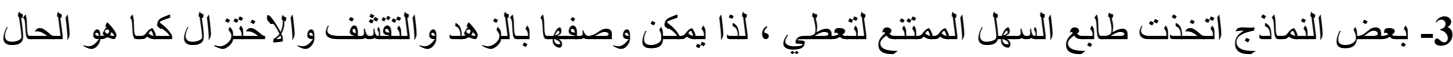

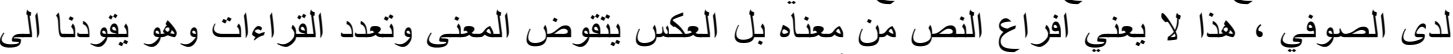

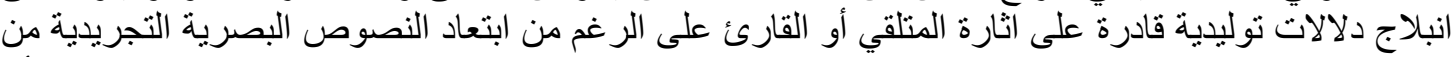

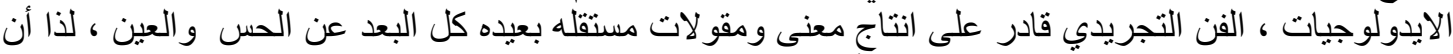

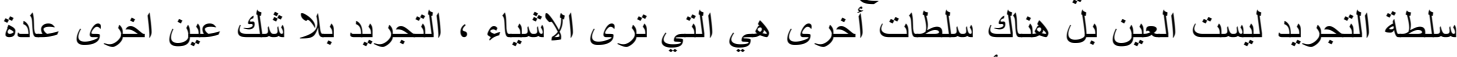

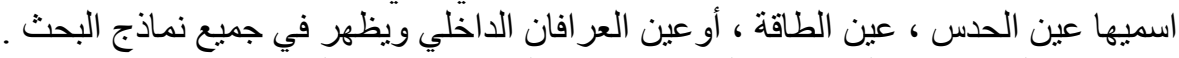

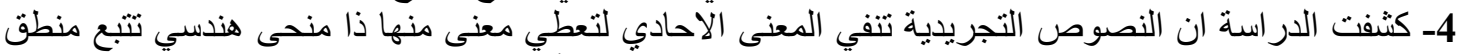

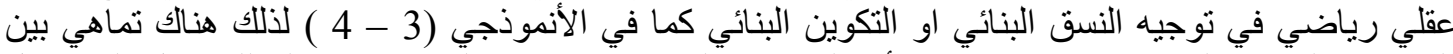

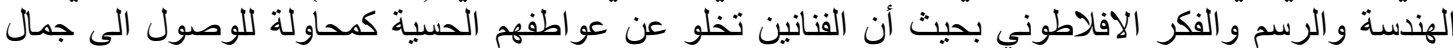

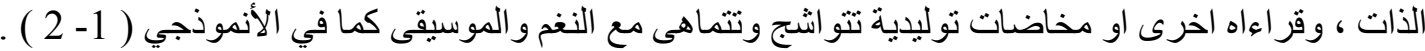

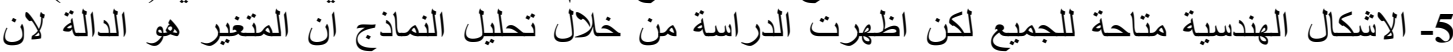

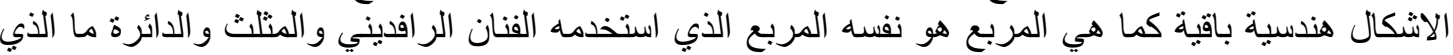

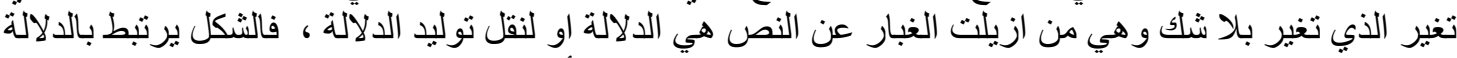

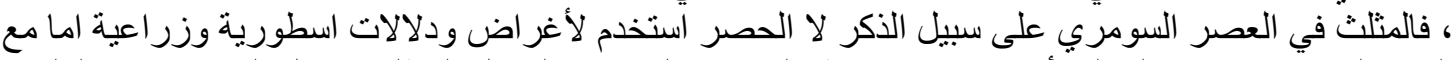

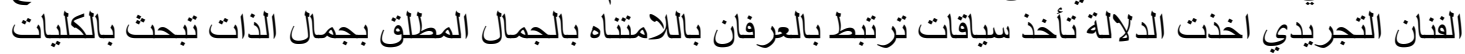

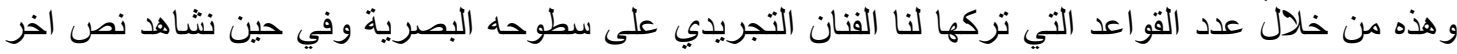
نلاحظ فيه اسقاط الدلالة بالكامل ويظهر في جميع نماذج البحث. لنان.

الاستنتاجات

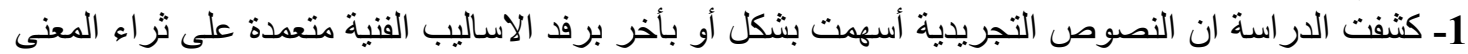

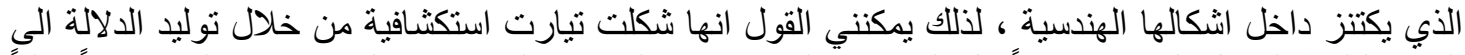

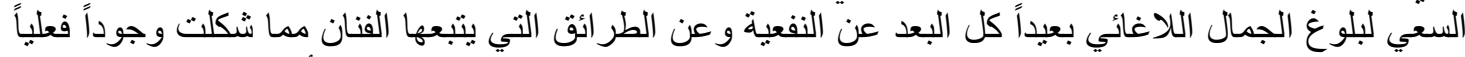

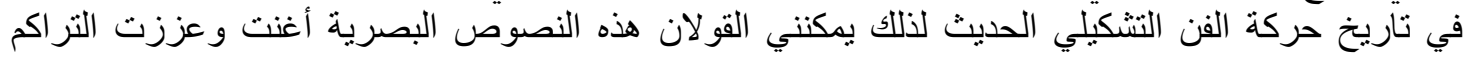

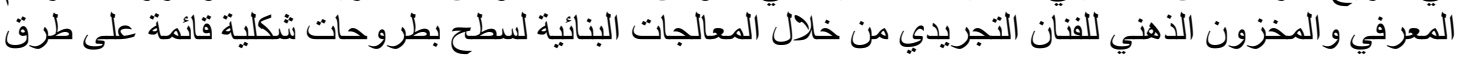

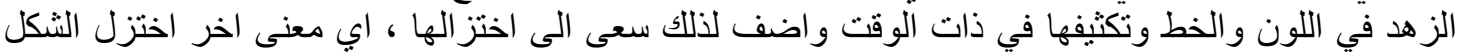

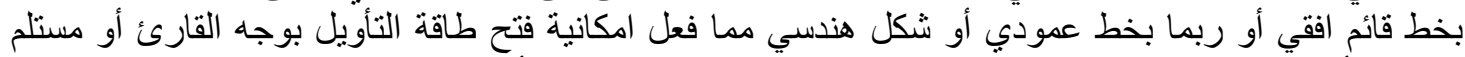

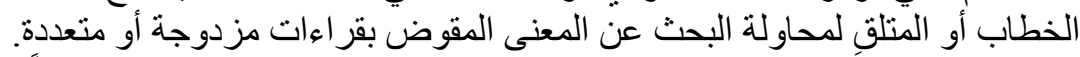

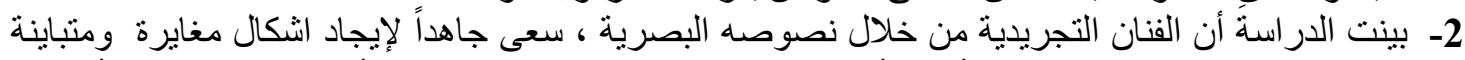

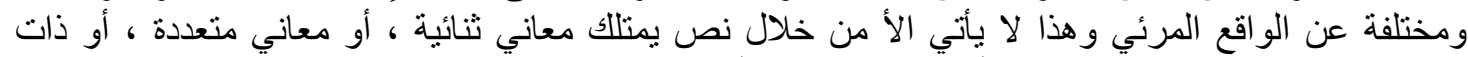

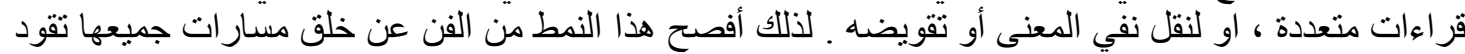

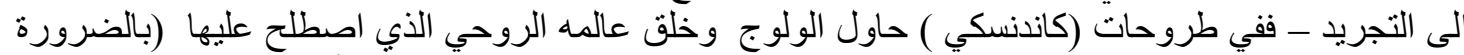

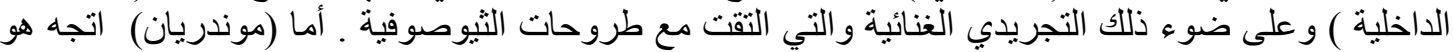

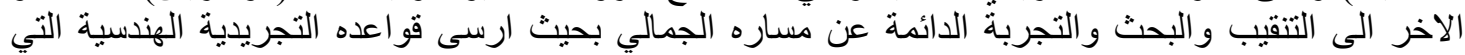

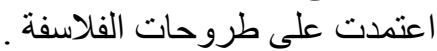

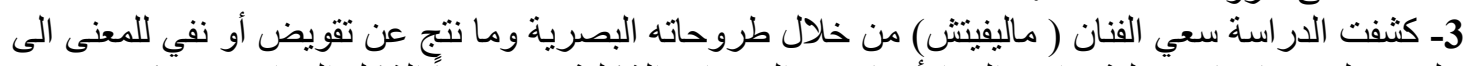

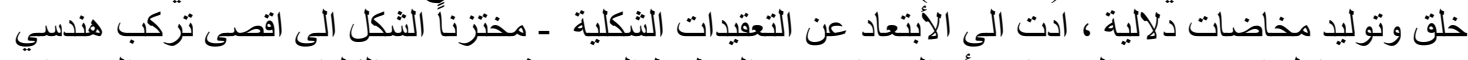

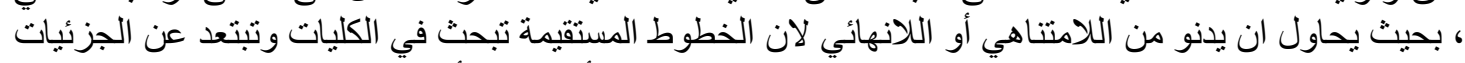

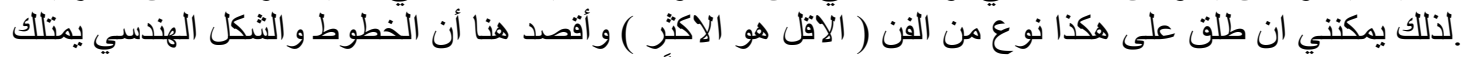

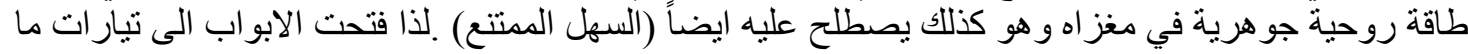

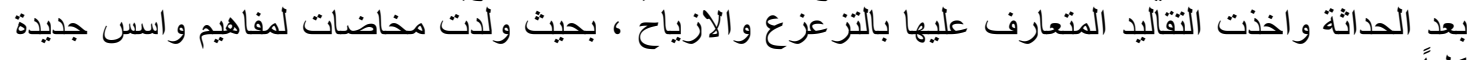




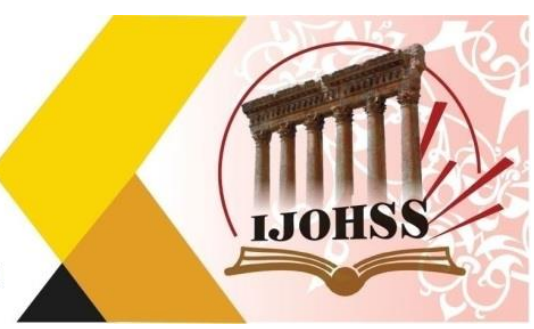

\begin{tabular}{|c|c|c|c|}
\hline الصفحة & المصدر & الموضوع & رقم المخطط \\
\hline 7 & الباحث & 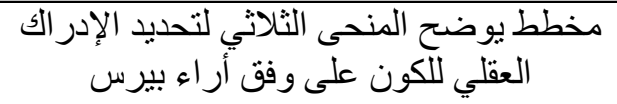 & 1 \\
\hline 7 & الباحث & مخطط يوضح مبدأ الثلاثية ومساره عند بيرس & 2 \\
\hline 8 & الباحث & مخطط يوضح تقسيم العلامة عند بيرس & 3 \\
\hline 9 & الباحث & مخطط يوضح اشتغال الدال و المدلول عند دي & 4 \\
\hline
\end{tabular}

الهوامش السفلية

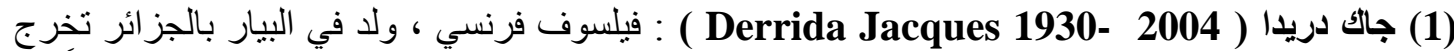

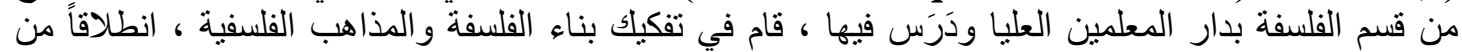

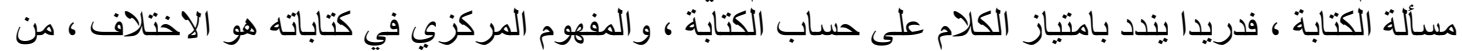

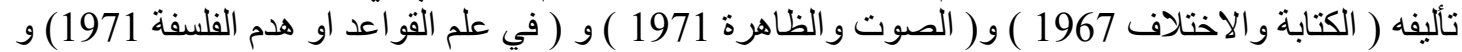

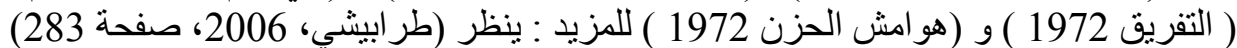

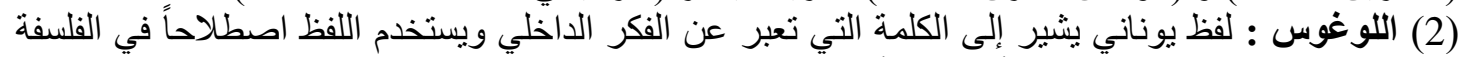

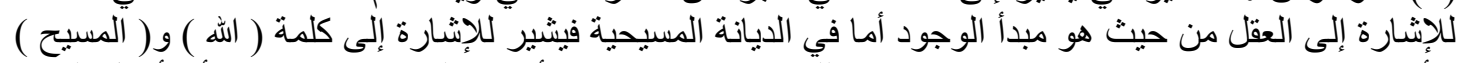

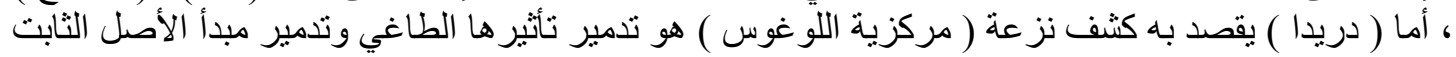

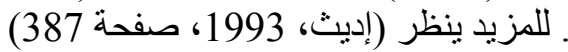

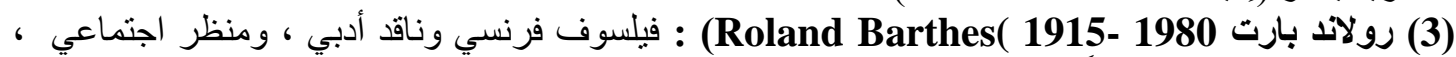

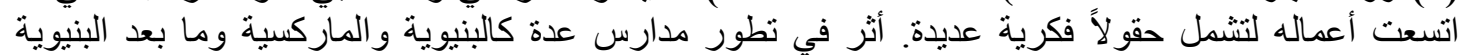

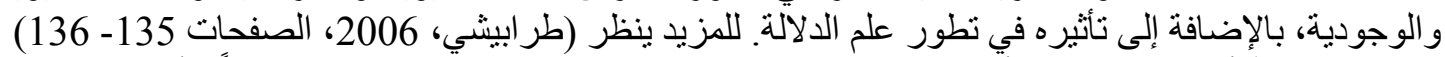

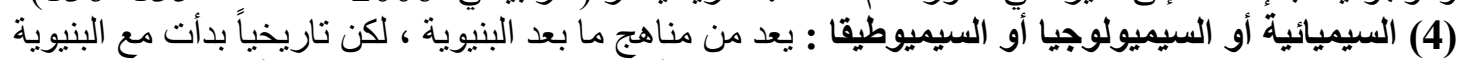

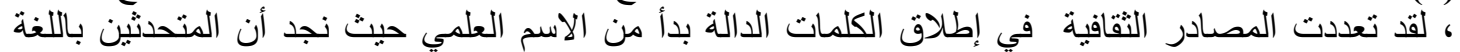

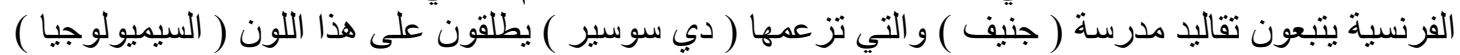

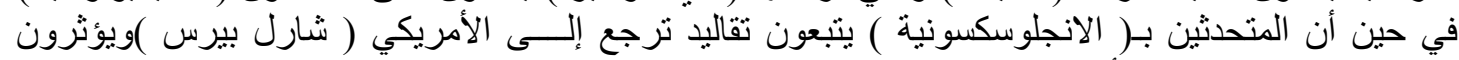

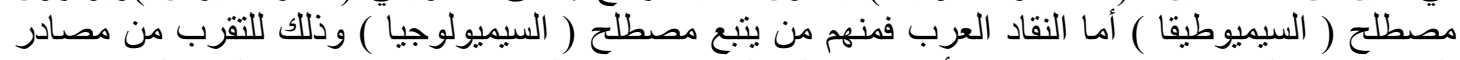

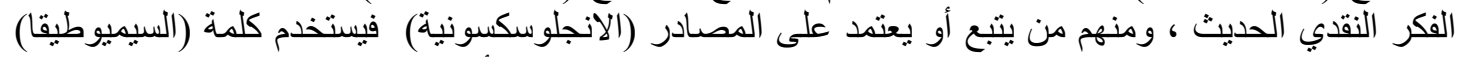

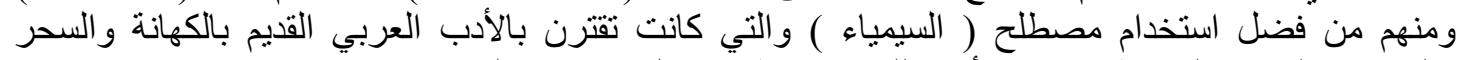

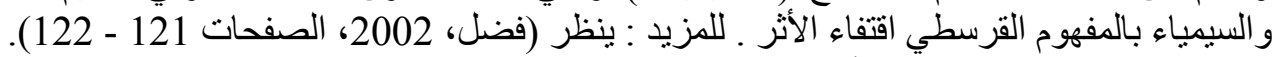

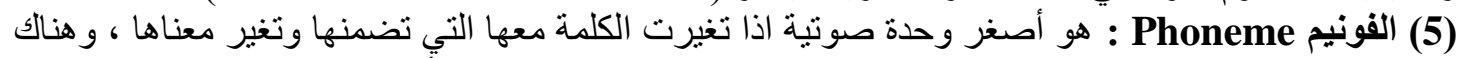

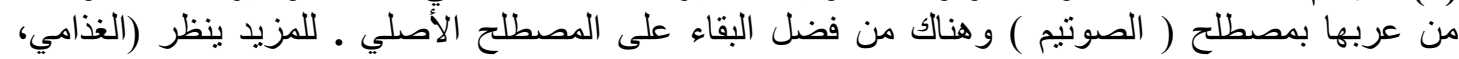

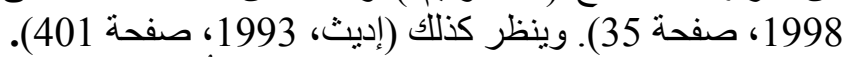

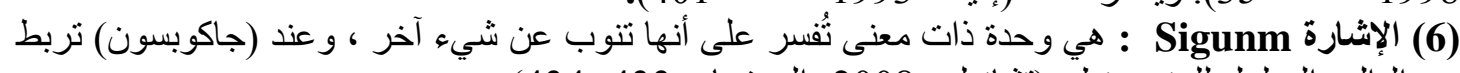

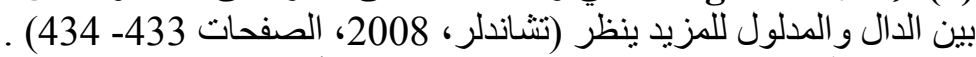

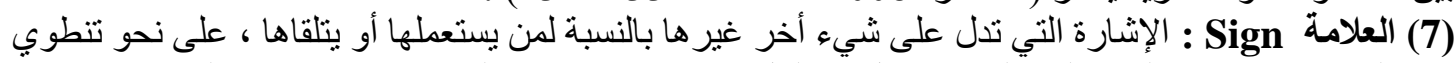

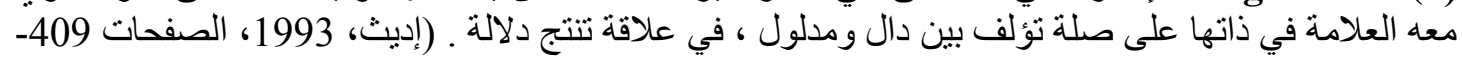




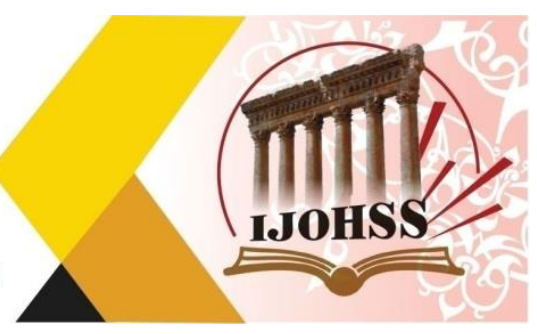

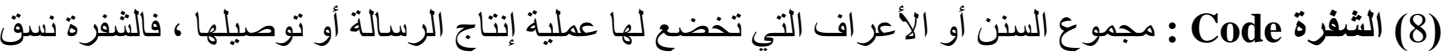

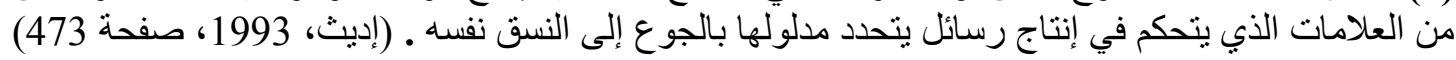

(9) تشالز سندرس بيرس Charles Sanders Peirce ( 1839 - 1914) : فيلسوف أمريكي درس (لإس السيميوطيقا واعتد على تقسيمها الى ثلاثة حقول هي : العلامات / الإشارات / الرموز ـ (الغذامي، 1998، صفحة 45). (10) (10) (10) الصوفية : يطلق لفظ الصوفية على الفلاسفة الذين يقولون بإمكان الاتحاد الباطني المباشر بين الفكر بوني

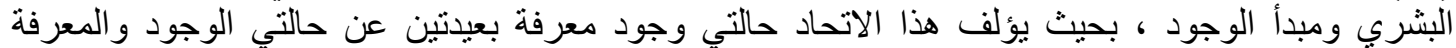

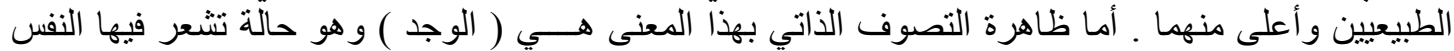

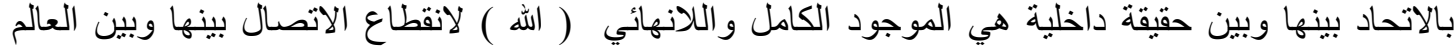

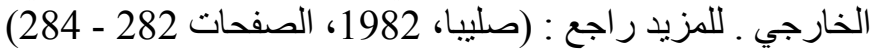
(11) التفوقية : اتجاه فني عقلاني قاده ماليفيتش (هيت، 1988، (1982، صفحة 10).

1. peirce .(1978) .Ecrits sur le signe .Paris: Ed Seil.

$$
\begin{aligned}
& \text { 2. ابر اهيم الحيدري. (2012). النقد بين الحداثة وما بعد الحداثة (المجلد ط 1). بيروت ـ لبنان: دار الساقي. } \\
& \text { 3. احمد خورشيد النوره جي. (1990). المفاهيم في الفلسفة والاجتماع (الدجلد الطبعة الاولى ). بغداد: دار }
\end{aligned}
$$

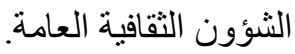

$$
\begin{aligned}
& \text { 4. احمد عبد الحليم عطيه. (2010). جالك دريدا و التفكيك (المجلد ط 1). بيروت ـ لبنان: دار الفار ابي. } \\
& \text { 5. احمد مختار. (1982). علم الدلالة. الكويت: مكتبة العروبة للنشر و التوزيع. }
\end{aligned}
$$

6. ادرين هيت. (1988). الفن التجريدي اصله ومعناه. (محمد علي الطائي، المثرجمون) بغداد: مطبعة اليقظة . 7. ال ياسين جعفر. (2012). فلاسفة يونانين من طاليس الى سقر اط (المجلد ط 1). لبنان - بيروت: دار ومكتبة البصائر.

8. الاء علي عبود الحاتمي. (2011). الابعاد المفاهيمية والجمالية للادادئية في فن ما بعد الحداثة (المجلد ط 1). عمان: دار صفاء للنشر و التوزيع.

9. الدليمي رياض هلال. (2005). بنائية الثكلالخالص في الرسم الحديث ـ بابل ، اطروحة دكتور اه غير منشورة ، جامعة بابل : كلية الفنون الجميلة .

10. المبارك ، عدنان. (1973). الاتجاهات الرئيسة في الفن الحديث على ضوء نظرية ريد. بغداد: وزارة

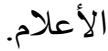
11. اميرة حلمي مطر. (ب ت). فلسفة الجمال ـ القاهرة : دار المعارف . . 12. امينة رشيد. (ب ت). السيموطيقا. (سيزا قاسم ونصر حامد ابو زيد، المحرر) القاهرة: دار الياس العصرية. 13. بالمر اف ار. (1985). علم الدلالة. (مجيد الماشطة، المترجمون) بغداد: وزارة التعليم العالي ـ الجامعة 


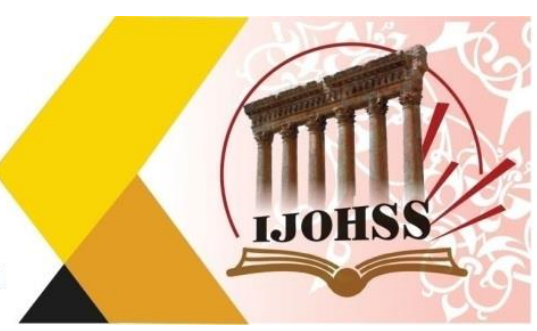

14. بسام الجمل. (2006). من الرمز الى الرمز الديني: بحث في المعنى و الوظائف والمقاربات (المجلد طبعة

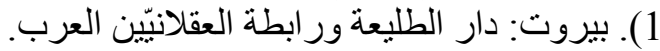

15. بلاسم محمد. (2008). الفن التشكيلي - در اسة سيميائية في انساق الرسم (المجلد ط 1). عمان ـ الاردن: دار مجدلاوي للتوزيع والنشر.

16. نوفيق البزاز. (2010). علم اللغة المعاصر نظرية وتطبيقاً (المجلد ط 1). الأردن: دار زهر ان للنشر. 17. جاك دريدا. (2008). أحادية الاخر اللغوية (المجلدط1 ). (عمر مهيبل، المنرجمون) الجزائر: منشورات الاختلاف. 18. جروج طر ابيشي. (2006). معجم الفلاسفة (المجلد ط 3). بيروت ـ لبنان: دار الطليعة. 19. جميل صليبا. (1982). المعجم الفلسفي (المجلد ج 1). بيروت ـ لبنان: دار الكتاب اللبناني. 20. حسن محمد حسن. ( ب ت ). مذاهب الفن المعاصر و الرؤية التشكلية للقرن العشرين ـ القاهرة : دار الفكر

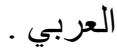

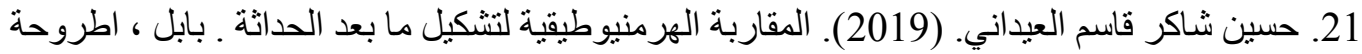
دكتور اه غير منشورة ، العراق ـ كلية الفنون الجميلة : جامعة بابل ـكلية الفنون الجميلة . 22. حمدية كاظم. (2008). التفكيكية وتطبيقاتها في فن ما بعد الحداثة . بابل ، اطروحة دكتور اه غير منشورة ، العر اق : جامعة بابل ـ كلية الفنون الجميلة . 23. دانيال تشاندلر . (2008). أسس السيمياء (المجلد ط1). (ميشال زكريا، المحرر، و طلال و هبة، المنرجمون) بيروت: المنظمة العربية للترجمة و النشر.

24. دايت مورنون. (1975). عصر التحليل ـ فلاسفة القرن العشرين. (أديب يوسف ستين، المترجمون) دمشق. 25. ديفيد كوزنز هوي. (2007). تحميل كتاب الحلقة النقدية ـ الأدب و التاريخ و الهرمنيوطيقا الفلسفية (المجلد

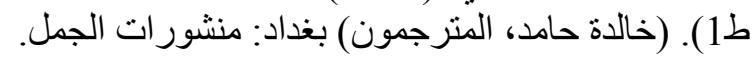

26. راضي حكيم. (1986). فلسفة افن عند سوزان لانجر ـ بغداد: دار الثؤون الثقافية العامة ـ وزارةالثقافة

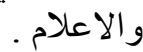

27. روبرت شولز. (1994). السيمياء و التو اصل (المجلد ط 1). (سعيد الغانمي، المترجمون) بيروت: المؤسسة

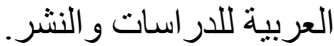

28. روجيه غارودي. (1979). البنيوية فلسفة موت الأنسان (المجلد ط 1 ). (جورج طر ابيشي، المترجمون) بيروت ـ لبنان: دار الطليعة للنشر.

29. رياض هلال مطلك الدليمي. (2005). بنائية الثكل الخالص في الرسم التجريدي الحديث ـ بابل ، اطروحة

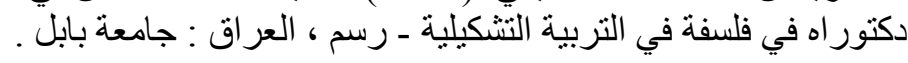

30. ساره نيوماير. (1960). قصة الفن الحديث. (رمسيس يونان، المترجمون) مكتبة الأنجلو المصرية. 


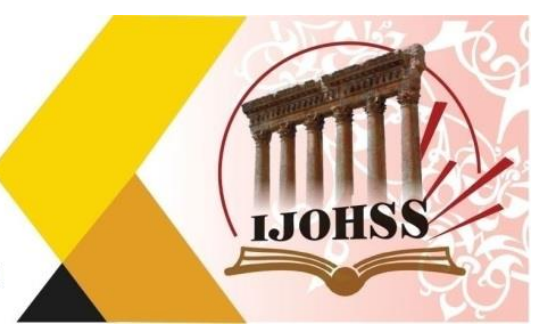

31. سعيد بنكر اد. (2005). السيميائيات و التأويل مدخل لسيميائيات ش. س. بورس (المجلد ط1). بيروت ـ

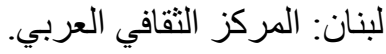

32. سعيد علوش. (1985). معجم المعاصرة لمصطلحات الأدبية (المجلد ط 1). بيروت: دار الكتاب اللبناني. 33. سها محمد سلوم. (2013). إنكالية اللاموضو عية (المعادل الهندسي ) في تجريدية كاندنسكي الغنائية. مجلة جامعة دمشق الهندسية، المجلد التاسع و العشرون (العدد الثاني). 34. شاكر عبد الحميد. (1990). العملية الابداعية في فن التصوير ـ الكويت: عالم المعرفي ـ المجلس الوطني

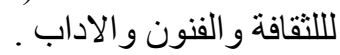

35. صبحي البستاني. (1982). مفهوم الدلالة عند أبن فارس فيكتابة الصحابة. مجلة الفكر العربي المعاصر( (19-18)، صفحة النقان. 36. صلاح فضل. (2002). مناهج النقد المعاصر (المجلد ط1). القاهرة: ميريت للنشر و المعلومات. 37. عبد العزيز حموده. (1998). المر آيا المحدبة من البنيوية الى التفكيك ـ الكويت: المجلس الوطني للثقافة

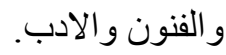

38. عبد الله محمد الخذامي. (1998). الخطيئة و التكفير من البنيوية الى التشريحية (المجلد ط4). الاسكندرية:

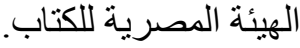

39. عر ابي عبد الحي. (2018). ما بعد الحداثة. مجلة السبيل، 1 -5. 40. عز الدين اسماعيل. (1974). الفن والإنسان. بيروت ـ لبنان: دار القلم. 41. علي حرب. (2010). هكذا أقر أ ما بعد التفكيك (المجلد ط 2). بيروت: المؤسسة العربية للدراسات و النشر. 42. عمر التاور. (2016). الميتافيزيقا بين هاجر ودريدا. مجلة السبيل، ./https://modernitysite.wordpress.com/2016/08/17

43. كريزويل إديث. (1993). عصر البنيوية (المجلد ط 1). (حلمي توني، المحرر، و جابر عصفور، المترجمون) الكويت: دار سعاد الصباح.

44. كريستوفر نورس. (2008). التفكيكية النظرية و التطبيق (المجلد ط 1). (رعد عبد الجليل جواد، المترجمون) سوريا: دار الحوار.

45. كير ايلام. (1992). سيمياء المسرح و الدر اما. (رئيف كرم، المترجمون) بيروت: المركز الثقافي العربي. 46. لويس معلوف. (2002). المنجد في اللغة (المجلد ط39). بيروت: دار المشر اق. 47. مجمع اللغة العربية. (1979). المعجم الفلسفي (المجلد ط 1). القاهرة: الهئية المصرية العامة للكتاب. 48. محمد سالم سعد. (2007). الأسس الفلسفية لنقدما بعد البنيوية (المجلد ط1). سوريا: دار الحوار. 


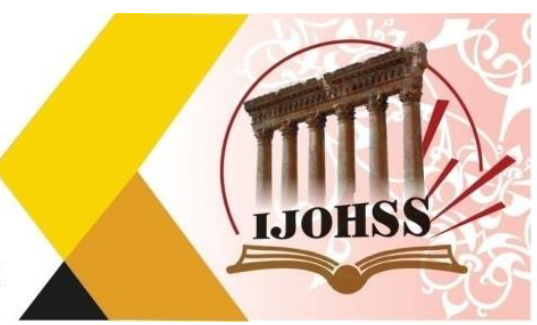

49. محمد علي عوان القره غولي. (2006). جماليات التصميم في رسوم ما بعد الحداثة . بابل ، اطروحة دكتور اه غير منشورة ، العراق - جامعة بابل : كلية الفنون الجميلة . 50. محمد مختاري. (24 - 4 - 2017). السيميوطيقا البورسية . شبكة الالوكة.

51. محمد يوسف موسى. (1945). فلسفة الاخلاق في الاسلام وصلاتها بالفلسفة الار غيقية ـ مطبعة الرسالة.

52. محمود البسيوني. (2002). الفن في القرن العشرين ـ الهيئة المصرية العامة للكتاب ـ مكتبة الاسرة .

53. محمود أمهز. (2009). التبار ات الفنية المعاصرة (المجلد الطبعة الثانية ). بيروت ـ لبنان: المطبوعات اللنشر و التوزيع. 54. منذر عياشي. (1996). اللسانيات والدلالة. سوريا - حلب: مركز الانماء الحضاري. 55. ميجان الرويلي. (2002). دليل الناقد الادبي (المجلد ط 3). الدار البيضاء المغرب: المركز الثقافي العربي.

56. نصر حامد أبو زيد. (1986). أنظمة العلامات في اللغة والأدب مدخل الى السيميوطيقا ـ الدار البيضاء: منشورات عيون.

57. هربرت ريد. (1989). الموجز في تاريخ الرسم الدديث (المجلد ط1). (سلمان الواسطي، المحرر، و لمعان البكري، المترجمون) بغداد: دار الثؤون الثقافية العامة.

58. هربرت ريد. (1989). الموجز في تاريخ الفن الحديث (المجلد ط1). (سليمان الو اسطي، المحرر، و لمعان

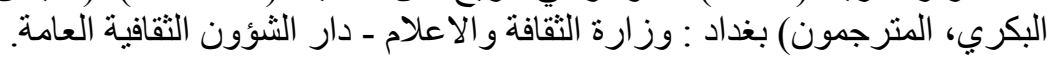
59. يوسف خياط. (ب ت ). معجم المصطلحات العلمية و الفنية . بيروت ـ لبنان : دار لسان العرب. 60. يوسف كرم. (2012). تاريخ الفلسفة اليونانية ـ القاهرة: مؤسسة هنداوي للتعليم و الثقافة .

61. peirce. (1978). Ecrits sur le signe. Paris: Ed Seil.

62. Ibrahim Haidari. (2012). Criticism between modernity and postmodernism (Volume I 1). Beirut - Lebanon: Dar Al-Saqi.

63. Ahmed Khurshid Noura J. (1990). Concepts in Philosophy and Sociology (Volume 1st ed.). Baghdad: House of General Cultural Affairs.

64. Ahmed Abdel Halim Attia. (2010). Jacques Derrida and Deconstruction (Volume 1 i). Beirut - Lebanon: Al-Farabi House.

65. Ahmed Mukhtar. (1982). Semantics. Kuwait: Al-Urubah Library for Publishing and Distribution.

66. Adrien Heat. (1988). Abstract art its origin and meaning. (Muhammad Ali AlTai, translators) Baghdad: Al-Waqah Press.

67. Al Yassin Jaafar. (2012). Greek Philosophers from Thales to Socrates (Volume i 1). Lebanon - Beirut: Insights House and Library. 


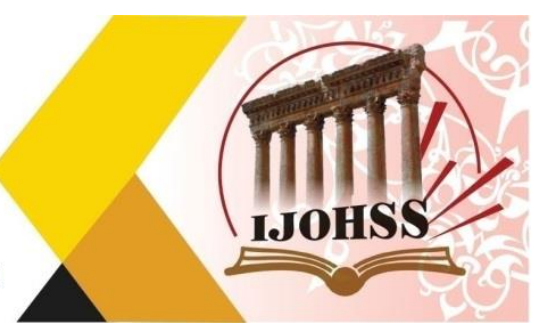

68. Alaa Ali Abboud Al Hatmi. (2011). Conceptual and Aesthetic Dimensions of Dada in Postmodern Art (Volume I 1). Amman: Dar Safaa for Publishing and Distribution.

69. Al-Dulaimi Riad Hilal. (2005). Constructivism pure form in modern painting. Babylon, unpublished doctoral thesis, University of Babylon: College of Fine Arts.

70. Mubarak, Adnan. (1973). The main trends in modern art in the light of Reed's theory. Baghdad: Ministry of Information.

71. Amira Helmy Matar. (Bit). beauty philosophy. Cairo: House of Knowledge.

72. Amina Rashid. (Bit). semiotics. (Sisa Qassem and Nasr Hamid Abu Zaid, editor) Cairo: Dar Elias Modern.

73. Palmer Fr. (1985). Semantics. (Majid Al-Mashata, translators) Baghdad: Ministry of Higher Education - Al-Mustansiriya University.

74. Bassam El-Gamal. (2006). From Symbol to Religious Symbol: An Inquiry into Meaning, Functions, and Approaches (Volume 1). Beirut: Dar Al-Tali ah and the League of Arab Rationalists.

75. Blasim Muhammad. (2008). Plastic art - a semiotic study of painting formats (Volume I 1). Amman - Jordan: Majdalawi House for Distribution and Publishing.

76. Tawfiq Al-Bazzaz. (2010). Contemporary Linguistics Theory and Application (Volume I 1). Jordan: Zahran Publishing House.

77. Jacques Derrida. (2008). Monolingualism of the other (Volume I 1). (Omar Mohebel, The Translators) Algeria: Publications of Difference.

78. Grooj Tarabishi. (2006). Dictionary of Philosophers (Volume 3). Beirut Lebanon: Dar Al-Tali'a.

79. Beautiful cross. (1982). The Philosophical Dictionary (Volume C 1). Beirut Lebanon: Lebanese Book House.

80. Hassan Mohamed Hassan. ( Bit ). Doctrines of contemporary art and the plastic vision of the twentieth century. Cairo: Arab Thought House.

81. Hussein Shaker Qassem Al-Eidani. (2019). The hermeneutic approach to the formation of postmodernism. Babylon, unpublished doctoral thesis, Iraq College of Fine Arts: Babylon University - College of Fine Arts.

82. Hamdiya Kazem. (2008). Deconstruction and its applications in postmodern art. Babylon, unpublished doctoral thesis, Iraq: Babylon University - College of Fine Arts.

83. Daniel Chandler. (2008). The Foundations of Semiotics (Volume I 1). (Michel Zakaria, editor, and Talal Wahba, translators) Beirut: The Arab Organization for Translation and Publishing.

84. Diet Morton. (1975). The era of analysis - philosophers of the twentieth century. (Adeeb Yusef Steen, translators) Damascus. 


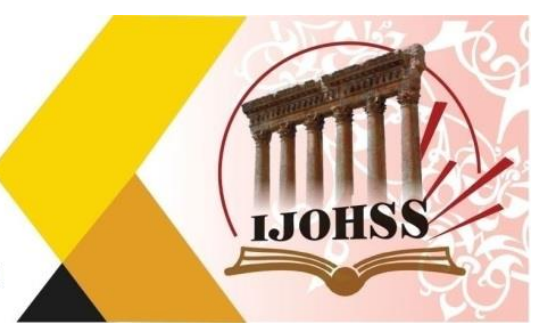

85. David Cousins Howe. (2007). Download the book Critical Circle - Literature, History and Philosophical Hermeneutics (Volume 1). (Khaleda Hamid, translators) Baghdad: Al-Jamal Publications.

86. Radhi is wise. (1986). The philosophy of Avne by Susan Langer. Baghdad: House of General Cultural Affairs - Ministry of Culture and Information.

87. Robert Schulze. (1994). Alchemy and Communication (Volume i 1). (Saeed Al-Ghanimi, translators) Beirut: The Arab Institute for Studies and Publishing.

88. Roger Garaudy. (1979). Structuralism The Philosophy of the Death of Man (Volume i 1). (George Tarabishi, translators) Beirut - Lebanon: Dar Al-Tali'a Publishing.

89. Riad Hilal Mutlaq Al-Dulaimi. (2005). Structural pure form in modern abstract painting. Babylon, doctoral thesis in philosophy in plastic education drawing, Iraq: University of Babylon.

90. Sarah Neumayer. (1960). The story of modern art. (Ramses Younan, Translators) Anglo-Egyptian Library.

91. Said Penkrad. (2005). Semiotics and Interpretation Introduction to Semiotics u. s. Burse (Volume I 1). Beirut - Lebanon: Arab Cultural Center.

92. Said Alloush. (1985). Contemporary Dictionary of Literary Terms (Volume I 1). Beirut: Lebanese Book House.

93. Suha Mohamed Salloum. (2013). The problem of subjectivity (geometric equivalent) in Kandinsky's lyrical abstraction. Damascus Engineering University Journal, Volume Twenty-Nine (Second Issue.(

94. Shakir Abdel Hamid. (1990). The creative process in the art of photography. Kuwait: Knowledge World - National Council for Culture, Arts and Letters.

95. Sobhi Boustany. (1982). The concept of significance according to Ibn Faris in the writing of the Companions. Journal of Contemporary Arab Thought (1819), $p$.

96. Salah Fadl. (2002). Methods of Contemporary Criticism (Volume I 1). Cairo: Merit Publishing and Information.

97. Abdul Aziz Hammouda. (1998). Convex mirrors from structuralism to deconstruction. Kuwait: The National Council for Culture, Arts and Literature.

98. Abdullah Mohammed Al-Ghadami. (1998). Sin and Atonement from Structural to Anatomical (Volume I 4). Alexandria: The Egyptian Book Organization.

99. Orabi Abdel Hai. (2018). Postmodernism. Al-Sabil Magazine, 1-5.

100. Ezz El Din Ismail. (1974). Art and man. Beirut - Lebanon: Dar Al Qalam.

101. Ali Harb. (2010). This is how I read Beyond Deconstruction (Volume i 2).

Beirut: The Arab Foundation for Studies and Publishing.

102. The age of the tower. (2016). The metaphysics between Hagar and Derrida.

Al-Sabil Magazine, https://modernitysite.wordpress.com/2016/08/17./

103. Edith Criswell. (1993). The Age of Structuralism (Volume i 1). (Helmy Tony, editor, and Jaber Asfour, translators) Kuwait: Dar Suad Al-Sabah. 


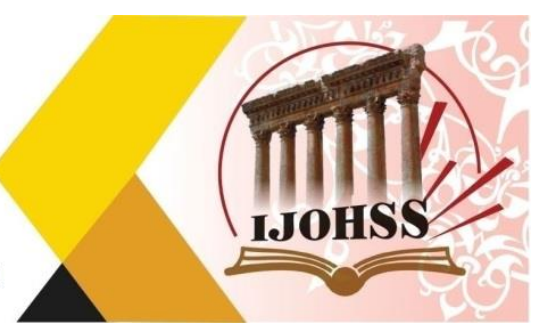

104. Christopher Norse. (2008). Deconstruction Theory and Practice (Volume i 1). (Raad Abdul-Jalil Jawad, translators) Syria: Dar Al-Hiwar.

105. Care Elam. (1992). Semiotics of theater and drama. (Raif Karam, translators) Beirut: Arab Cultural Center.

106. Louis Maalouf. (2002). Al-Munajjid in the Language (Volume 39). Beirut: Al-Mishraq House.

107. Arabic Language Academy. (1979). Lexicon

108. Muhammad Salem Saad. (2007). The Philosophical Foundations for Progress after Structuralism (Volume 1). Syria: House of Dialogue.

109. Muhammad Ali Awan Al-Qara Gholi. (2006). Design aesthetics in postmodern drawings. Babylon, unpublished doctoral thesis, Iraq - University of Babylon: College of Fine Arts.

110. Muhammad Mukhtari. (24 - 4 - 2017). Bursa semiotics. Alukah network.

111. Muhammad Yusuf Musa. (1945). Philosophy of ethics in Islam and its links to the philosophy of Araghic. Message printing.

112. Mahmoud El-Bassiouni. (2002). Art in the twentieth century. Egyptian General Book Organization - Family Library.

113. Mahmoud Amhaz. (2009). Contemporary Art Currents (Volume 2nd ed.). Beirut - Lebanon: publications for publishing and distribution.

114. Munther Ayachi. (1996). Linguistics and semantics. Syria - Aleppo: Center for Civilization Development.

115. Megan Al-Ruwaili. (2002). The Literary Critic's Handbook (Volume 3). Casablanca, Morocco: Arab Cultural Center.

116. Nasr Hamid Abu Zeid. (1986). Sign systems in language and literature, an introduction to semiotics. Casablanca: Oyoun Publications.

117. Herbert Reed. (1989). The summary in the history of modern painting (volume 1). (Salman Al-Wasiti, editor, and Lumaan Al-Bakri, translators) Baghdad: House of General Cultural Affairs.

118. Herbert Reed. (1989). The Brief in the History of Modern Art (Volume 1). (Sulaiman Al-Wasiti, editor, and Lumaan Al-Bakri, translators) Baghdad: Ministry of Culture and Information - House of General Cultural Affairs.

119. Youssef Khayat. (Bit ). Dictionary of scientific and technical terms. Beirut Lebanon: Lisan Al Arab House.

120. Youssef Karam. (2012). History of Greek Philosophy. Cairo: Hendawy Foundation for Education and Culture 